\title{
The Digital Athena Contemporary commentaries and Greek mythology explored through 3D printing
}

Rose Lastovicka

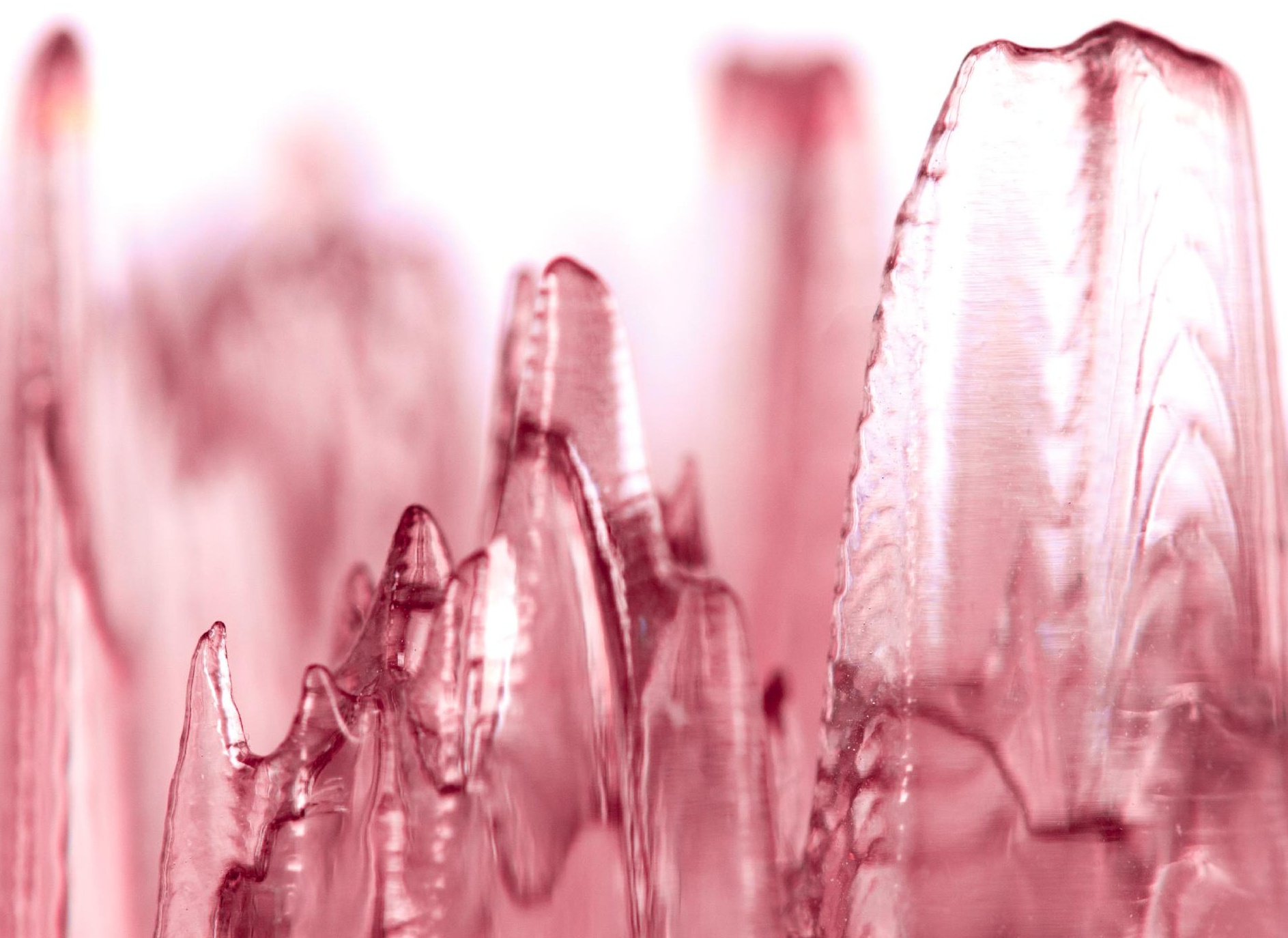


The Digital Athena

Contemporary commentaries and Greek mythology explored through 3D printing

\author{
by \\ Rose Lastovicka \\ A 90-point thesis submitted to Victoria University of Wellington \\ in partial fulfilment of the requirements for the degree of \\ Master of Design Innovation.
}

Victoria University of Wellington | 2019 
Bright-eyed Athena: she likes wars and the doings of Ares, battles and fights, and fine workmanship — she first taught joiners on earth to make carriages and chariots ornamented with bronze, and she taught fine workmanship to tender-skinned girls in their houses, putting it into each one's mind.

Homeric Hymn 5.8-15 
This thesis uses the font Gilbert Color. Ogilvy and Mather Design Team designed the font in collaboration with NYC Price and NewFest as a tribute to Gilbert Baker, the original creator of the Rainbow Flag who sadly passed away in 2017. Baker was an LGBT + activist and an artist who helped friends create banners for protests and marches. The font was designed to help create attractive banners which can be held high at marches and rallies. The font is an OpenType-SVG format which hosts the ability to have multiple colours within a single glyph. These colours have been used repeatedly throughout this research portfolio to recognise Baker's contribution to the LGBT+ community and reflect the original meaning of the Flag: to represent the diversity of the LGBT+ community.

Gilbert Color is licensed under a Creative Commons AttributionShareAlike 4.0 International License. For more information on the font, go to www.typewithpride.com.

Due to the spectrum of gender and sexual identities encapsulated by the LGBT + community, this section will refer to a group of members of this community as queer, unless the group includes individuals of one identifier e.g. bisexual individuals. Historically, the term queer has been used as a slur against the gay population, but since the 1990s it has been "reclaimed" by the gay community as a term used to describe individuals who are gender deviant, i.e. those who do not conform to the male/female binary. "We [queers] don't conform to traditional heterosexist assumptions of male and female behaviour, in that we have sexual and emotional relationships with the same sex" (Tatchell, as cited by Abrehart, 2009, para. 12). Therefore, as a personal choice, the author has used the reclaimed term queer within this research portfolio.

This research portfolio is written by a proud queer person with friends and family members of a variety of sexualities and gender identities. Every possible consideration has been made to ensure that the opinions voiced in this research portfolio do not belittle or discriminate against any members of the LGBT + community. 
Coreword 
During my Bachelor of Design Innovation, I completed a minor in Classical Studies, focusing on Greek history and art. I struggled with how to integrate the fields of Design and Classics cohesively during this time and took a year off from study after graduating to reassess what I hoped to achieve with my degree. I came to the Victoria University of Wellington School of Design End of Year exhibition in 2017 and saw a collaborative project between the School of Design and the Classics Programme, blending classical iconography and contemporary $3 \mathrm{D}$ printing. $3 \mathrm{D}$ printing was a relatively unexplored technology for me during my undergraduate studies, but the project I saw at the exhibition was the spark that lit my passion for learning again. The following research portfolio is the result of that spark. 
Abstract 
Greek myth and art acted as tools to think with, and a lens through which to explore complex topics, like a form of social media. In particular, coins were a form of propaganda to communicate the wealth and power of the city-states they originated from as they circulated from person to person. Using these media as a starting point, how can the application of $3 \mathrm{D}$ printing technologies explore the infusion of ancient forms with contemporary commentaries to promote discussion? The digital reconstruction of artifacts is a topic that has been researched by various groups all over the globe. The exploration of Greek myth through objects infused with contemporary issues is currently unexplored in this medium. Using the Stratasys J750 3D printer - a multi-material, fullcolour 3D printer - a series of coins inspired by ancient Greek currency and myth was created to present commentaries on the adversities surrounding individuals in the LGBT+ community. Using the J750 as the medium for expression allows for complete control and precision of the models to create complex, highresolution iconography. A hard, translucent material was used to print the coins, with coloured $3 \mathrm{D}$ visuals embedded into the coins for viewing in close contact by the audience. These coins as commentaries present an avenue for broader understanding by drawing perspectives not only from sources concerned with the contemporary LGBT + community but also from sources exploring ancient homosexuality and the perception and regulation of it in antiquity. By displaying what are usually points of contention between anti- and pro-LGBT+ parties, this visual medium opens up a discussion to both parties, suggesting heritage can play a vital interpretative role in the contemporary world.

Keywords - 3D Printing, Design, Greek mythology, LGBT+ community. 


\section{Acrnowledgements}


Bernard Guy and Diana Burton, thank you for your unwavering guidance through this thesis, and for our discussions to help broaden my perspectives. Thank you for making me realise my passion.

Postgraduate coordinators, Catherine Caudwell and Gillian McCarthy, thank you for providing a welcoming environment for postgraduate students to prosper in. A special thanks to Catherine for your support during the hard early months of this thesis.

A god amongst workshop technicians, Phil Jarrett. Thank you for your work with the J750 and for entertaining all the stressed-out emails I sent to you when things didn't go to plan.

I have so many thanks to give Selma Simmons, and Michelle and Patricia Lastovicka I could write a second thesis. Selma, thank you in particular for fostering my love for learning at a young age and being my number one supporter in everything I do. Michelle, thank you for being the voice of reason on the other end of my frantic phone calls when I thought the world was crashing down around me. Patricia, thank you for being unwaveringly supportive of me in all aspects of my life, but especially this thesis (look who got published first!).

Brian Simmons, and Kathryn, Zavier and Adam Boyles, thank you for remaining supportive even when I was indignant and for always loving and supporting me.

To the MDI 2018-9 cohort: we made it. A special thank you goes to Jess Freire, Max Syme, Maddy Hazelton and Will Zheng for their assistance with photography.

Phoebe Zeller, thank you for listening to my ravings and the innumerable coffee and lunch dates to keep me sane.

To everyone else in my life, thank you for tolerating me during my writing of this thesis. 


\section{Contents}

Author's note ..................... iii

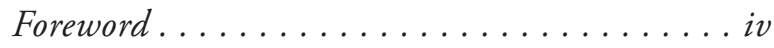

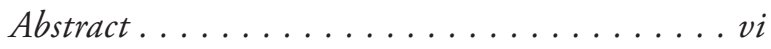

Acknowledgements................ viii

Contents ....................

List of Figures $\&$ Tables $\ldots \ldots \ldots \ldots \ldots \ldots$

Introduction $\ldots \ldots \ldots \ldots \ldots \ldots \ldots \ldots \ldots \ldots$

Thesis Overview . . . . . . . . . . . . . 10

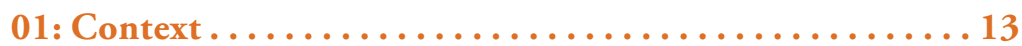

Myth of the Greek pantheon ............ 16

$L G B T+$ community . . . . . . . . . . . 18

Ancient Greek homosexuality . . . . . . . . . . 20

Greek homosexuality in myth . . . . . . . . . 22

Myth in Greek art . . . . . . . . . . . . . . 24

Digital technologies in cultural settings . . . . . . 27

02: Research through Context.....................

Research Methods ................... 36

Design process . . . . . . . . . . . . . . 37

Case study . . . . . . . . . . . . . . . . . 37

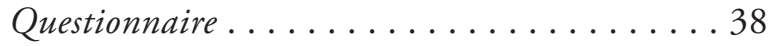

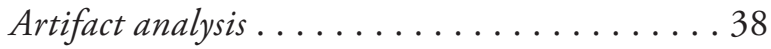

Making .................... 39

Technologies used . . . . . . . . . . . . . 40

Precedent Review . . . . . . . . . . . . . . . . 42

Sleeping Hermaphrodite . . . . . . . . . . . . . 45

Red-figure vase painting . . . . . . . . . . . 46

The Labours of Herakles . . . . . . . . . . . . . 49

Gilbert Color.................. 50

Precious Printing . . . . . . . . . . . . 53

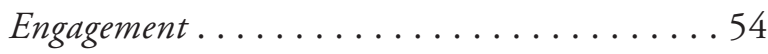

03: Research through Design ................. . 59

Introductory Experiments in Visualisation . . . . . . 62

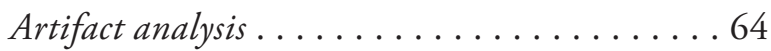

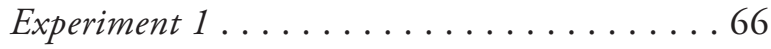

Experiment 2... . . . . . . . . . . . . 69

Experiment $3 \ldots \ldots \ldots \ldots$. . . . . . . . . 70 
Experiments in Form . . . . . . . . . . . . 72

Batch 1.................. 74

Batch 2..................... 77

Batch 3................. 78

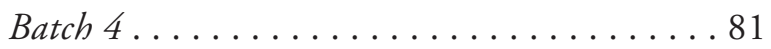

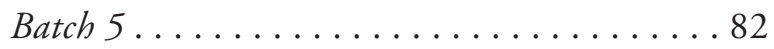

Batch 6................... 85

Batch 7.....................89

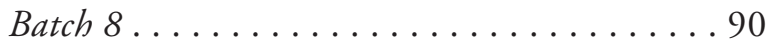

Metal 3D printing ................92 92

Designed Resolution . . . . . . . . . . . . . . 96

Blue Medusa ..................... 98

Encapsulated Medusa . . . . . . . . . . . . 101

Medusa Currency ................... 102

Transgender Red-Figure . . . . . . . . . . . . 107

Red-Figure coin: Tribute to Gilbert Baker. . . 108

Digital Athena ................... 111

04: Design Implementation . . . . . . . . . . . . 113

Discussion ......................... . 114

Conclusion ..................... 120

References....................... 122

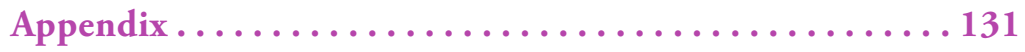




\section{List of Figures \& Tables}

Figure 1. Detail of a bridal scene with Eros seen flying between the couple. Reprinted from Pandora: Women in Classical Greece (p. 166), by E. Reeder, 1995, Princeton, NJ: Princeton University Press.

Figure 2. Group $\alpha$ example by the Phrynos painter. Adapted from $A$ companion to Greek and Roman sexualities (p. 106), by T. K. Hubbard, 2014, Chichester, England: Blackwell.

Figure 3. Group $\beta$ example of a man offering a cockerel to a boy.

Reprinted from Greek Homosexuality (R791), by K. J. Dover, 1978, London, England: Gerald Duckworth \& Co.

Figure 4. Group $\gamma$ example of a scene of intercrural intercourse.

Adapted from A companion to Greek and Roman sexualities (p. 108), by T. K. Hubbard, 2014, Chichester, England: Blackwell.

Figure 5. Group $\delta$ example of a boy mounting an erect, seated erastes.

Reprinted from Greek Homosexuality (R954), by K. J. Dover, 1978, London, England: Gerald Duckworth \& Co.

Figure 6. Satyr holding a wineskin with his erect penis.

Figure 7. A Sleeping Hermaphrodite from Rome; mattress by G.

L. Bernini, 1620. Adapted from Classical Art from Greece to Rome (133-134), by M. Beard \& J. Henderson, 2001, Oxford, NY: Oxford University Press.

Figure 8. Ancient Greek vase with red-figure decoration.

Figure 9. Herakles goes to Gallipoli. Reprinted with permission, courtesy of Marian Maguire.

Figure 10. LGBTQ Fly Posters. From Type With Pride. Retrieved from https://www.typewithpride.com. Copyright 2017 by Ogilvy and Mather Design Team.

Figure 11. A group of the completed 3D printed amphora, each amphora is approximately $100 \mathrm{~mm}$ high. Courtesy of Diana Burton.

Figure 12. A student's depiction of an Amazon warrior stabbing a

Greek soldier during the Amazonomachy. Printed with permission. 
Figure 13. A student's depiction of Sisyphus during his eternal

punishment under the supervision of Persephone. Printed with permission.

Figure 14. A student's depiction of Narcissus admiring himself in a pond while the nymph Echo watches. Printed with permission.

Figure 15. A student's depiction of the deaths of Astyanax and

Polyxena during the Trojan War. Printed with permission.

Figure 16. Theoretical external support material needed for various pottery forms shown in red.

Figure 17. Areas of decoration on various pottery forms shown in orange.

Figure 18. Vase template depicting Hermaphroditos and Salmacis.

Figure 19. Vase template depicting Aphrodite (left), and Eros (right)

flanking a confused girl.

Figure 20. Figures with transgender flag overlay.

Figure 21. Figures with natural skin and hair tones.

Figure 22 Figures in adapted red-figure style.

Figure 23. Batch 1 with embedded visuals.

Figure 24. Batch 2 with embedded visuals. $\quad 76$

$\begin{array}{ll}\text { Figure 25. Assembly } 7 \text { detail with embedded visual. } & 76\end{array}$

Figure 26. Assembly 8 detail with embedded visual. 76

Figure 27. Assembly 9 detail with embossed visual. $\quad 76$

Figure 28. Assembly 10 detail with embossed visual. 76

Figure 29. Assembly 11 detail with embossed visual. $\quad 76$

Figure 30. Assembly 12 detail with embedded visual. 76 
Figure 33. Assembly 14 detail with embedded visual. $\quad 79$

Figure 34. Assembly 15 detail with embedded visual. 79

Figure 35. Assembly 16 detail with embedded visual. 79

Figure 36. Assembly 17 detail with embedded visual. 79

Figure 37. Assembly 18 detail with embedded visual. $\quad 79$

Figure 38. Batch 4 with embedded and embossed visuals. $\quad 80$

Figure 39. Assembly 19 detail with embossed visual. $\quad 80$

Figure 40. Assembly 20 detail with embossed visual. $\quad 80$

Figure 41. Assembly 21 detail with embossed visual. $\quad 80$

Figure 42. Assembly 22 detail with embedded visual. $\quad 80$

Figure 43. Assembly 23 detail with embossed visual. $\quad 80$

Figure 44. Assembly 24 detail with embedded visual. $\quad 80$

Figure 45. Batch 5 with embedded visuals. 83

Figure 46. Assembly 25 detail with embedded visual. 83

Figure 47. Assembly 26 detail with embedded visual. 83

Figure 48. Assembly 27 detail with embedded visual. 83

Figure 49. Assembly 28 detail with embedded visual. 83

Figure 50. Assembly 29 detail with embedded visual. 83

Figure 51. Batch 6 with embedded visuals. 84

Figure 52. Assembly 30 detail with extruded visual. $\quad 84$ 
Figure 54. Assembly 32 detail with embossed and extruded visual.

Figure 55. Tetradrachm of Athens. From Ancient Greek coinage.

Retrieved from https://en.wikipedia.org/wiki/Ancient_Greek_coinage

Figure 56. Obverse of coin with the face of Medusa. From Ancient

Greek coinage. Retrieved from https://en.wikipedia.org/wiki/Ancient_ Greek_coinage

Figure 57. Reverse of Medusa coin with an Incu square. From Ancient

Greek coinage. Retrieved from https://en.wikipedia.org/wiki/Ancient_ Greek_coinage

Figure 58. Colours isolated from the Gilbert Color font.

Figure 59. Batch 7 with embedded visuals and faulty colours.

Figure 60. Batch 8 with embedded visuals.

Figure 61. Assembly 33 detail with embedded visual.

Figure 62. Assembly 34 detail with embedded visual.

Figure 63. Assembly 35 detail with embedded visual.

Figure 64. Assembly 36 detail with embedded visual.

Figure 65. Assembly 37 detail with embedded visual.

Figure 66. Initial geometric ideation for metal printing.

Figure 67. Greek patterns used in vase painting.

Figure 68. Render of Net metal ring.

Figure 69. Render of Palmette metal ring.

Figure 70. Render of Baker metal ring.

Figure 71. Blue Medusa in palm (right). 
Figure 72. Close-up of Blue Medusa (below).

Figure 73. Encapsulated Medusa with backlighting (left).

Figure 74. Encapsulated Medusa showing print lines (below).

Figure 75. Medusa currency changing hands (right).

Figure 76. Close-up of Medusa currency (below).

Figure 77. Side view of Medusa currency.

Figure 78. Close up of Medusa currency peaks and valleys.

Figure 79. Light shining through Medusa currency.

Figure 80. Light shining through the underside of Medusa currency.

Figure 81. Trasngender red-figure close-up (left).

Figure 82. Close up of metal casing of Transgender red- figure (below).

Figure 83. Red-figure tribute to Gilbert Baker metal casing close-up (right).

Figure 84. Obverse side of red-figure tribute to Gilbert Baker (below).

Figure 85. Digital Athena close up (left).

Figure 86. Close up of coin insert showing an owl, an olive branch and the inscription $\mathrm{A} \Theta \mathrm{E}$ (below).

Figure E1. Participant 1 vase illustration. Printed with permission.

Figure E2. Participant 1 essay. Printed with permission.

Figure E3. Participant 2 vase illustration. Printed with permission.

Figure E4. Participant 2 essay. Printed with permission.

Figure E5. Participant 3 vase illustration. Printed with permission. 
Figure E6. Participant 3 essay. Printed with permission.

Figure E7. Participant 4 vase illustration. Printed with permission.

Figure E8. Participant 4 essay. Printed with permission.

Figure E9. Participant 5 vase illustration. Printed with permission.

Figure E10. Participant 5 essay. Printed with permission.

Figure E11. Participant 6 vase illustration. Printed with permission.

Figure E12. Participant 6 essay. Printed with permission.

Figure E13. Participant 7 vase illustration. Printed with permission.

Figure E14. Participant 7 essay. Printed with permission.

Figure E15. Participant 8 vase illustration. Printed with permission.

Figure E16. Participant 8 essay. Printed with permission.

Figure E17. Participant 9 vase illustration. Printed with permission.

Figure E18. Participant 9 essay. Printed with permission.

Figure E19. Participant 10 vase illustration. Printed with permission.

Figure E20. Participant 10 essay. Printed with permission. 
Introduction 
Storytelling through history has taken many guises such as paint, dance, spoken narrative, song and text. Storytelling is a method to convey human thoughts. As technology progresses, so do the means of telling stories. With the emergence of $3 \mathrm{D}$ printing in mainstream manufacturing in the last two decades, society has seen a boom of innovative uses for this method of making. This research explores a new avenue for $3 \mathrm{D}$ printing, combining old and new narratives to tell a story.

The question to guide this exploration is, "How can the application of contemporary $3 D$ printing technologies to classical formats encourage new ways of visual storytelling?"

To answer this question, three areas of interest are discussed: 3D printing, Greek myth and the LGBT + community. These areas are compared in order to assess how they may be integrated to create a cohesive design that tells a story. A case study was conducted with an undergraduate Classical Studies class to see how Classics and 3D printing are being combined currently within a cultural environment. From this, a narrative had to be developed to pursue within this method of making. Influence was drawn from Ancient Greek myth as a narrative to discuss the LGBT+ community. This community is a prominent part of contemporary society and is gaining more support across the world. However, members of the community still face hatred and prejudice. This research aims to explore areas of the LGBT+ community to inspire understanding and love between all people.

To answer the research question, the research:

- Explores the design opportunities between the shape and function of classical artifacts and contemporary digital making strategies.

- Assesses the print capabilities of various 3D printing technologies.

- Analyses the subsequent narrative possibilities.

- Uses visual storytelling through physical objects as a medium to spark debate and discussion.

- Identifies pressing issues within the LGBT+ community to be communicated in this medium.

- Creates iconography to convey these issues through visual storytelling. 


\section{Thesis Overview}

How can the application of contemporary 3D printing technologies to classical formats encourage new ways of visual storytelling? 


\section{Chapter 1 - Context}

This section provides a detailed overview of the different areas of research and how they are situated within this research.

\section{Chapter 2 - Methodology}

This section defines the methods of enquiry for this thesis and specifies examples of visual inspirations through a precedent review.

\section{Chapter 3 - Design Investigation}

This section is the visual story of the experiments and technology analyses, culminating in the final designed resolution of this research.

\section{Chapter 4 - Design Implementation}

This section discusses the findings of the research and their impact, as well as possibilities for future research.

\section{Appendix}

A glossary of key terms used in this thesis can also be found here. This section also exhibits the student work from the Engagement case study, as well as the information sheet and consent form for the study. 


\section{이: \\ Contert}


This research is situated between the disciplines of Design and Classical Studies to combine the old with the new to create new visual stories. More specifically, this research explores aspects of homosexuality in ancient Greek myth and art and aims to effectively integrate it with a contemporary view of the LGBT+ community through the technology of $3 \mathrm{D}$ printing. To fully understand these different fields, it is essential to understand the definitions and research that support both of them, as well as the methods of thinking that were present in their societies. A literature review was conducted to identify the key parallels and contrasts between the ancient Greek world and the modern world, as well as the way in which they converge currently so as to understand and critically examine how these histories are relevant to this research portfolio. 


\section{Myth \& the Greek pantheon}

In ancient Greece the literacy level was much lower than it is in contemporary times. Therefore, individuals passed on stories orally. These stories became widely known across the Mediterranean, and Northern Africa as the Greeks expanded their influence. Images on vase-paintings and statues were widely used to convey the ideas and characters from these myths and woven into the everyday life of the Greek citizen. Greek myth has a rich interwoven tapestry of stories that host a variety of roles from the daring but flawed hero (Odysseus) to the gentle and strong-willed wife (Penelope). These characters and their stories have a depth to them that is still relevant to our contemporary society, as can be seen in the emergence of Greek-inspired media over the last two decades such as Rick Riordan's book and movie series Percy Jackson and the Lightning Thief (2005); the TV series Troy: Fall of a City (Reisz, 2018); and the video game Assassin's Creed Odyssey (Ubisoft Quebec, 2018).

The word 'myth' is derived from the Greek word mythos which meant 'word', 'saying', or 'story'. As the idea of historical fact became established, mythos then also came to mean 'fiction' or 'falsehood' (Willis, 1996). Contemporary definitions of myth tend towards the notion of falsehood. Myths are fantastical stories that tell a story while educating the audience on an aspect of society. Myth, as the Greeks saw it, was comparable to a scientific theory (Goldhill, 1996). They sought to uncover how the world functions through the doings of a group of godly beings who command all of nature and Greek society. Because of this, 'myth' and 'history' must be seen as integral and complementary elements of Greek culture. Myth served as a collective memory that retold the distant past (Henrichs, 1999). Myth made a statement about everything human existence depends on, from society and its institutions to the relationships between the gods and humans (Graf, 1993). Heroic stories were at the forefront of Greek myth, following the noble acts of heroes boasting godly parentage. These mythical heroes helped tell historical events as a "fictitious story that tells the truth" (Theon, as cited in Graf, 1993, p. 4).

Each mythic hero was localised in an area of Greece and became known across the country as they completed various feats and travelled abroad. As a myth moved around Greece, it took on the sociocultural context of the independent city-states and adapted to their independent cultures, taking on the local 
traditions and creating a rich tapestry of Greek mythic history (Shapiro, 1994). Fritz Graf explains this flexibility:

A myth is not a specific poetic text. It transcends the text: it is the subject matter, a plot fixed in broad outline and with characters no less fixed, which the individual poet is free to alter only within limits. $(1993$, p. 2)

The individual myth storylines were not an immovable concept. They were adapted as society changed and were moulded to fit the issues of the world at the time. A myth is not sterile; mythmaking was just as much a part of Greek religion and society as the sharing of said myths. The tales themselves were multilayered to be relevant to issues and social realities. By way of example, Greek tragedians Aeschylus, Sophocles and Euripides each used heroic myth as "a vehicle for reflecting on the most pressing issues of his day" (Shapiro, 1994, p. 4.). Each tragedian used the conventions of drama differently; however, the myth was a common thread. Greek myth was never viewed as sacrosanct, which allowed the artists to adapt and change myths to reflect individual situations within their favoured myths (Shapiro, 1994). This utilisation of myth as an adaptive tool indicates how myths were distributed in Greek society, often told before a large group where they were bound to, and the narration of them was controlled by, the group (Graf, 1993). The reinterpretation of the gods and heroes opened a dialogue between the classical Greeks and their heroic past, keeping the myths alive and relevant to everyday life. This adaptation is still happening in the contemporary world. Stephen Fry's book Mythos (2018) retells Greek myth for the modern reader. Fry's mythical narrative is written to bring out the humour and tragedy of the tales in contemporary English language so everyone, not just scholars of Greek literature and those familiar with the syntax of ancient Greek language, can enjoy the myths. Similarly to the ancient Greek tragedians, Fry retells the myths to make them more appropriate for his time and to reflect his sense of humour, but has remained faithful to the 'original' myths.

To expand on this, John Gould (1999) explains there are two different perspectives of myth: that of the ancient audience, and the modern reader. The significance of myth comes from the audience (Graf, 1993) and consequently their interpretation of the subject concerns, and is rooted in, the customs of their society. 
Because of this, Greek myth becomes interpreted differently in the contemporary world, as the analysis is distorted due to the fact that our societal ideals and customs no longer run parallel to those shown in the myths.

\section{LGBT+ community}

Most contemporary societies strive to maintain a heteronormative order where any sexual or gender deviance is stigmatized (Harper, Brodsky, \& Bruce, 2012). Even with the rise in supporters for the Lesbian, Gay, Bisexual, and Transgender (LGBT+) community, most societies still regard sexual and gender deviances with a mixture of revulsion and contempt (Altman et al., 2012; Harper \& Schneider, 2003).

Because of the pervasiveness of the heteronormative societal model, many queer individuals, especially adolescents, still deal with discrimination, persecution and even violence becasue of how they identify. This discrimination has been labelled homophobia by psychologist George Weinberg to describe "the dread of being in close quarters with homosexuals - and in the case of homosexuals themselves, self-loathing" (Weinberg, as cited by Altman et al., 2012, p. 439). The term homophobia has since been redefined as homonegativity (Herek, as cited by Bregman, Malik, Page, Makynen, \& Lindahl, 2013) to distinguish between negative feelings toward queer individuals and fear of queer individuals. Often, prejudice and homophobia stem from religious teachings, as almost all institutionalised religions either do not fully accept homosexuality or condemn it (Altman et al., 2012). Because of this, much of Africa, Asia, and the Middle East still view homosexuality as a cardinal sin. This shapes homosexuality by codes of silence, secrecy, and taboos as to speak of issues surrounding sexuality is not socially acceptable (Altman et al., 2012). Interestingly, more LGBT+ males (50\%) reported experiencing discrimination than females $(25 \%)$. This could potentially be attributed to the contemporary fetishisation of female same-sex couples within adult films, whereas sex between men is often misunderstood or feared in most parts of the world due to the HIV/AIDS crisis (originally termed GRID, or Gay-Related Immune Deficiency) (Altman et al., 2012).

Even in countries where public policy protects individuals from discrimination, it does not fully change toxic attitudes towards members of the LGBT+ community. These attitudes can 
echo themselves within the queer individual's psyche. Meyer (as cited by Shilo \& Savaya, 2012) identified five stressor types based on proximity to the individual that contribute to negative emotions within LGBT+ individuals: two distal (external) stressors, and three proximal (internal) stressors. The distal stressors are general stressors, such as job loss, and prejudice events, such as violence or discrimination due to minority status. The proximal stressors relate to the individual themselves: expectations of rejection, concealing sexual orientation or gender identity from others, and the internalisation of societal heterosexist attitudes and expectations. This last stressor is often referred to as internalised homophobia/negativity (Bregman et al., 2013; Shilo \& Savaya, 2012). Because of this internal negative monologue, it is found that LGBT+ youth are more likely than their heterosexual, cisgendered peers to have depressive symptoms and incur a greater likelihood of reporting self-harm and suicidal ideation (Almeida, Johnson, Corliss, Molnar, \& Azrael, 2009).

Every year there are many suicides of young LGBT+ individuals resultant of constant taunts and bullying because of their gender or sexual identities (Altman et al., 2012). Suicide is the third most common cause of death among adolescents and non-suicidal self-harm occurs in $13-45 \%$ of individuals within this age group (Liu \& Mustanski, 2012). After suicide attempt history, homonegativity victimisation is the strongest predictor of self-harm, proving that something needs to change within society about how it reacts to those challenging the heteronormative model. Richard Liu and Brian Mustanski (2012) outline that the first lifetime onset of suicidal ideation for LGBT+ youth increases dramatically around the age of 12 years, and continues to increase until mid- to late adolescence. This could be attributed to the onset of puberty at age 10-12 years. With the increase of hormones in the young body, the individual often begins to form attractions to other individuals, and therefore sexuality can manifest in the realisation of where that attraction is directed.

Bisexuals have been found to have poorer mental health and less social support than their gay or lesbian peers (Kertzner et al., 2009; Rosario et al., 2001; Russell \& Consolacion, 2003; Shilo \& Savaya, 2012). Self-identifying bisexual individuals make up roughly $1.8 \%$ of the population - versus $1.7 \%$ who identify as gay or lesbian (Cooper, 2016). Even while being a slight majority, bisexuals are viewed especially negatively and stigmatised by 
society and the LGBT+ community (Herek, as cited by Shilo \& Savaya, 2012) which contributes to the poor mental health in these individuals.

With all of the negativity still surrounding the LGBT+ community (Bontempo \& D'Augelli, 2002; D'Augelli, 2002, 2006; D’Augelli \& Hershberger, 1993; Garofalo \& Harper, 2003; Pilkington \& D’Augelli, 1995; Ryan, Huebner, Diaz, \& Sanchez, 2009; Savin-Williams \& Cohen, 1996; Telljohann \& Price, 1993), this research portfolio aims to promote cultural awareness and societal sensitivity to help reduce the stigma some queer individuals still face.

\section{Ancient Greek homosexuality}

Greek homosexuality has been the subject of intensive discussion over the last few decades, and there is still no consensus as to its interpretation. Most of the following discussion focuses on ancient Athens, both because of the preponderance of evidence from the city and also because of the centrality of homosexuality in Athenian society. The focus of this section is to discuss male homosexuality in Greece due to the readiness of evidence and discussion surrounding this topic. Almost all of our evidence on ancient homosexuality comes from a male point of view, that will not allow for an informed opinion on female homosexuality within the scope of this research and therefore has been omitted from this review.

According to one school of thought, the essence of Greek love was possession and the identification of dominant and submissive parties within the relationship (Adămuţ, 2011). In terms of sexual activities, the dominant party is the 'active' partner (i.e. the penetrator); while the submissive party is the 'passive' partner (i.e. the one penetrated). Entertaining this sexual model, penetration is seen by some scholars as both social and sexual dominance (Arthur-Katz, 1989). However, there are numerous theories as to how homoerotic relationships were perceived by the Greeks; the most convincing will be discussed in this section.

The Greeks did not have words such as homosexuality, bisexuality or heterosexuality to categorise people's sexual preferences. Homosexuality fell under the category of sexual inversion until the adoption of the word 'homosexual' in the 1890s which referred to a wide range of 'gender deviant' behaviours 
(Halperin, 1990). The term 'homosexual' is an etymological hybrid of the Greek prefix homo- meaning 'same' (not to be confused with the Latin homo-, meaning 'man'), and the Latin root sexwhich is self-explanatory (homosexual, n.d.). However, this term was meaningless to the Greeks as sexuality was not a defining characteristic of the self (Arthur-Katz, 1989). It is a very modern approach to categorise people by the object of their desire ${ }^{1}$. The Greeks understood that humans, by nature, are sexual beings and therefore the attractions they felt were not a defining factor of the individual (Arthur-Katz, 1989).

Greek pederasty was a temporary relationship between an erastes (the lover) - a mature man, older than twenty and sometimes extending beyond middle age - and an eromenos (the beloved) - a boy or youth around the age of puberty until the late teens (an age range suggested by scholars is between the ages of 12 and 18) (Adămuţ, 2011; Smith, 1996). Pederastic relationships were a component of a young boy's education (paideia) and were, therefore, nothing unnatural in Greek society (Adămuţ, 2011). The erastes was responsible for teaching the eromenos social and cultural customs, and assisting in any and all aspects of his paideia as required. While not all pederastic relationships held a sexual aspect (as in the case of Alkibiades and Sokrates, where Sokrates would not reciprocate the boy's advances but slept beside him), it was a common occurrence for there to be flirting, gift-giving and physical affection being given by the erastes to the eromenos, similar to heterosexual courtship (Smith, 1996). Andrew Lear (2014) argues that instead of the heavily sexual relationships implied by Anton Adămuţ (2011), the boys underwent a ritualised kidnapping, and were sent outside of the community to learn to hunt in the company of their kidnapper/lover before returning to the community. A boy's paideia included various valourised activities and attitudes such as athletics, hunting, symposia, and the development of self-restraint (sophrosyne) and bravery to shape the boy into the ideal Greek man (Lear, 2014). Some scholars argue that Greek pederasty developed out of the erotic relations between soldiers; others believe that pederasty was part of the initiation rites of an adolescent rising to manhood (Lear, 2014).

1 i.e. heterosexual or "straight" to describe those with an attraction only to those of the opposite sex; homosexual or gay to describe those with an attraction only to those of the same sex; bisexual to describe those with an attraction to both the same sex and other sexes. 
The attribution of dominant and submissive sexual roles proposed by Marilyn Arthur-Katz (1989) and Anton Adămuţ (2011) grows murky when applied to same-sex couplings. When two adult male citizens (citizenship being the socially superior position) have a sexual relationship, one of them is assumed to take a submissive role during copulation (Percy, 1996). Therefore, these relationships were criticised, not because of the androphilia, but because of the citizen's assumption of the feminine, and consequently derogatory, position. A citizen who assumed this role was known as a malthakos, an 'unmasculine' man who departs from the cultural norm of masculinity (Halperin, 1990). Anal passivity could also be understood metaphorically as a capitulation to one's appetites, including sexual appetites, but also overindulgences with food and drink. A proper Greek man in control of himself did not wholly abstain from bodily pleasures, but trained in virtue to use pleasure wisely, never allowing desires to overcome rational judgement; he practiced the paramount virtue of sophrosyne, selfcontrol (Skinner, 2014).

\section{Greek homosexuality in myth}

There are several Greek myths about how homosexuality came into being. One such myth tells the story of Khrysippos and Laios. Khrysippos was the son of Pelops, and Laios was overcome by desire for his extraordinary beauty and carried him off, according to Euripides' Chrysippus (test. iv.a, as cited by Hubbard, 2006). Laios was the first of humankind to fall in love with a person of his own sex (it is worth noting that Laios' abduction of Khrysippos was a rape that transgressed the laws of hospitality and was frowned upon for this). Laios thus became the 'inventor' of homosexuality in Greek tradition (Dover, 1978).

In Plato's Symposium, Aristophanes invents a myth that human beings originally had eight limbs, two heads, and two genital systems. These ancestors were powerful, ambitious creatures of three sexes (male, female, and androgyne). Zeus had them bisected to put them in their place, "their skin stretched over the exposed flesh and tied at the navel, and their heads rotated so as to keep that physical reminder of their daring and its consequences constantly before their eyes." (Plato, as cited by Halperin, 1990, p.19.) Following this, the new individuals spend their lives attempting to reunite with their other halves. The products of the first male sex are gay males, while the original female sex results in lesbian females. The rest are heterosexual, originating from the 


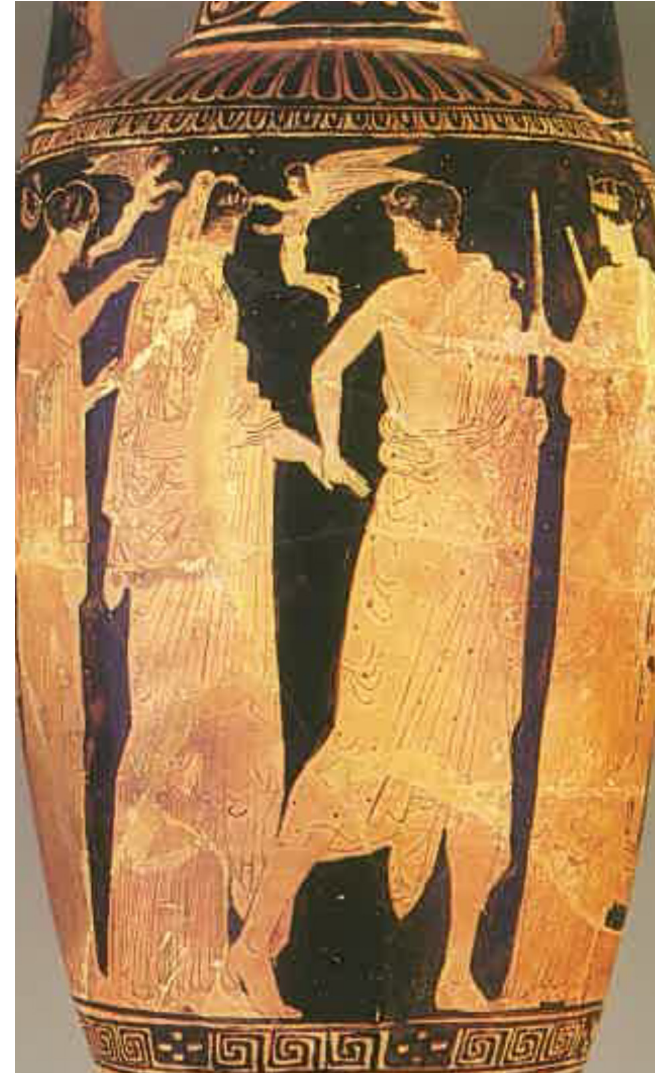

Figure 1. Detail of a bridal scene with Eros seen flying between the couple. Reprinted from Pandora: Women in Classical Greece (p. 166), by E. Reeder, 1995 , Princeton, NJ: Princeton University Press. androgyne sex (Dover, 1978).

To complement these myths depicting homosexuality, the Greeks also had patron gods for love as well. Most well-known is Aphrodite, the goddess of sex and desire. However, K. J. Dover argues that the realm of what we know as 'falling in love' and romance is squarely in Eros' domain (Dover, 1978). Aphrodite commonly signified the sexual relations between a man and a woman, while Eros presided over the devotion of a grown man to a boy - in other words, pederasty (Percy, 1996). This interpretation is debated, and there are examples of wedding scenes where a small Eros flies between the bride and groom to indicate the mutual desire between the pair, as shown, in Figure 1. (Reeder, 1995). Aphrodite has also been shown as the driving force in some depictions of Zeus' abduction of Ganymede as shown in Pindar's Olympian 10:

And I praised the lovely son of Archestratus, whom I saw at that time beside the Olympic altar, winning victory with the valor of his hands-beautiful in form, and blended with that youthful bloom which once kept Ganymede from shameless death, with the help of Cyprian Aphrodite. (10.99-106)

The Greeks did not, however, create pederastic myths as a method to excuse an immoral human custom; they instead considered this custom an improvement over an earlier, more primitive time (Percy, 1996). For example, one of the most prominent myths displaying pederasty between a god and a mortal is of Zeus and Ganymede. Zeus abducted Ganymede to replace Hebe as Zeus' cupbearer. The story of Ganymede shows that the eromenos was not merely an object of desire or possession, but a revered part of society (Lear, 2014; Percy, 1996; Skinner, 2014). Their role as an eromenos does not tarnish their standing in the community as they reach citizenship. There are many pairings between gods and mortals, and heroes and men such as Poseidon 
and Pelops; Achilles and Patroklos; and Herakles and Hylas (Percy, 1996). Being under the guidance of a powerful erastes means that the eromenos is getting the very best education. Most notably, the pairing of Achilles and Patroklos in Homer's Iliad is a non-typical pederastic relationship that bears mention because of the reversal of roles between the two men. It is debated by modern scholars whether or not Achilles and Patroklos were anything more than good friends, however surviving fragments from a lost play by Aeschylus Myrmidons which covered Achilles' refusal to fight and Patroklos' fighting in Achilles armour, and subsequent death:

fr. 135: And you did not respect the sacred honour of the thigh-bond, ungrateful that you were for those countless kisses!

fr. 136: And I honoured the intimacy of your thighs by bewailing you.

fr. 137: And yet to me, because I love him, this is not loathsome. (Sommerstein, 2009, p. 145-7)

These fragments are probably spoken by Achilles over Patroklos' corpse, the reference to thighs refer to intercrural sex. Patroklos was the elder of the two, but Achilles is obviously the dominant figure in the pairing due to his hero status. This, therefore, contradicted the protocols of the usual mentor-mentee dynamic in which pederasty was conceptually grounded (Skinner, 2014). The possibility that the two were in a pederastic relationship shows that the pederastic model was not as rigid as some scholars present it to be.

Textual sources are not usually as explicit about sex as vase painting is. Therefore, it is tempting to use vase painting as unambiguous evidence for the sexual practices of the Greeks, especially relating to pederasty (Lear, 2014). The next section will discuss vase painting and how it relates to the portrayal of pederasty and sexual practices of the Greeks.

\section{Myth in Greek art}

The late seventh century saw the introduction of explicit pederastic art, especially on pottery. Almost all of the erotic vases were manufactured in Athens (Percy, 1996), due to the high volume of vases made in Athens over other regions. This once again highlighting the centrality of homosexuality in the Athenian society. It is important to bear in mind that vase painting is its

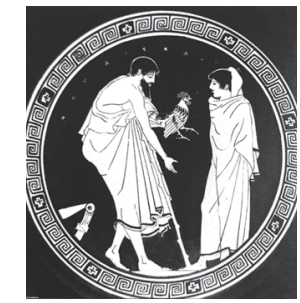

Figure 3. Group $\beta$ example of a man offering a cockerel to a boy. Reprinted from Greek Homosexuality (R791), by K. J. Dover, 1978, London, England: Gerald Duckworth \& Co. 


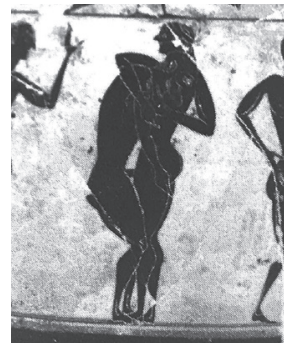

Figure 4. Group $\gamma$

example of a scene of

intercrural intercourse.

Adapted from $A$

companion to Greek and

Roman sexualities ( $\mathrm{p}$.

108), by T. K. Hubbard,

2014, Chichester

England: Blackwell.

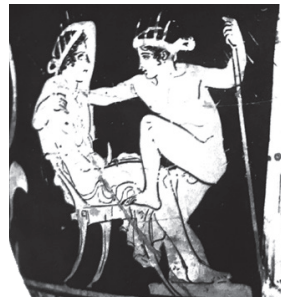

Figure 5. Group

$\delta$ example of a

boy mounting an

erect, seated erastes.

Reprinted from Greek

Homosexuality (R954),

by K. J. Dover, 1978,

London, England:

Gerald Duckworth \&

Co. own genre, similar to literary genres (Lear, 2014). Rather than a documentary of how the Greeks interacted, vase painting depicts an ideologically driven version based on elements of truth.

The depiction of pederasty in vase painting is highly stylised with the erastes on the left. The sexually explicit scenes are similarly ritualised, occurring face-to-face (Arthur-Katz, 1989). More often than not, intercrural intercourse is depicted rather than anal intercourse. As Lear (2014) explains, this is most likely due to the artist being able to portray the eromenos upright and therefore uninvolved with the sexual act. The eromenos is almost always flaccid even in situations where it is unlikely.

John Beazley classified pederastic vases into three groups, using over one hundred examples (Percy, 1996). These groups are split into alpha $(\alpha)$, beta $(\beta)$ and gamma $(\gamma)$ groups.

\section{Group $\alpha$ (Figure 2)}

The erastes stands with bent knees, reaching for the chin of the eromenos with one hand as a gesture of request, and for the genitals with the other. The eromenos is positioned opposite the erastes.

\section{Group $\beta$ (Figure 3)}

The erastes presents a gift to the eromenos. The gift could be a small animal or another trivial present so as not to look as if buying the favour of the eromenos.

\section{Group $\gamma$ (Figure 4)}

The erastes and eromenos are entwined in a standing position, with the erastes apparently intending to climax from rubbing his penis between the thighs of the eromenos, who commonly remains flaccid, submitting out of affection rather than reciprocal excitement. This shows sophrosyne in action.

Following these three groups, Percy (1996) argues for a delta group $(\delta)$ :

\section{Group $\delta$ (Figure 5)}

A seated and erect erastes approached by the eromenos, climbing on to his lap as if intending to prepare for anal intercourse. This depiction can be similarly seen on other 
vases depicting women mounting seated males for vaginal sex.

These depictions of Group $\delta$ are very unique from the categories classified by Beazley and therefore are worthy of a separate grouping. Interestingly, there is never oral-genital contact between erastes and eromenos is less frequently shown than in heterosexual scenes (Arthur-Katz, 1989; Percy, 1996).

The societal expectations which

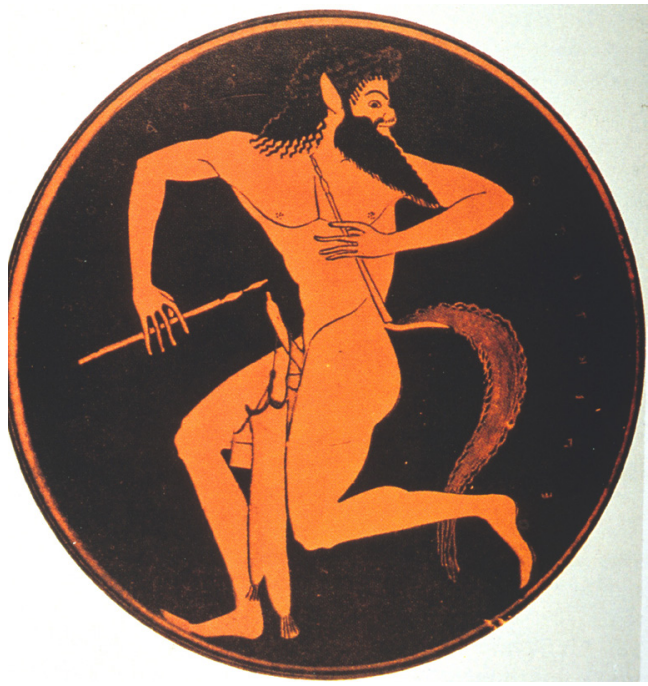

Figure 6. Satyr holding a wineskin with his erect penis. when we consider their antithesis. In Greek antiquity, satyrs are the followers of the wine god, Dionysus. Satyrs are half-human, half-beast, with human torsos and animalistic legs, ears, and tails. Satyrs became a symbol of excess, frenzied celebration and lust due to their lack of sophrosyne. Depictions of satyrs were common on wine cups as a warning to the drinker about the dangers of drinking to excess. The mythical figure of the satyr has persevered in contemporary vocabulary as a sign for sexual excess. The satyrs had a gigantic, erect penis, which sometimes functioned as a fifth limb to hold objects such as wine cups or flutes, as seen in Figure 6. The sexual activities of satyrs included elements of Greek societal taboo, particularly bestiality and fellatio. It is worth noting in Classical Period depictions that although the satyrs avidly pursued maenads (the female followers of Dionysus), it rarely results in sexual intercourse, to highlight the fact that they are not entirely human. Satyrs are depicted in both heterosexual and homosexual couplings (and also self-stimulatory situations). Where pederastic paintings rarely showed penetrative intercourse, satyrs are shown as both the penetrator and the penetrated. The use of satyrs in vase painting does not depict the Athenians' sexual behaviours, rather a countermodel (Lissarrague, 1990). Amongst the wanton behaviours of the satyrs, there are also depictions of satyrs in pederastic situations, following the conventions of such paintings.

This section shows the idea introduced at the start of this literature review that myth is a tool to think with. The satyrs are a good example of the dangers of sexual excess, whereas Zeus and Ganymede show a more stable paradigm of the pederastic relationship. Both of these scenarios discuss sexual relationships 
by showing the dichotomy between the healthy and unhealthy aspects to inform and warn the audience.

\section{Digital technologies in cultural settings}

The technology of additive manufacturing ( $3 \mathrm{D}$ printing) has been around since the 1980s, and yet has only been making traction in the mainstream since the late 1990s. Steadily, more people have become fascinated by this incredible technology and the possibilities it opens up. More prominently, the cultural heritage field has quickly adopted $3 \mathrm{D}$ printing and the related $3 \mathrm{D}$ scanning. These technologies, including photogrammetry, laser scanning, $3 \mathrm{D}$ modelling, and various forms of additive manufacturing, are being used to aid in the preservation of cultural sites, to catalogue artifacts and to create enhanced cultural exhibits.

Over the last decade, there has been an emergence of the use of 3D technologies in the cultural heritage field. Many museums, such as the Museum of Modern Art (MOMA, San Francisco, USA), Te Papa (Wellington, New Zealand), and the Smithsonian Institution (Washington D.C., USA), have started to digitise items that are not part of their regular exhibits to allow more access to these items. The digitisation of artifacts provides for more people to view and learn from the objects that are not on display, creating a more diverse cultural environment. Alongside digitisation, cultural environments have started to explore the use of technologies such as three-dimensional (3D) scanning and 3D printing for a variety of applications. This section will review some of the methods by which various cultural environments have used $3 \mathrm{D}$ technology to enrich the experiences of these environments.

The most common uses of digital technologies in the cultural heritage field are preservation and reconstruction. Cultural heritage is vital in understanding the history of ancient civilisations, how their people behaved and how culture influences the modern world (Al-Baghdadi, 2018). Cultural heritage sites are increasingly frequent victims of both natural and humaninduced adversities. These adversities could include neglect, decay, bad restorations, looting or illicit excavation of sites, or more prominently, war and conflict. Mosul Museum in Iraq is one such site affected by war and conflict. In February 2015, artifacts within the museum were documented being destroyed by the extremist group of the Islamic State of Iraq and the Levant (ISIS) (Vincent et al., 2015). 
Photogrammetry and 3D scanning are essential technologies in preserving lost or decaying heritage. Photogrammetry refers to the use of a series of $2 \mathrm{D}$ images taken of an object from every angle to make a 3D model. The software recognises similar features in each image and 'stitches' them together to form the 3D model. In the case of the Mosul Museum, crowd-sourced images from visitors of the museum were used to reconstruct exhibits in a virtual museum, and even $3 \mathrm{D}$ print them (Coughenour, 2016). One of the challenges with using crowdsourced images is the high concentration of images from the front and sides of artifacts only ("How many of you when you visit a museum, take photographs of all parts of the statue, even the back side of it?" (Coughenour, 2016, 5:11)). Other sites utilising similar technologies to reconstruct decaying heritage are Najaf's holy city in Iraq (Al-Baghdadi, 2018), and Tiwanaku in Bolivia (Vranich, 2018).

$3 \mathrm{D}$ scanning is very similar to photogrammetry in that it generates a $3 \mathrm{D}$ image of an object from a series of photos taken by the scanner. 3D scanning allows for larger objects such as buildings and entire cultural sites to be translated into a $3 \mathrm{D}$ form (Al-Baghdadi, 2018). In Najaf, Al-Baghdadi proposed several different methods of preservation stemming from this technology including a 3D printed replica of the 3D scanned map of Najaf, and a virtual reality model of the Kufa Mosque that has the potential to be walked through digitally by visitors. The Tiwanaku site and resulting paper (Vranich, 2018) was concerned with the technicalities of $3 \mathrm{D}$ printing, rather than the possibilities of the technology. When printing 3D components from Tiwanaku, Vranich tested many different methods of 3D printing. Firstly, the cheaper Fused Deposition Modelling (FDM) with a polymerbased filament was found to be "unsatisfyingly light" (Vranich, 2018, p. 12) and the heat of the nozzle caused warping in some models. Vranich also tested Selected Laser Sintering (SLS) with a powder-based material. The powder-based method proved more expensive but also more successful as it did not warp or bend like the FDM method during printing. The resultant models were more cumbersome and thus had a tactile quality familiar to the archaeologists. For those focusing on ceramic artifacts, the powder-based method also allowed for replication that more closely represented the original artifact (Vranich, 2018). Vranich echoes what other sources had previously found: that SLS printing 
is currently the most successful method of $3 \mathrm{D}$ printing for cultural heritage (Capurro, Nollett \& Plentickx, 2015; D’Agnano, Balletti, Guerra \& Vernier, 2015).

An issue faced by cultural environments is the accessibility of exhibits to those who are visually impaired or blind. Alongside preservation and restoration, digital technologies can be used to create open displays for visually impaired museum visitors. These include projects such as Tooteko (D'Agnano et al., 2015) and Virtex (an acronym for VIRTual EXhibit) (Capurro et al., 2015). These technologies allow for the introduction of a tactile component to traditional museum exhibits. Tooteko incorporated a ring that the user wore and passed over the 3D scanned and 3D printed artifacts to gain information via audio output relating to the part of the surface touched (D'Agnano et al., 2015). Virtex is a similar idea to Tooteko; however, it does not utilise external technology for the exhibits to function. Instead, the artifacts (usually larger items that it would be difficult to get a full tactile assessment of) were 3D scanned and modified after printing to integrate switches in slots within the surface of the model. The visitor then presses the switches to get an audio output with information about the artifact. While these studies focused on visually impaired visitors, this technology can also be used to enhance the museum experience of all visitors further.

The use of tactility challenges the current culture of museums that discourages patrons from touching the exhibits. Inviting the patrons to interact with the artifacts more directly creates a more intimate relationship with each object. Creating interactable objects that can be used directly by the viewer creates a more open museum experience and could promote a better learning environment. This method could translate to other contexts, such as learning environments to aid understanding for students studying artifacts that are usually too fragile to be held.

Of course, it is foolish to assume that $3 \mathrm{D}$ printed replicas will entirely replace the original artifacts, as there is a sense of awe and wonder when looking at an item from ancient times, knowing the history that the object has seen. But the use of $3 \mathrm{D}$ printed replicas paired with the original artifact can enrich the learning experience, as explored by D'Agnano et al. (2015) and Capurro et al. (2015). 3D printing allows for rapid production of replicas if a printed artifact is worn or accidentally destroyed. And, in the 
case of Greek vases, 3D printed objects can be used in ways that the originals, now too valuable to risk, were intended to be used (Guy, Burton \& Challies, 2018).

The discussed methods of digital preservation are but one way $3 \mathrm{D}$ technologies are being utilised within the $\mathrm{CH}$ field. This research portfolio aims to explore a different avenue for this technology, using Greek myth to inform the design to create narratives about the LGBT+ community. Using a design methodology this research will creatively explore the bounds of contemporary $3 \mathrm{D}$ printing technologies and its possible implementation in storytelling. 


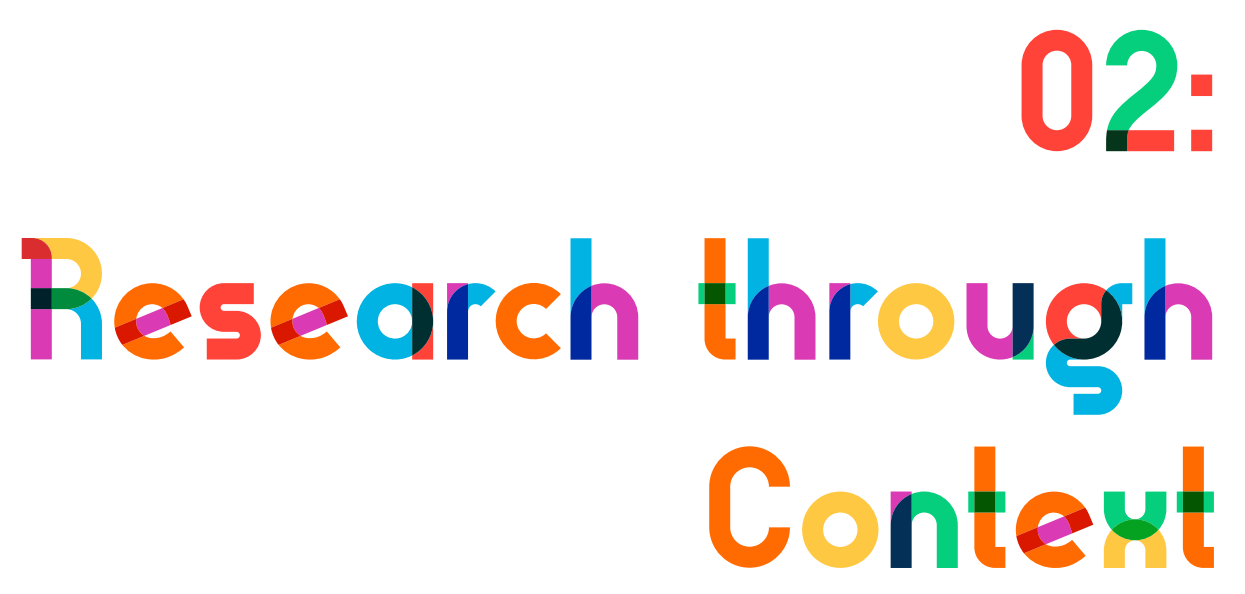


This research is cross-disciplinary and explores the integration of Design and Cultural Heritage through physical objects. This exploration was guided by research through context leading to a research through design (RTD) methodology to allow for an in-depth study into the integration of these two fields. This methodology is outlined by Christopher Frayling (1993) which builds on Bruce Archer's concept from his 1968 doctoral thesis (1995) as a means to justify the implementation of the design field in research environments (Frayling, 1993). RTD describes the use of physical design craft as a form of research. These crafts could include prototyping, such as sketches, card models or computer-aided design (CAD) models, material testing, and experimentation. Through this, the act of making encompasses the design process as a methodology of analytic research (Martin \& Hanington, 2012). The following research methods have been chosen as appropriate methods for inquiry through design to obtain valid results through design research. 
Research Methods 


\section{Design process}

This research portfolio will follow an investigation process to support the RTD methodology set out by Frayling (1993). The process is adjustable within the parameters of the project. This research has used an adapted version of the process outlined by Stone (2010). This process follows four stages: Discover, Define, Develop, and Deliver.

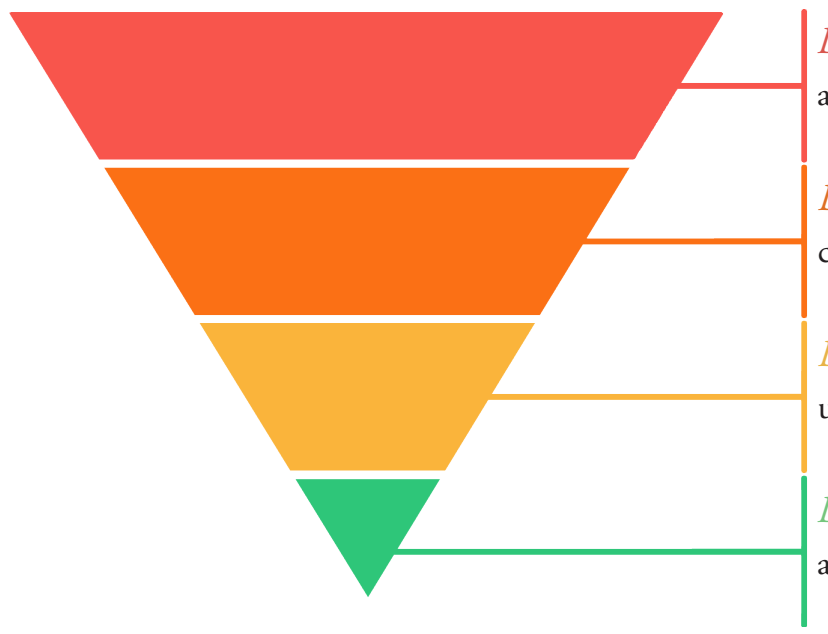

Discover establishes basic project parameters, clarifies aims and objectives, and sets initial criteria.

Define outlines the overall strategy for the project, creates preliminary concepts and evaluates them.

Develop is the focused designing, and developing until reaching a final design that addresses all criteria.

Deliver is the production of the final product, as well as a time for reflection upon the design process.

Evaluation of concepts and refinements throughout this process will be discussed briefly at the end of each phase of experiments before the overall discussion at the end of this research portfolio.

\section{Case study}

The use of case studies allows for an in-depth exploration into a single instance to explore first-hand the impacts of this instance within its context. Case studies as exploratory research enables the researcher to gain information for comparison or inspiration and can be used to observe the effects of innovation (Hanington \& Martin, 2012). Case studies follow a process similar to the design process. During a case study, the researcher identifies a problem (Discover), makes initial hypotheses (Define), and uses various methods of information gathering (Develop). The researcher then revises the hypotheses and tells a story (Discuss) (Hanington $\&$ Martin, 2012). As the Design field encapsulates telling a story through objects, this method of research is appropriate in the context of this research.

A case study was conducted in mid-2018 with a first-year undergraduate Classical Studies class and one of their assignments. 
The assignment situated itself between Design and Cultural Heritage and provided a first-hand experience on how the two fields meld in an educational setting. The resulting data informed the direction this research would take, and formed initial criteria for experimental outputs. This case study was paired directly with a questionnaire given to the students.

\section{Questionnaire}

Questionnaires allow for a first-hand account from participants in events such as case studies, and are a primary component in designing with people in mind. The results of a questionnaire are a vital element in meaningful research and give insight into the thoughts and feelings of the participants (Hanington \& Martin, 2012). The use of multiple choice answers allows a general quantitative overview of how the research was received, paired with the text entry answers to gather individual opinions of the study.

Upon the completion of the above case study, an anonymous questionnaire was run through Qualtrics to gather opinions from the students who took part in the case study. The survey surrounded the design decisions made by the students during the assignment. The questionnaire also clarified the worth of cross-disciplinary learning.

\section{Artifact analysis}

Artifact analysis applies to the systematic review and examination of artifacts in a physical, social or cultural context to ask "what do objects have to say about people and their culture, time, and place?” (Hanington \& Martin, 2012, p.138). Artifact analysis can be broken down into several smaller investigations: material analysis, aesthetic analysis, and interactive analysis. The material analysis addresses the material composition of the artifacts, as well as durability and disposability. The aesthetic analysis is a visual assessment of the object, as well as consideration of the time and place the object originated, and the implications they hold. The interactive analysis looks at the functionality and the intent of the object, as well as considering potential adjustments and design opportunities (Hanington \& Martin, 2012).

Using the Victoria University of Wellington Classical Museum as the subject, an artifact analysis was conducted to assess a variety of classical forms to formulate criteria for $3 \mathrm{D}$ printing. A 
visual analysis, as well as an interactivity analysis, were performed to fully evaluate the benefits and constraints of each form and how this would translate when $3 \mathrm{D}$ printed.

\section{Making}

A physical representation of a design idea is critical for evaluating ideas during the design process. There are two main groups of prototypes, low-fidelity and high-fidelity. Low-fidelity prototypes can include card models or sketches as proof of concept for form and scale. High-fidelity prototypes are more refined and represent the appearance of the final output, such as renders, animations and wireframes (Hanington \& Martin, 2012). As discussed in Hanington \& Martin (2012), the terms low-fidelity and high-fidelity indicate that they are endpoints on a spectrum. Therefore there are many variations of prototyping between these two groups, which could include CAD models or renders which show the aesthetic qualities of the models without the interactive functionality of the high-fidelity models.

Prototyping is an essential aspect of the design process, primarily when focusing on the final physical output. This research portfolio included several stages of prototyping, including sketches, CAD models, renders, and material and technology tests. 


\section{Technologies used}

Several 3D printing methods and services were explored to assess the differences between Fused Deposition Modelling (FDM) and Selective Laser Sintering (SLS), as shown in Table 1.

FDM is an easily accessible technology through the School of Design with free-to-use machines in almost every studio, and the only cost is the filament rolls. This technology is mono-material and not colour-capable but is useful for prototyping simple forms. SLS, at the beginning of this research, was accessible through the School of Design, but not with full-colour capabilities. Therefore, US-based 3D printing service Shapeways was explored as a viable candidate for full-colour printing; however, the long shipping time to New Zealand and the expensive shipping and handling costs were a deterrent. The sandstone material available through Shapeways, while being colour-capable, has a similar tactility to pottery artifacts and can be seen used in Guy, Burton and Challies (2018). In January 2019, the School of Design acquired a Stratasys J750 3D printer which is full-colour and multi-material capable. This $3 \mathrm{D}$ printer allows for highly detailed models and is, therefore, the preferred candidate for full-colour printing in the scope of this research portfolio. 
Table 1

$3 D$ printer comparison

\begin{tabular}{|l|l|l|l|}
\hline Printer & Technology & Pros & Cons \\
\hline UPBOX & FDM & Rapid prototyping & $\begin{array}{l}\text { Restricted print bed size } \\
\text { Mono-material } \\
\text { Not full-colour capable } \\
\text { Lengthy post-processing for } \\
\text { complex prints }\end{array}$ \\
\hline $\begin{array}{l}\text { Shapeways } \\
\text { Sandstone }\end{array}$ & SLS & $\begin{array}{l}\text { Full-colour capable } \\
\text { No post-processing required } \\
\text { Large print bed size }\end{array}$ & Mono-material \\
\hline $\begin{array}{l}\text { Stratasys } \\
\text { J750 }\end{array}$ & SLS & $\begin{array}{l}\text { Full-colour capable } \\
\text { Multi-material } \\
\text { Full control over detail and } \\
\text { colour }\end{array}$ & $\begin{array}{l}\text { Clear prints require sanding } \\
\text { and polish to achieve good } \\
\text { clarity }\end{array}$ \\
\hline
\end{tabular}


Precedent Review 
To inform the physical exploration of this research, some precedent works were examined. Because of the cross-disciplinary nature of this research, precedents from both classical and contemporary artists have been considered to create an overarching understanding of how visual elements are used to tell stories. This review will end with a case study conducted to explore how contemporary and classical elements combine within a learning environment to further inform the physical experimentation. 


\section{Sleeping Hermaphrodite}

3rd-1st century BCE

Artist unknown

From a mythological point-of-view, the Sleeping Hermaphrodite is a depiction of the androgynous offspring of Aphrodite and Hermes: Hermaphroditos. The sculpture resides in the Musee du Louvre, Paris, France. Hermaphroditos was a handsome young man with whom the nymph, Salmacis, fell in love with while he was bathing in a pond in the forest. When he refused her proposition, she leapt onto his back and prayed to the gods that they would be united. As the gods are wily, this resulted in the fusion of their physiques, creating an androgynous form, and thus the myth was used as the explanation for the condition of hermaphroditism, where the organism has both male and female features or reproductive qualities. The statue plays on the androgyny of the figure, creating surprise as the viewer inspects it from different angles. From one perspective, the character appears to be female, with curvaceous hips and a hint of breasts. However, once the viewer moves to the other side of the sculpture, they are greeted with a robust set of male genitals and full breasts (Figure 7). It is likely that this sculpture was made both to depict the myth and to provide an erotic provocation to disturb the familiar components of desire and make the viewer question what they are seeing and feeling.

The use of this precedent within this research is the element of surprise and a seemingly familiar narrative. Taking these elements through the lens of $3 \mathrm{D}$ printing will create complex narratives that beg for scrutiny from multiple angles that show different stories. 


\section{Red-figure vase painting}

\section{c. $530 B C E-400 B C E$}

Red-figure refers to the style of vase painting originating in Attica. The pot is painted with a black slip, with the silhouettes of figures left the unpainted red of the clay, and details brushed in using a black slip. The predecessor to red-figure is black-figure, which was the opposite arrangement, with figures painted in black slip and details incised with a sharp tool prior to firing. The switch to the red-figure technique allows for more detail resulting in a more realistic depiction. Red-figure allowed for frontal, back and threequarter views and the start of three-dimensional drawings within Greek art.

This style's allowance for realism is important within the context of this research as it is a technique that can be translated into $3 \mathrm{D}$ printing to create easily readable images. 


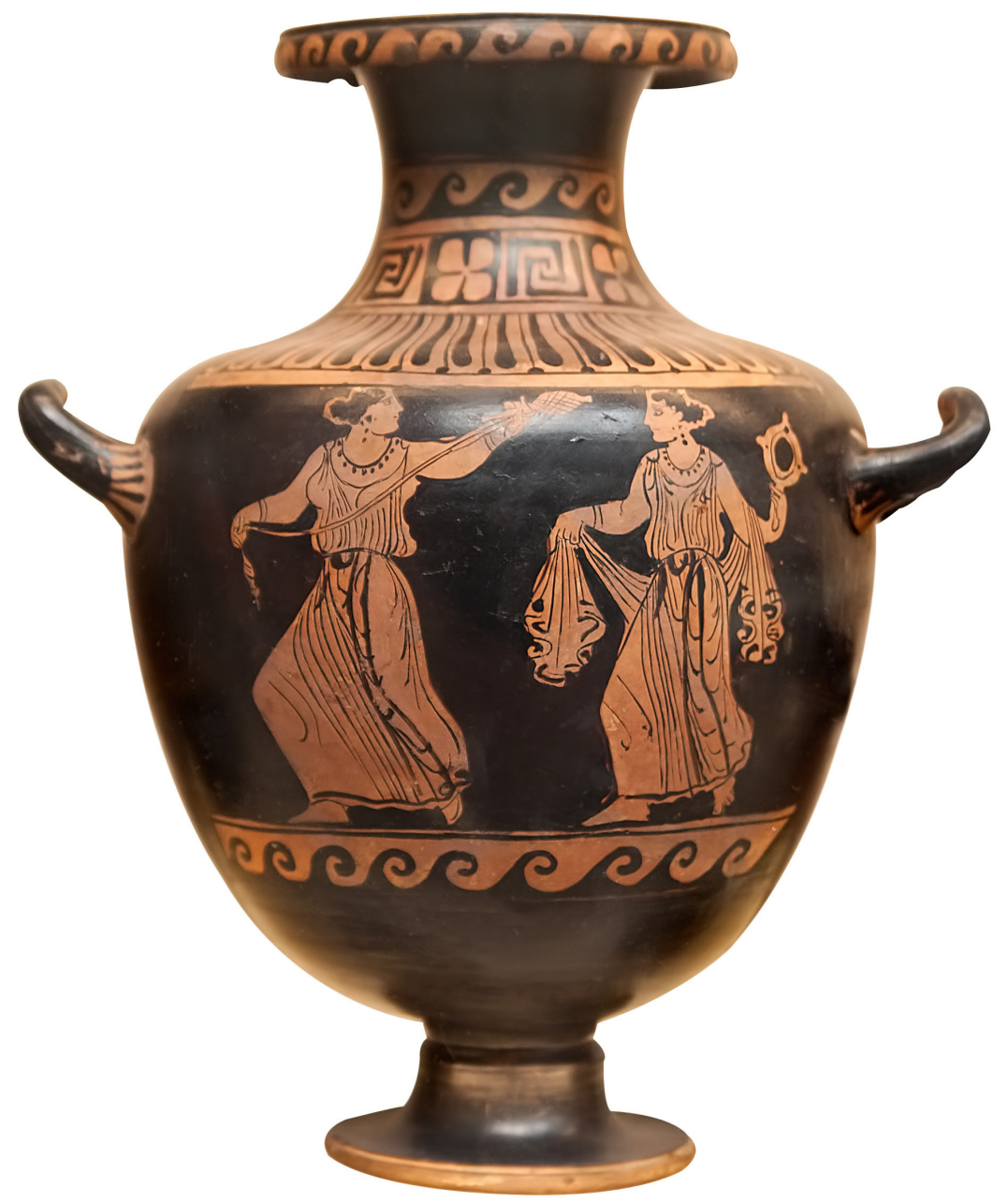

Figure 8. Ancient Greek vase with red-figure decoration. 


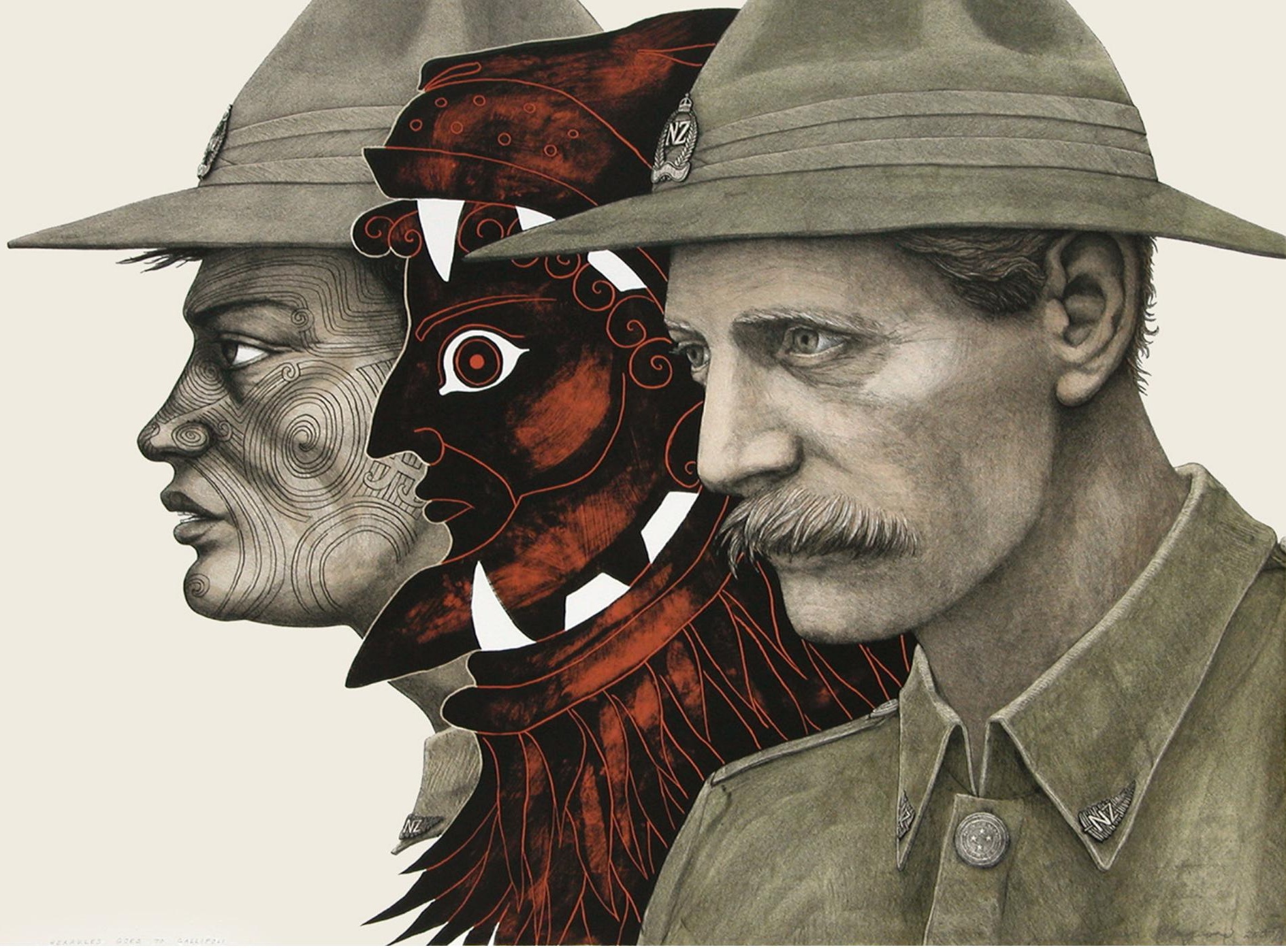

Figure 9. Herakles goes to Gallipoli. Reprinted with permission, courtesy of Marian Maguire. 


\section{The Labours of Herakles}

2008

Marian Maguire

As a continuation from Maguire's 2005 series 'The Odyssey of Captain Cook', this project follows Herakles as he attempts to "claim and tame the land" of New Zealand pre-Treaty of Waitangi. This project is an interplay between three cultures: ancient Greece, New Zealand in its early settler phase, and 'The Age of Enlightenment', a renaissance of interest in Classical thought and styles. In ancient Greece, Herakles was a paragon of courage and strength and is well-known for his completion of the 12 Labours requested by Eurystheus, King of Tiryns. Maguire transposed Herakles into New Zealand colonisation history, creating a bizarre narrative that challenges the audience to look more closely at the familiar tales. Unlike the classical hero, Maguire's Herakles did not always succeed, his Arkadia just out of reach. However, he portrays significant strength, patience, invention and endurance that would have been a boon to any pioneer attempting to tame wild New Zealand.

Maguire's work exhibits a combining of Classical and New Zealand histories. Using the well-known colonial history of New Zealand and the Treaty of Waitangi shows the similarities and differences between the two cultures to create a new narrative, as shown in Figure 9. 


\section{Gilbert Color}

2017

NYC Pride \& NewFest

Gilbert Color is a font created as a tribute to Gilbert Baker, the creator of the iconic Rainbow Flag, who sadly passed away in 2017. Baker was an LGBT+ activist and an artist who helped friends create banners for protests and marches. The font was designed to help create attractive banners which can be held high at marches and rallies. The font is an OpenType-SVG format which hosts the ability to have multiple colours within a single glyph. The font is comprised of the six colours of the Rainbow Flag that interact with each other to create a transparent effect (Figure 10). With the combined design influence and LGBT+ influence, the font is a perfect tool to help tell a compelling narrative. Gilbert Color is licensed under a Creative Commons Attribution-ShareAlike 4.0 International License and is therefore open for commercial use and adaptation; consequently, it can be used freely as the designer sees fit.

This font is an essential precedent within the context of this research portfolio as it embodies LGBT+ influenced design. The ability to adapt the font within the Creative Commons license allows it to be used to fit within the research and be adjusted if needed through experimentation. The significance and symbolism embodied by the font mean it is a strong message that can be paired with a variety of iconography. 


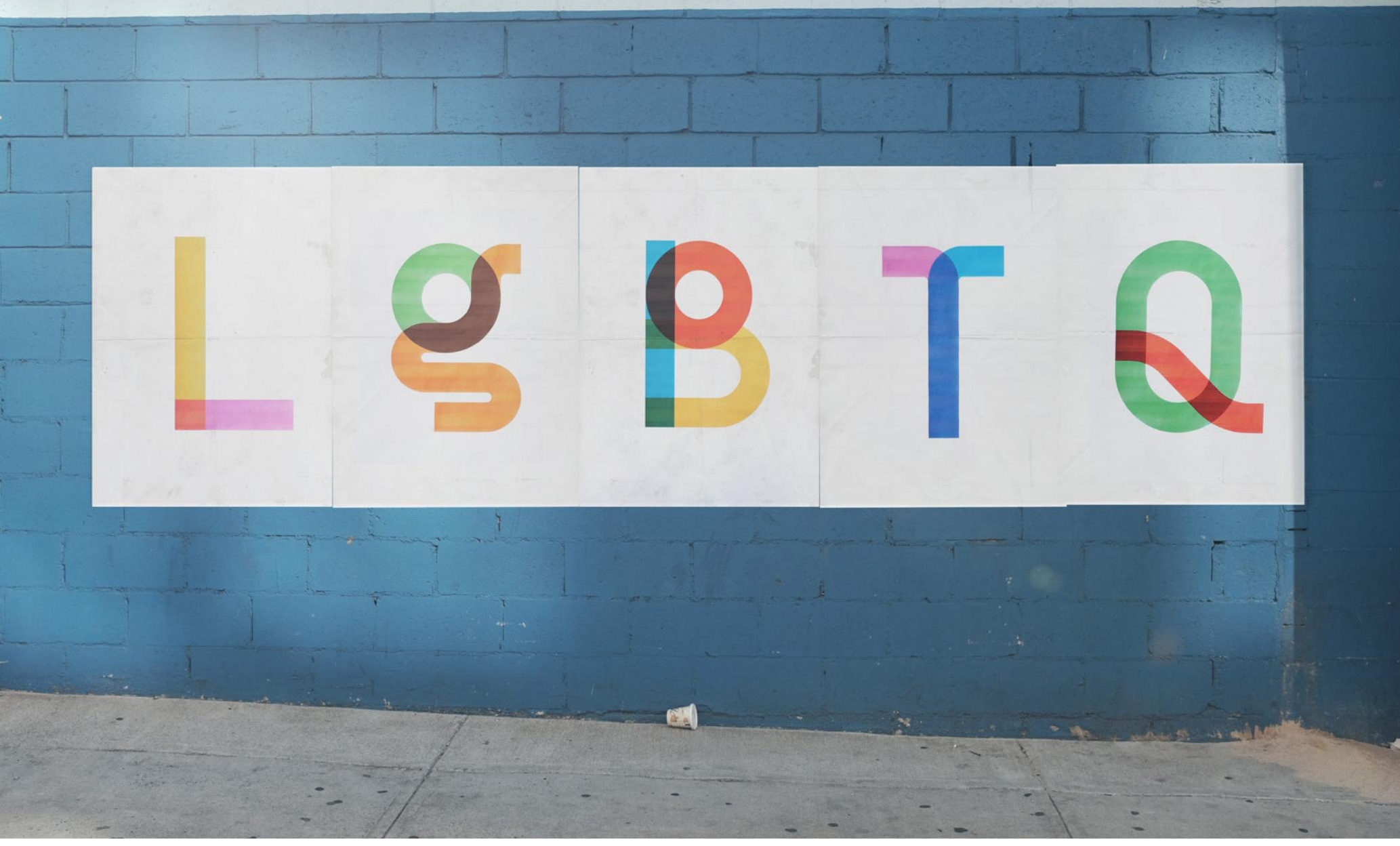

Figure 10. LGBTQ Fly Posters. From Type With Pride. Retrieved from https://www.typewithpride.com. Copyright 2017 by Ogilvy and Mather Design Team. 


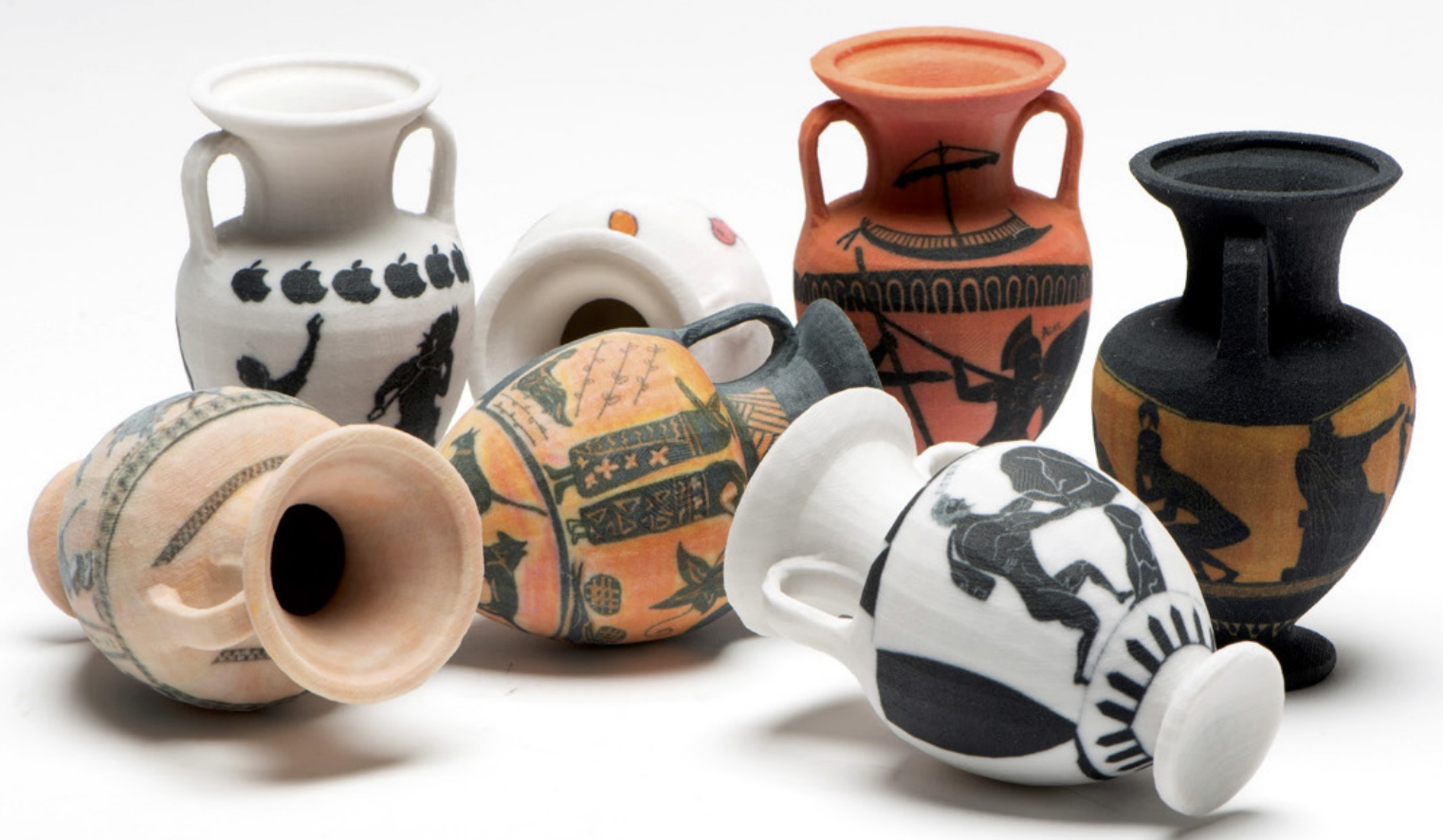

Figure 11. A group of the completed 3D printed amphora, each amphora is approximately $100 \mathrm{~mm}$ high. Courtesy of Diana Burton 


\section{Precious Printing}

2017

Bernard Guy, Dr. Diana Burton, and Zach Challies

Victoria University of Wellington School of Design and Classics Programme collaborated to undertake a project with an undergraduate first-year Classical Studies class to integrate Greek iconography with the contemporary art of 3D printing. The students recontextualised classical myth for the contemporary world and interpreted this as a vase painting drawn on a supplied 2-dimensional paper template. This image then was mapped onto a 3D model of an amphora and 3D printed with colourcapable additive manufacturing techniques through the online 3D printing service, Shapeways, as shown in Figure 11 (Guy, Burton \& Challies, 2017). This project allowed the students to explore contemporary issues as well as their identities, using myth as a tool to design stories and to scrutinise their society and culture.

This project was the driving force behind this research portfolio; therefore, there are some parallels in the early stages. This project is an excellent example of the integration of the two cultures within New Zealand, and because researchers from Victoria University of Wellington undertook the project, the proximity of the project makes this research valuable going forward into the future. Using the paper templates to construct a personal response to the project and using the 2018 class as a case study allows for an in-depth exploration into what the integration of these two fields mean. 


\section{Engagement}

2018

Rose Lastovicka

A case study was conducted in mid-2018 with a first-year undergraduate Classical Studies class. The study consisted of an anonymous questionnaire in a first-year undergraduate Classics class at Victoria University of Wellington about their first assignment. For the assignment, the students had to create a figured scene based on Greek myth to reflect some aspect of their life and illustrate the scene on a vase and then write a short essay on why they chose the myth and the design decisions they made while creating the image.

The students created a spectrum of narratives from a variety of myths, most with Greek myth, although a few students chose to depict myths from other cultures. Common myths illustrated included the Amazonomachy (Figure 12), Medusa and the Trojan Horse; however, the most common myths used by the students were Hades' abduction of Persephone, and the tale of Sisyphus.

The students who chose Hades' abduction of Persephone paired this myth with strong stories of balancing two cultures, New Zealand and their home country and the different ideas between the two countries. Students who chose the tale of Sisyphus (Figure 13) interpreted it for contemporary society as a metaphor for studying, saving money, and the general struggle of becoming an adult.

Along with the Greek myths used, several students chose to depict other cultures' myths in the Greek art style. Most notable was the English story of Cap o' Rushes. The tale has a strong message of being grateful for what you have and not valuing riches over the interactions that make your life meaningful. This story, in particular, bridged the gap between Greek myth and another culture. One student depicted the story of Matariki/the Pleiades, which tells the tale of the constellation of seven stars which the Maori call Matariki, and the Greeks called the Pleiades. This story shows the more direct intersection of cultures, and how the same elements can have significance with very different cultures.

Alongside the myths, many substantial and topical narratives came through. Familiar storylines were feminism, self- 


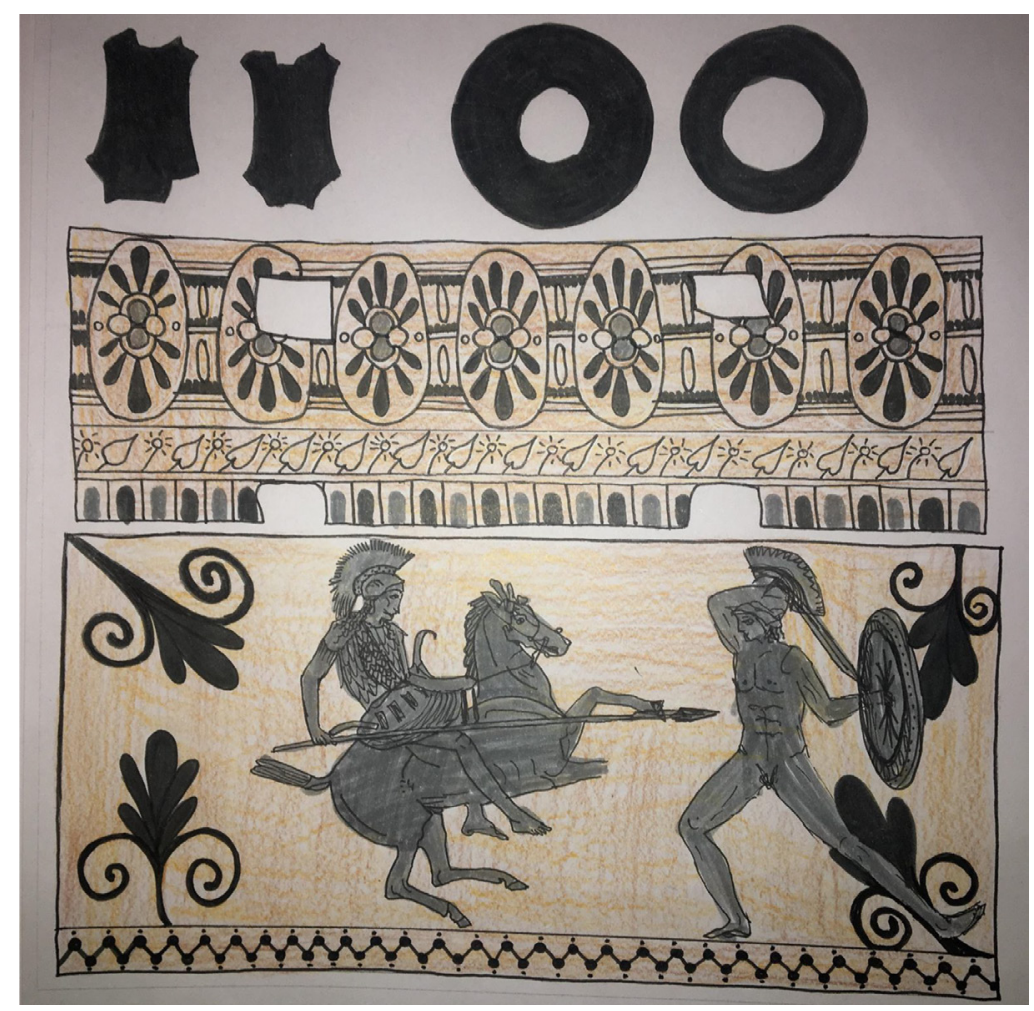

Figure 12. A student's depiction of an Amazon warrior stabbing a Greek soldier during the Amazonomachy. Printed with permission.
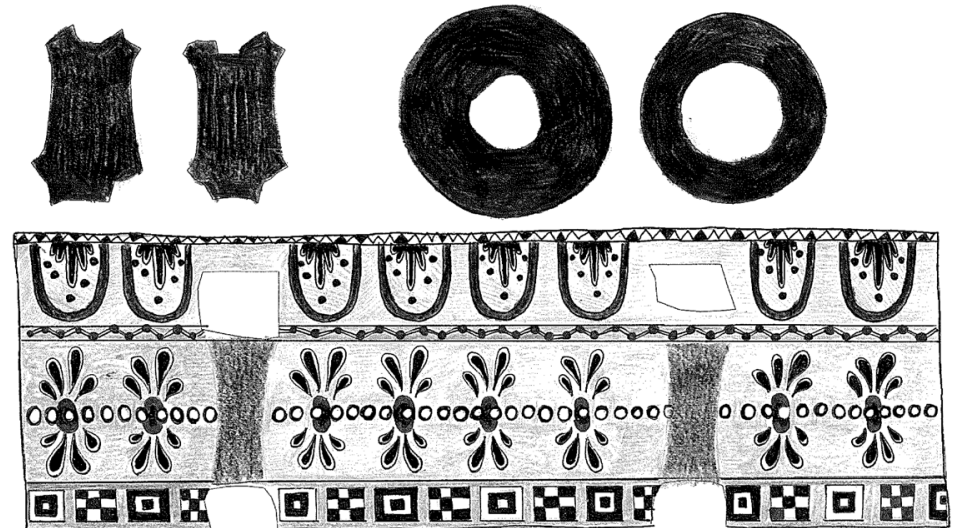

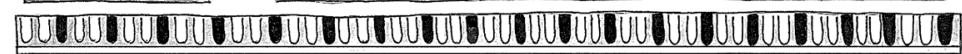

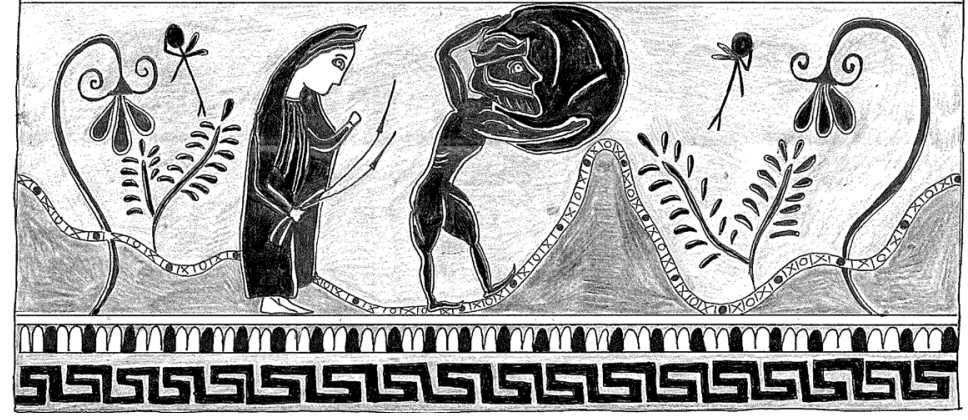

Figure 13. A student's depiction of Sisyphus during his eternal punishment under the supervision of Persephone. Printed with permission. 

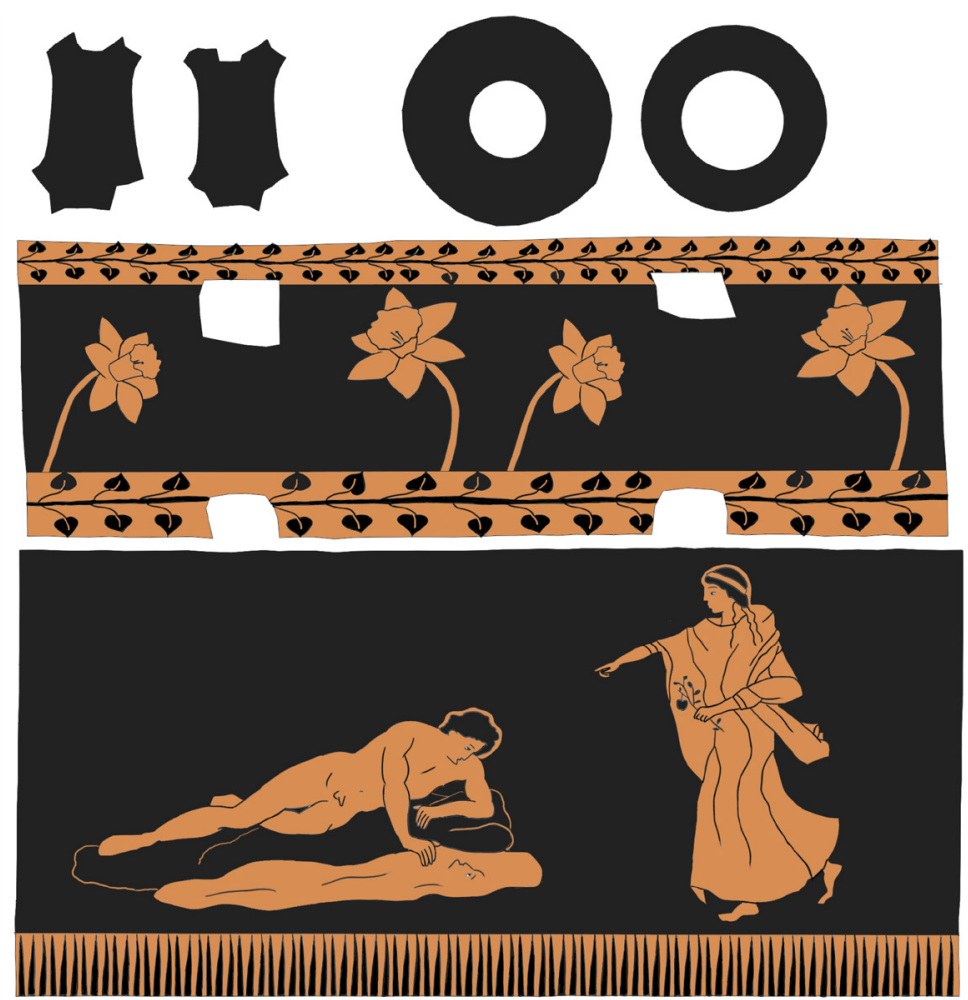

Figure 14. A student's depiction of Narcissus admiring himself in a pond while the nymph Echo watches. Printed with permission.
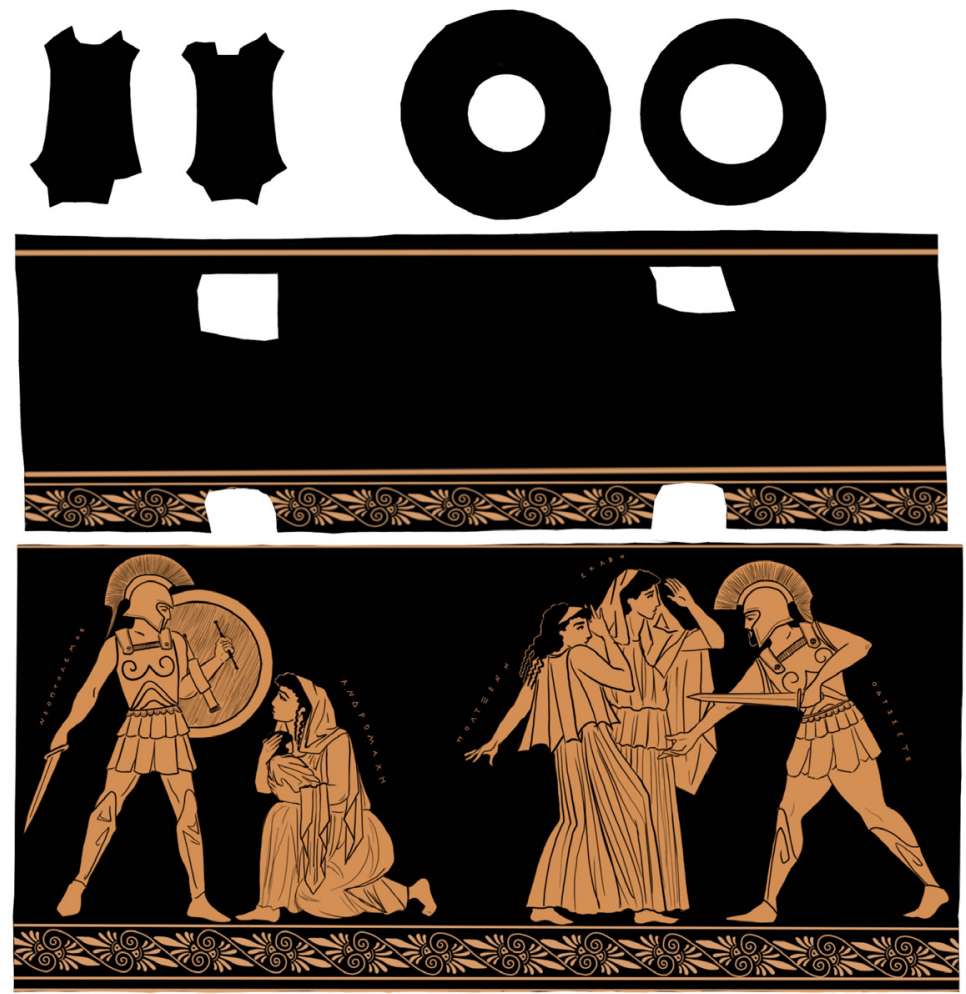

Figure 15. A student's depiction of the deaths of Astyanax and Polyxena during the Trojan

War. Printed with permission. 
image (Figure 14), mental illness and university culture. These topics are very prominent for university students and the many myths that were used to depict these shows just how malleable Greek myths are to fit any narrative, even 2500 years after their creation. Current events also played into the stories chosen by the students, such as the US-Mexico border tensions (Figure 15) and humanity's obsession with "true love" following the release of the film The Shape of Water (del Toro, 2018). There was an overwhelming majority of people who chose to comment on society and how it relates to their life, rather than a personal topic.

This study shows that the use of a graphic element aids the written work and that the students generally were not afraid to talk about personal matters in their assignment. The use of a vessel to reflect the premise of the myth is also helpful to consider when going into the Design Investigation phase of this research. 


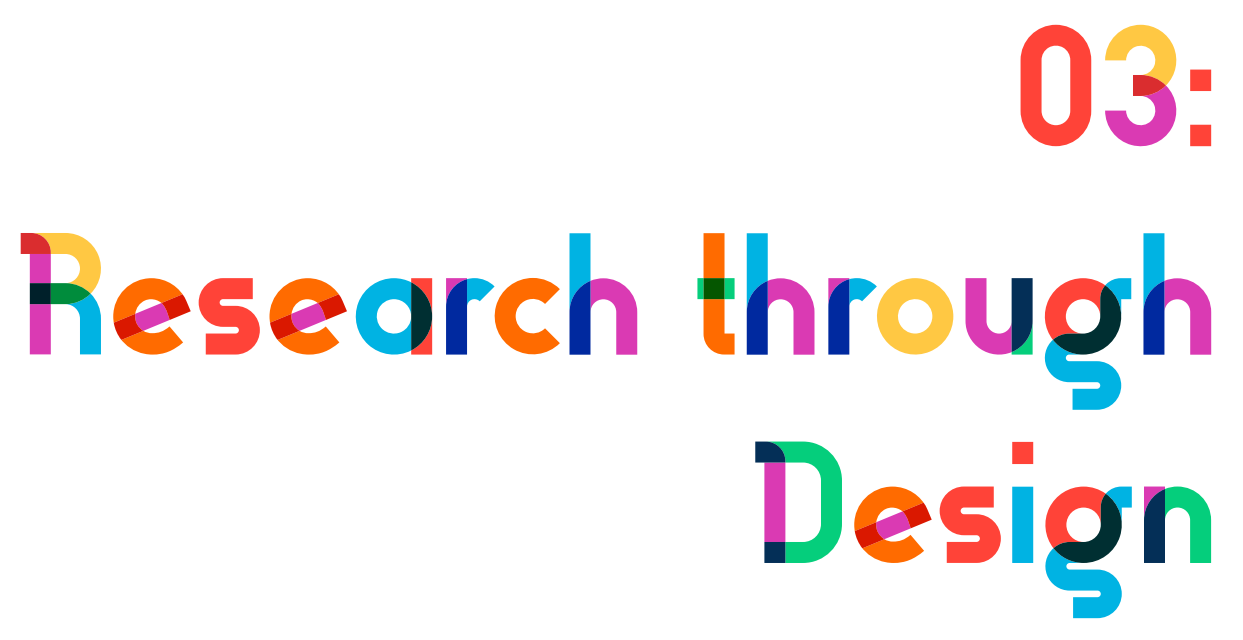


This chapter has been broken into three sections to reflect the three phases of design within this research. The first section includes an artifact analysis of forms and a series of drawings as a response to the Engagement case study. The second section covers the 3D printing exploration on the Stratasys J750. The third section outlines the final outputs that culminated from this research. 
Introductory

Emperiments in

Visualisation 
This Design phase starts with an artifact analysis of the forms in the Victoria University of Wellington Classics Museum to assess the printability of the available types.

Following the completion of the Engagement case study, a series of three visual responses were designed to precede the decision of which form was to be used going forward in the design investigation. Each of these visual explorations was created with the shape of an amphora in mind, as during the Engagement case study, students had the option of an amphora or a lekythos template. 


\section{Artifact analysis}

An artifact analysis of available forms within the Victoria University of Wellington Classics Museum was conducted to assess the printability of different types, as seen in Figure 16. These forms were (from top left) the alabastron, amphora, aryballos, askos, bell krater, chous, column krater, kalpis, kantharos, kylix, lekythos, oinochoe, olpe, pyxis, and squat alabastron.

This analysis also included the typical areas of decoration on each form, shown in Figure 17. The bell and column krater physically have the most significant decoration area because of the size of the vessels. However, proportionate to the size of the vessel, the alabastron, amphora, bell krater and pyxis have the largest decorated areas. 


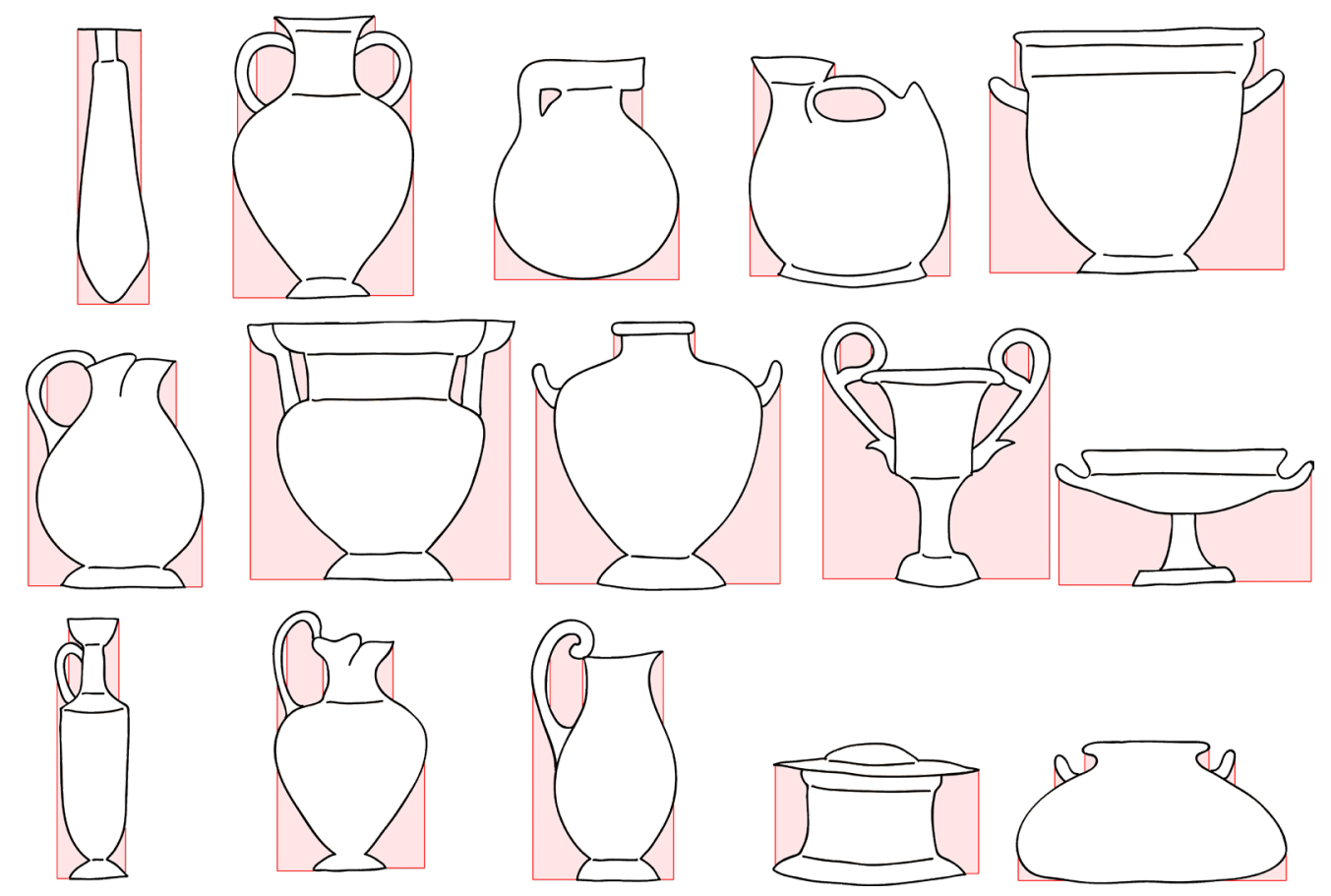

Figure 16. Theoretical external support material needed for various pottery forms shown in red.

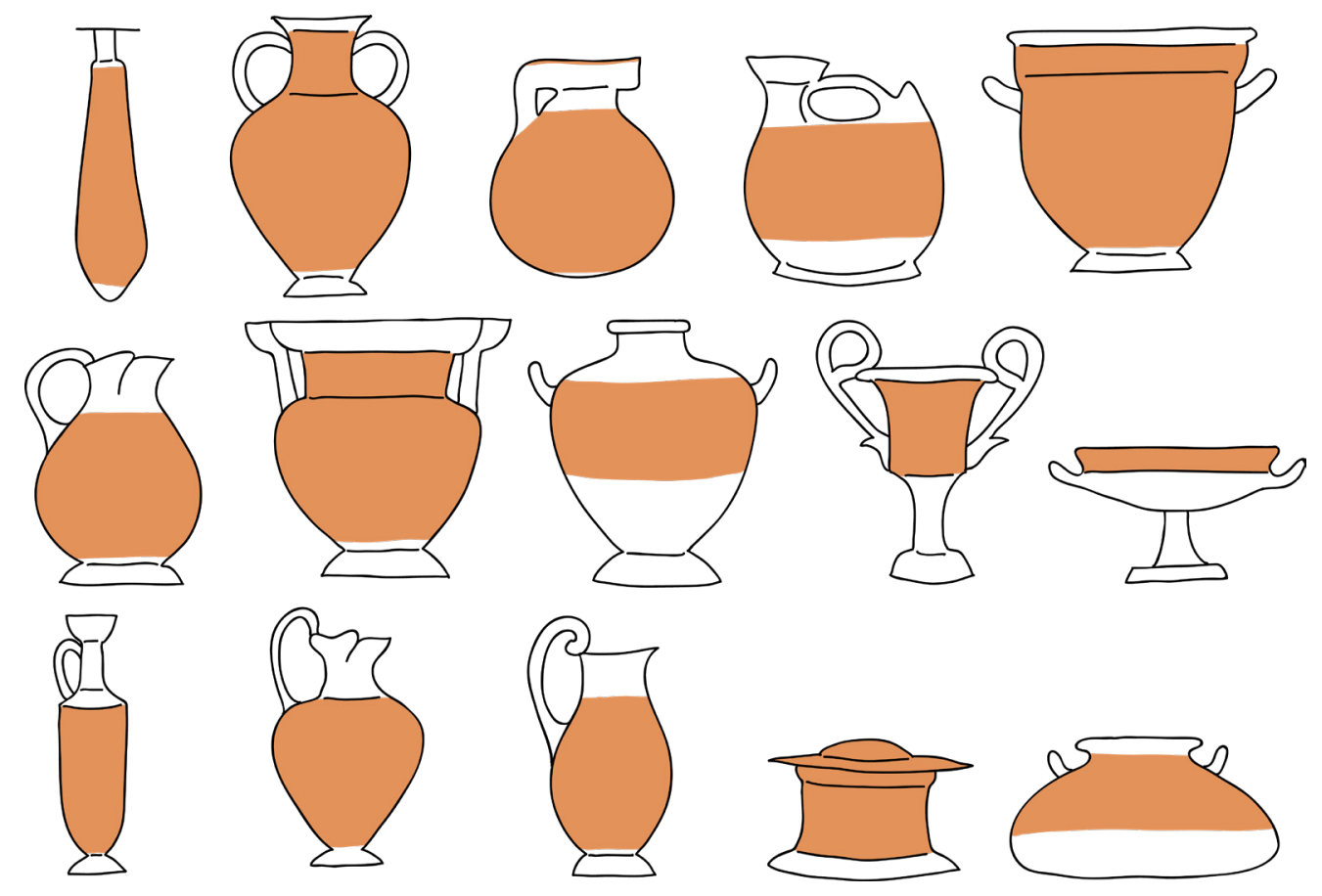

Figure 17. Areas of decoration on various pottery forms shown in orange. 


\section{Experiment I}

The vase depicts the moment where the nymph, Salmacis, fell in love with the beautiful youth, Hermaphroditos. The myth was chosen due to the domination of Hermaphroditos by Salmacis as a thematic reversal from the familiar trope of male power over a helpless female.

The painting 'Hermaphroditus and Salmacis' (Museum Boijmans Van Beuningen, Rotterdam) by Jan Gossart (c. 1517) portrayed Hermaphroditos trying to resist Salmacis' advances and is a loose base for this concept. Instead of the nymph harassing Hermaphroditos, as shown in Gossart's painting, the two figures' were merged to show the moment of metamorphosis (Figure 18). Through using the red-figure technique, the merging of the white flesh of Salmacis and the red flesh of Hermaphroditos is more striking and stands out against the black background. 


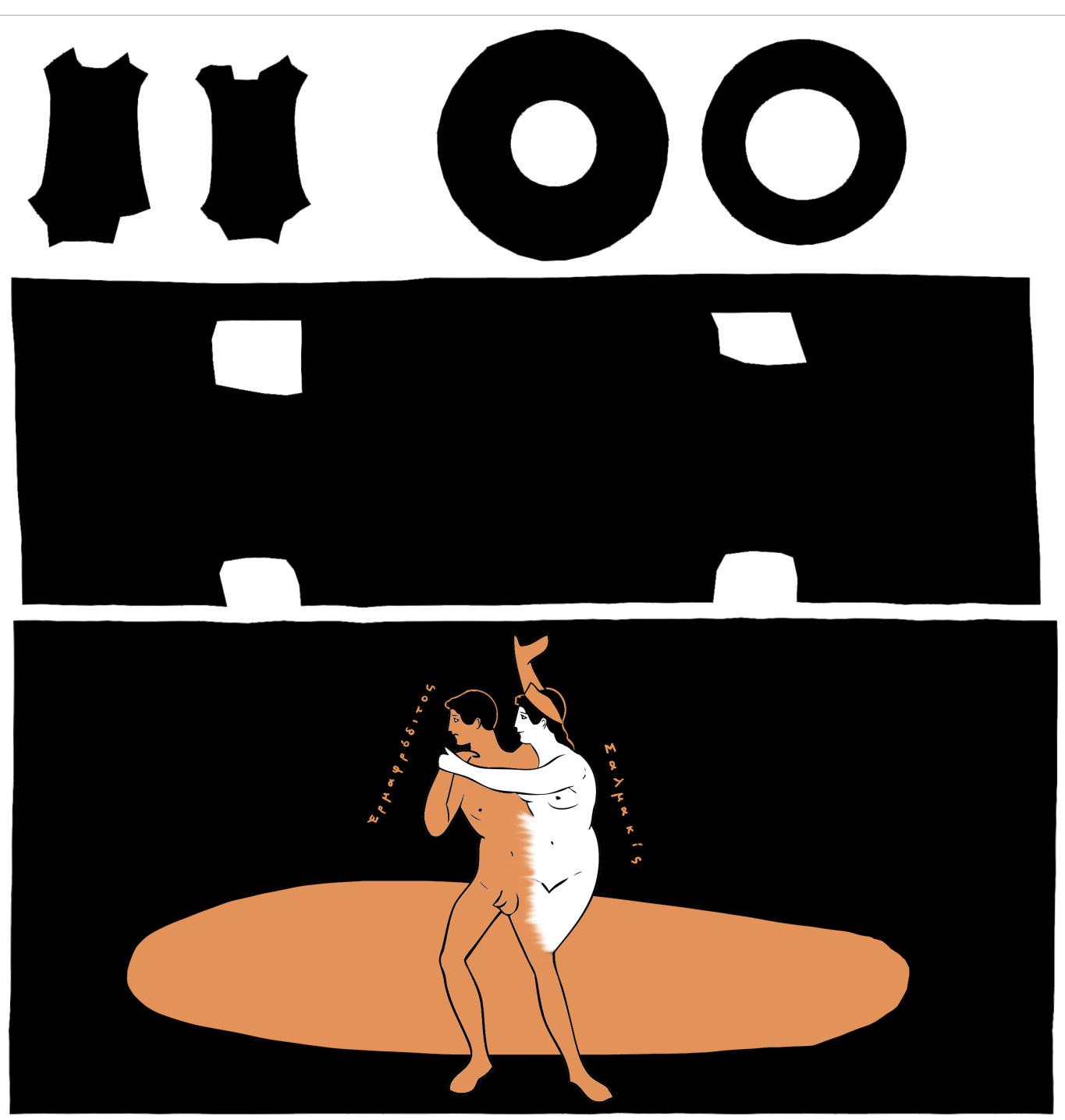

Figure 18. Vase template depicting Hermaphroditos and Salmacis. 


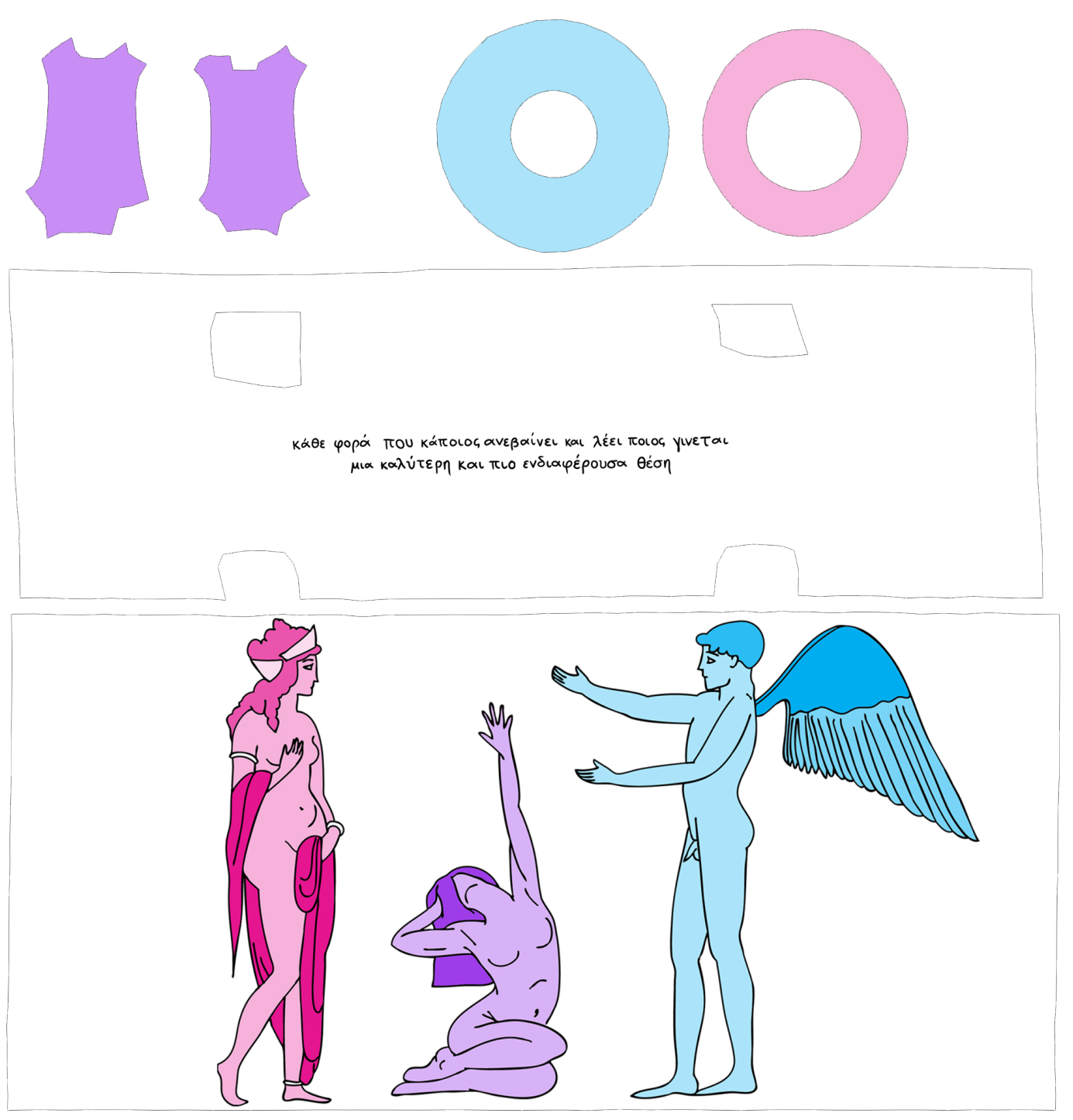

Figure 19. Vase template depicting Aphrodite (left), and Eros (right) flanking a confused girl. 


\section{Experiment 2}

Instead of basing this vase on an existing Greek myth, prominent mythological figures were used to tell a story about the LGBT+ community and the struggle of coming to terms with your sexuality.

The main image depicts three figures (Figure 19). On the left, Aphrodite, goddess of love, sexuality, and pleasure; on the far right, Eros, the god of sensual love and desire (and in some cases, the god of homosexual love). The two gods face inward towards the central figure, depressed on the ground, one arm grasping her hair in anguish to reflect the Greek visual cue for grief, and the other arm outstretched towards the sky as a plea to the gods. The colours were added to represent the colours on the bisexual flag. The flag represents attraction to those of the same sex (pink), to those of differing sex (blue). Where the two colours join (purple) indicates the mixing of the two attractions and how they coexist. In the image, purple was for the central figure to show her grief and difficulty understanding her sexuality. Coming to terms with your sexuality and your identity is complicated in the beginning as it is uncharted territory and scary, especially if you come from a family who do not understand or support the LGBT+ community. 


\section{Experiment 3}

For the final experiment in this series, the ideas on the two previous concepts were merged, using unique characters and exploring different thematic colour palettes. The characters are an interpretation of two transgender individuals.

The first theme (Figure 20) is an overlay of the colours from the transgender flag. Upon reflection, the bright colours do not allow the linework to be viewed easily.

The second colour scheme (Figure 21) used natural skin tone and hair colours. This experiment was a much more successful colour choice as it shows that transgender people are, in fact, people and are just as ordinary as cis-gender people.

The last colour theme (Figure 22) revisited Greek vase painting techniques and the colour merging used in the first concept. This technique requires development looking into transparency layering on the Stratasys J750. 


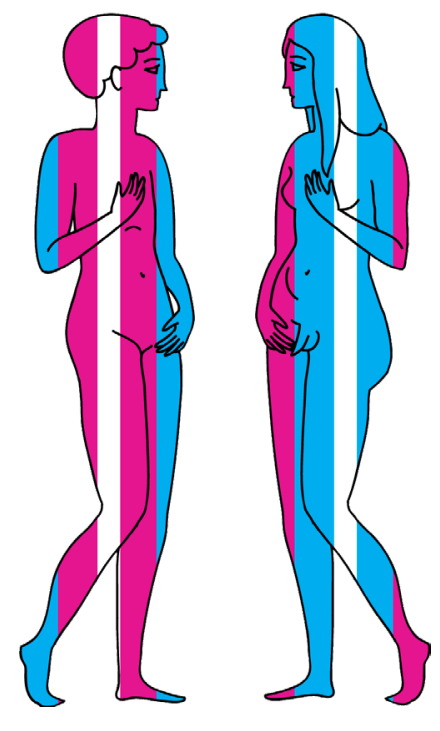

Figure 20. Figures with transgender flag overlay.

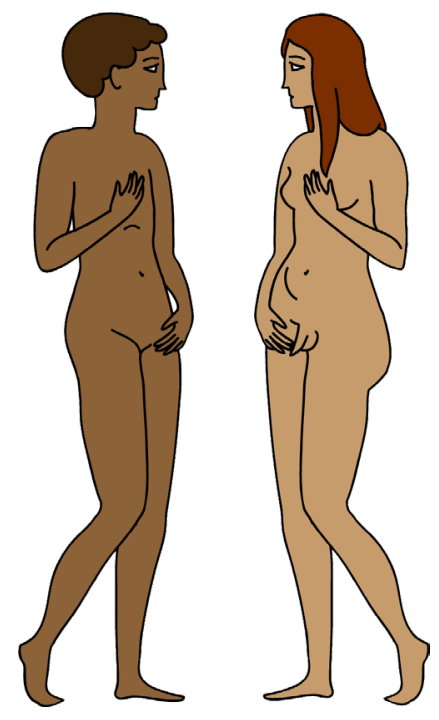

Figure 21. Figures with natural skin and hair tones.

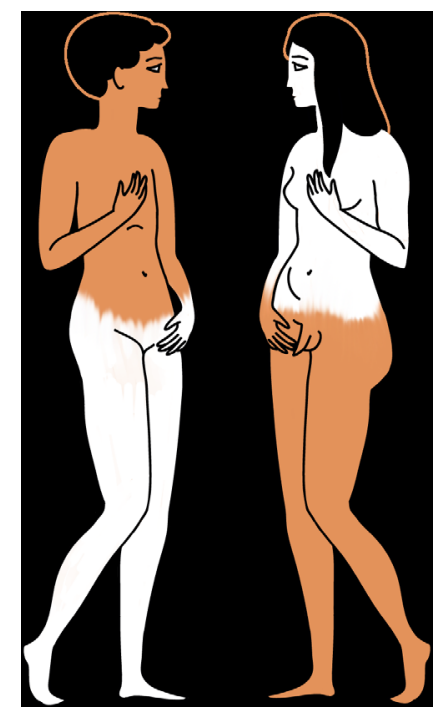

Figure 22 Figures in adapted red-figure style. 


\section{Experiments in Corm}


Following the completion of the visual experiments, the decision to print coins, rather than pottery, was settled by the small size of the object and its ease of printing, but also the societal connotation of coins within civilisations. Within ancient Greece, coins were used as propaganda to showcase the wealth and power of citystates. They were also a means of spreading myth. For example, the city of Knossos on the island of Crete is famous for its Bronze Age palace, a labyrinthine complex which gave rise to the myth of the labyrinth that housed the Minotaur; therefore a labyrinth is depicted on coins from the city.

With the selection of form, the method of making has been adapted to more thoroughly investigate the physicality of the object and how it relates to the imagery to be displayed. For this section, high-fidelity prototypes done on the Stratasys J750 are used. The J750 is an ink-jet photo-polymer $3 \mathrm{D}$ printer that is capable of full-colour parts at a high resolution. The use of this high-fidelity method will impart the findings of this research in a clear and highly detailed manner that will inform the final design resolution. 


\section{Batch I}

These prints tested the detail capabilities of the printer. For these tests, an open-source model of a Naboo Starfighter sourced from Thingiverse (www.thingiverse.com) was used to get the prints done as quickly as possible without having to worry about spending time on modelling this early in the investigation.

The coins were printed on the $\mathrm{Z}$-axis, so have clear lines running through the face of the coin. Printing the coin on the $\mathrm{X}$-axis reduces the layer lines on the coin face.

This batch found a bottom limit for internal model size. The internal models were too small, and some detail was lost. The colours were also not vibrant enough due to the small scale of the internal components (Figure 23). 


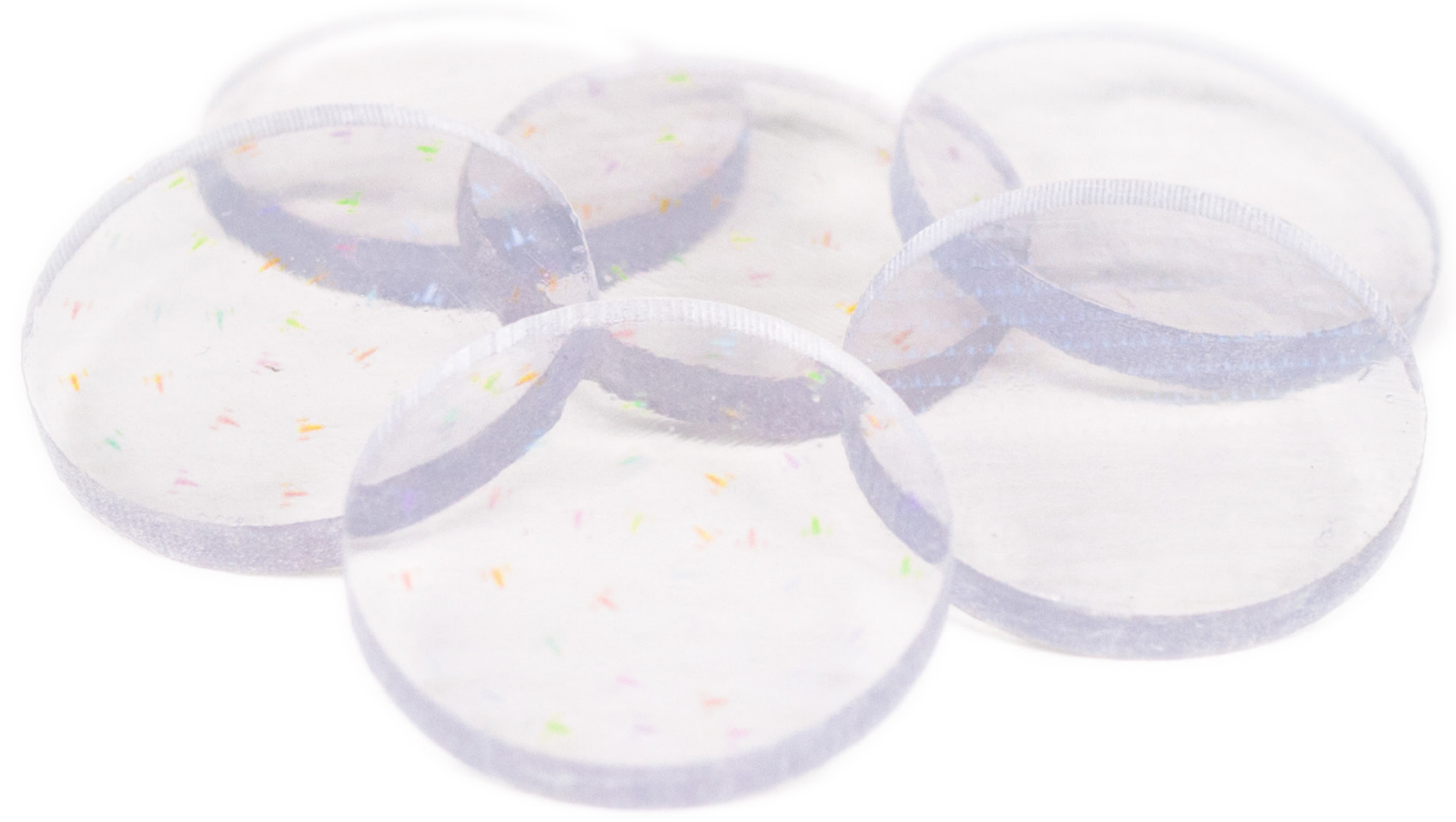

Figure 23. Batch 1 with embedded visuals. 


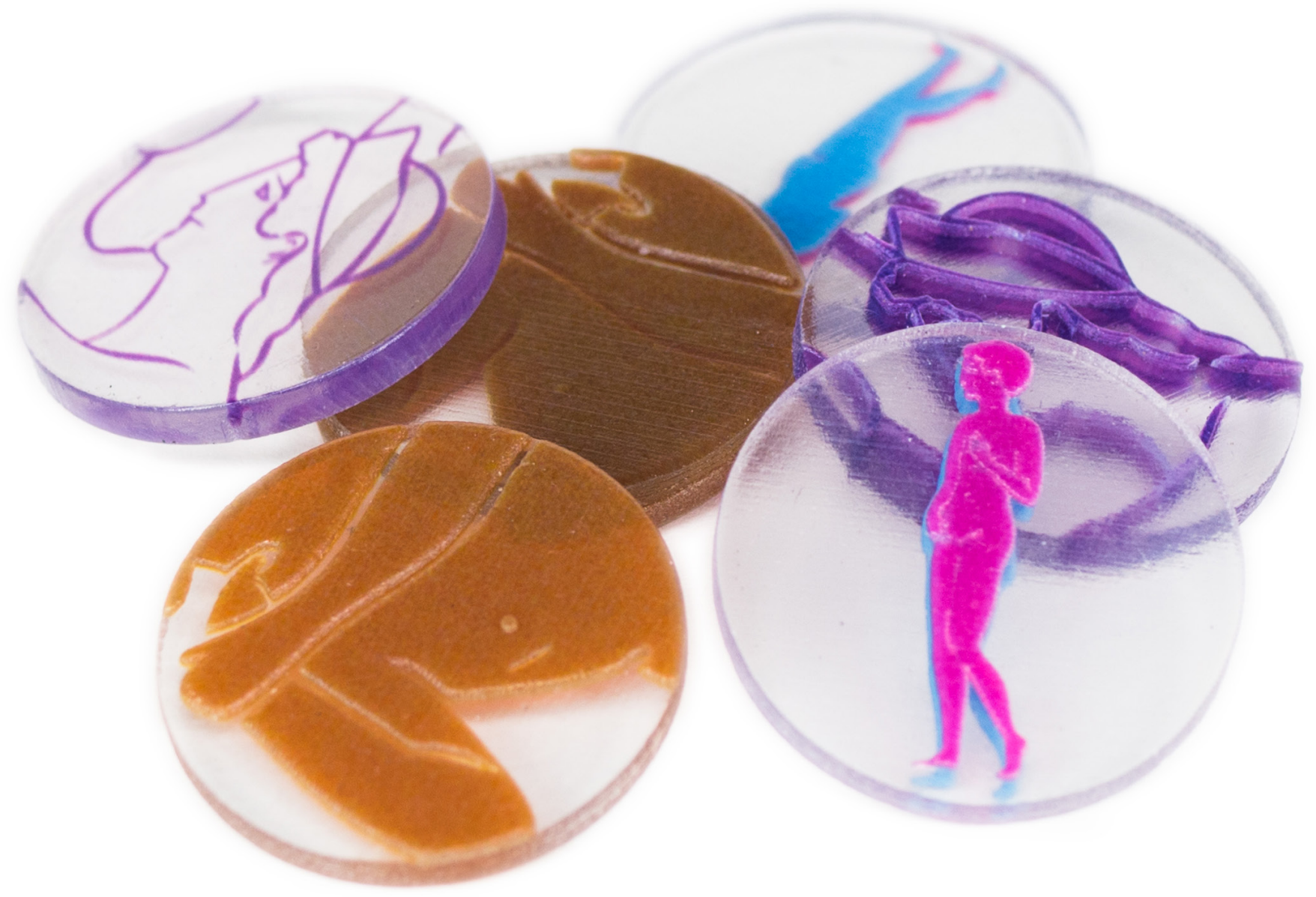

Figure 24. Batch 2 with embedded visuals.

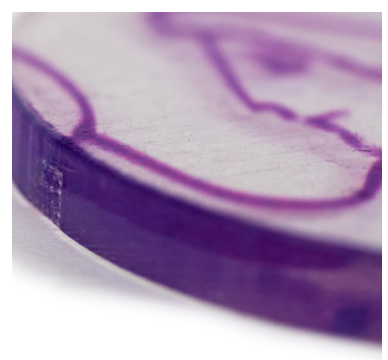

Figure 25. Assembly 7 detail with embedded visual.

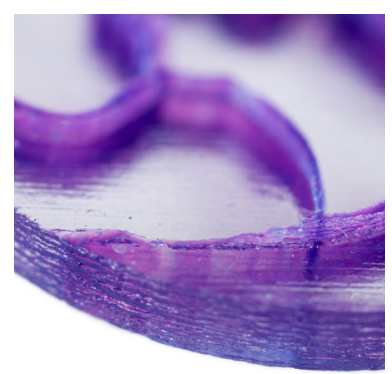

Figure 28. Assembly 10 detail with embossed visual.

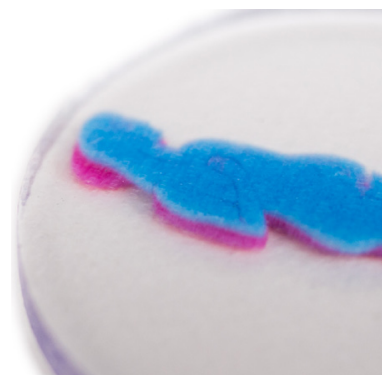

Figure 26. Assembly 8 detail with embedded visual.

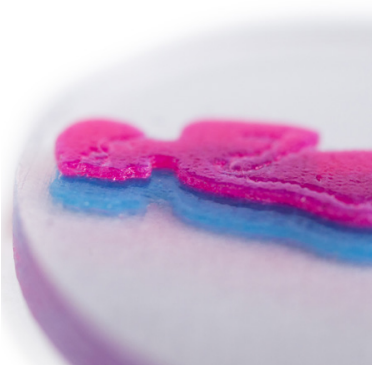

Figure 29. Assembly 11 detail with embossed visual.

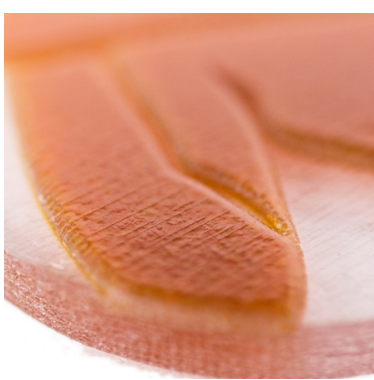

Figure 27. Assembly 9 detail with embossed visual.

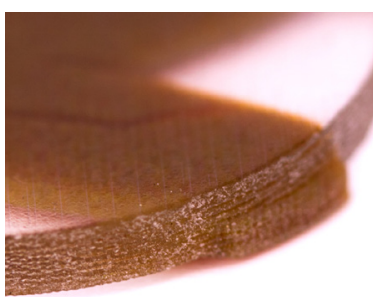

Figure 30. Assembly 12 detail with embedded visual. 


\section{Batch 2}

Imagery from Phase 1 was utilised to start exploring Greek iconography. Each image was taken into Adobe Illustrator and vectorised. From this vector, the outline and fill of each image were made into two seperate AutoCAD drawings (.dwg). These .dwg files were then brought into Solidworks to be fixed if required and extruded for printing. Three images were taken from Phase 1, Concept 3 and two detail images from Concept 1 . These three images were printed embedded into the clear coin, and then embossed using different techniques to explore how this effect affected the print. Overall, Assembly 11 (Figure 29) was the most successful, being embossed $0.5 \mathrm{~mm}$ above the coin surface.

This batch shows an exploration into embossed visuals and the upper limitations of how far to push the embossing without breakages. Assembly 10 had a $1 \mathrm{~mm}$ extrusion on each side which broke during cleaning, as shown in Figure 28. From this, it was found that $0.5 \mathrm{~mm}$ was the most successful extrusion height during this batch of testing. 


\section{Batch 3}

This batch showed an iteration of the previous, with an expansion of the layering of images and experimentation with the translucency of images. This batch also shows the use of both the outline and fill of images, as well as the introduction of text into the coins. Opacity of layers works under $0.5 \mathrm{~mm}$ thickness of model, which can be seen in Figures $32 \& 35$. Figure 37 shows the translucency has not worked. Assemblies 14 (Figure 33) and 17 (Figure 36) revisits the red-figure vase painting colour scheme explored in Phase 1 Concept 1 (Figure 18).

The main finding from this batch was the optimum thickness for translucent colour layers. $0.5 \mathrm{~mm}$ worked the best to get a strong colour while still maintaining the translucency. 


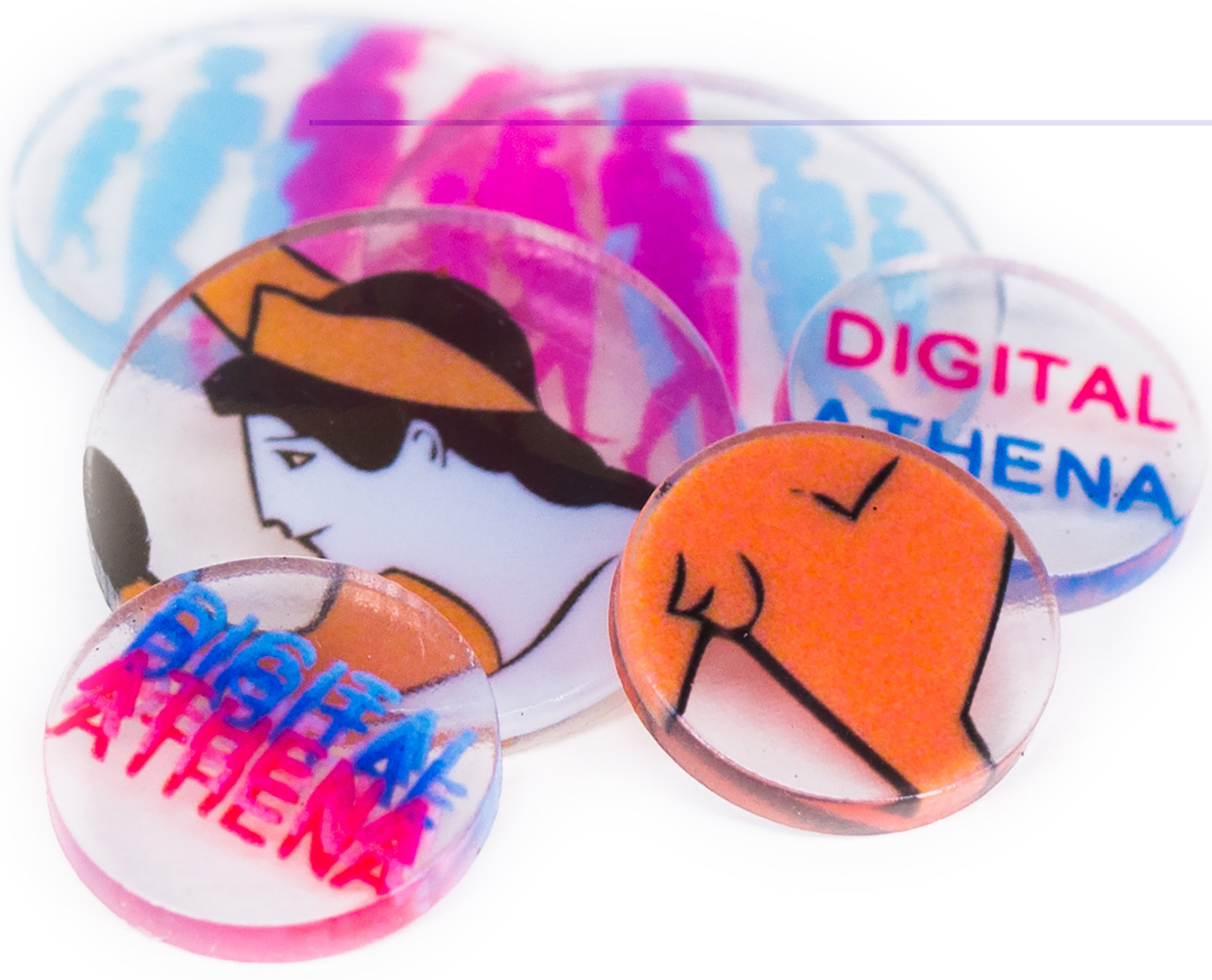

Figure 31. Batch 3 with embedded visuals.

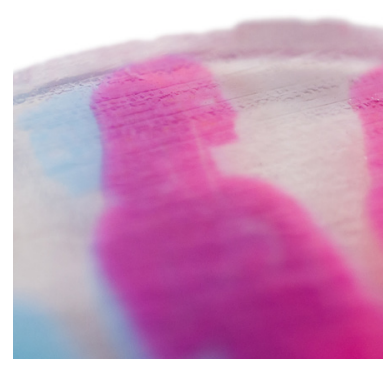

Figure 32. Assembly 13 detail with embedded visual.

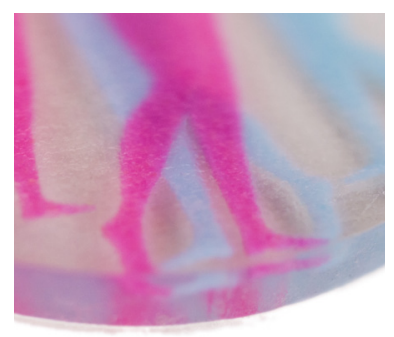

Figure 35. Assembly 16 detail with embedded visual.

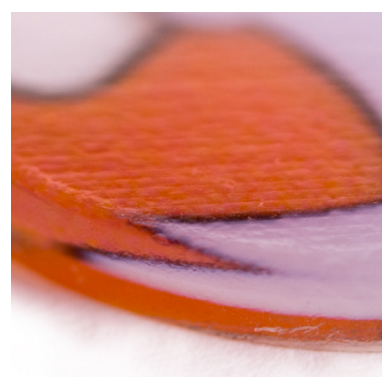

Figure 33. Assembly 14 detail with embedded visual.

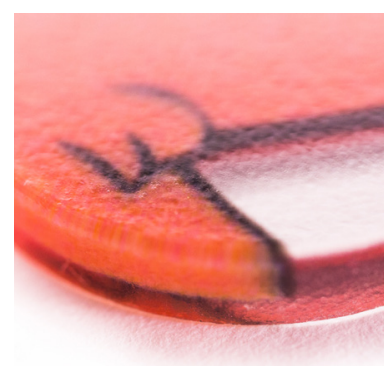

Figure 36. Assembly 17 detail with embedded visual.

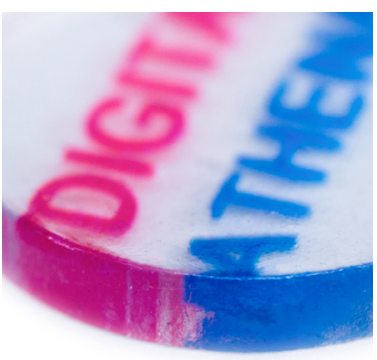

Figure 34. Assembly 15 detail with embedded visual.

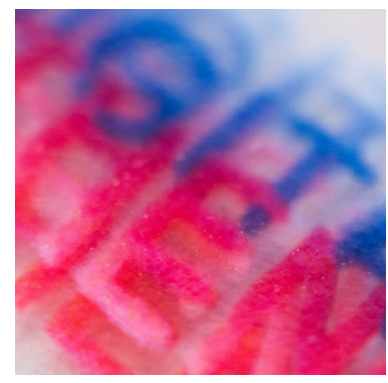

Figure 37. Assembly 18 detail with embedded visual. 


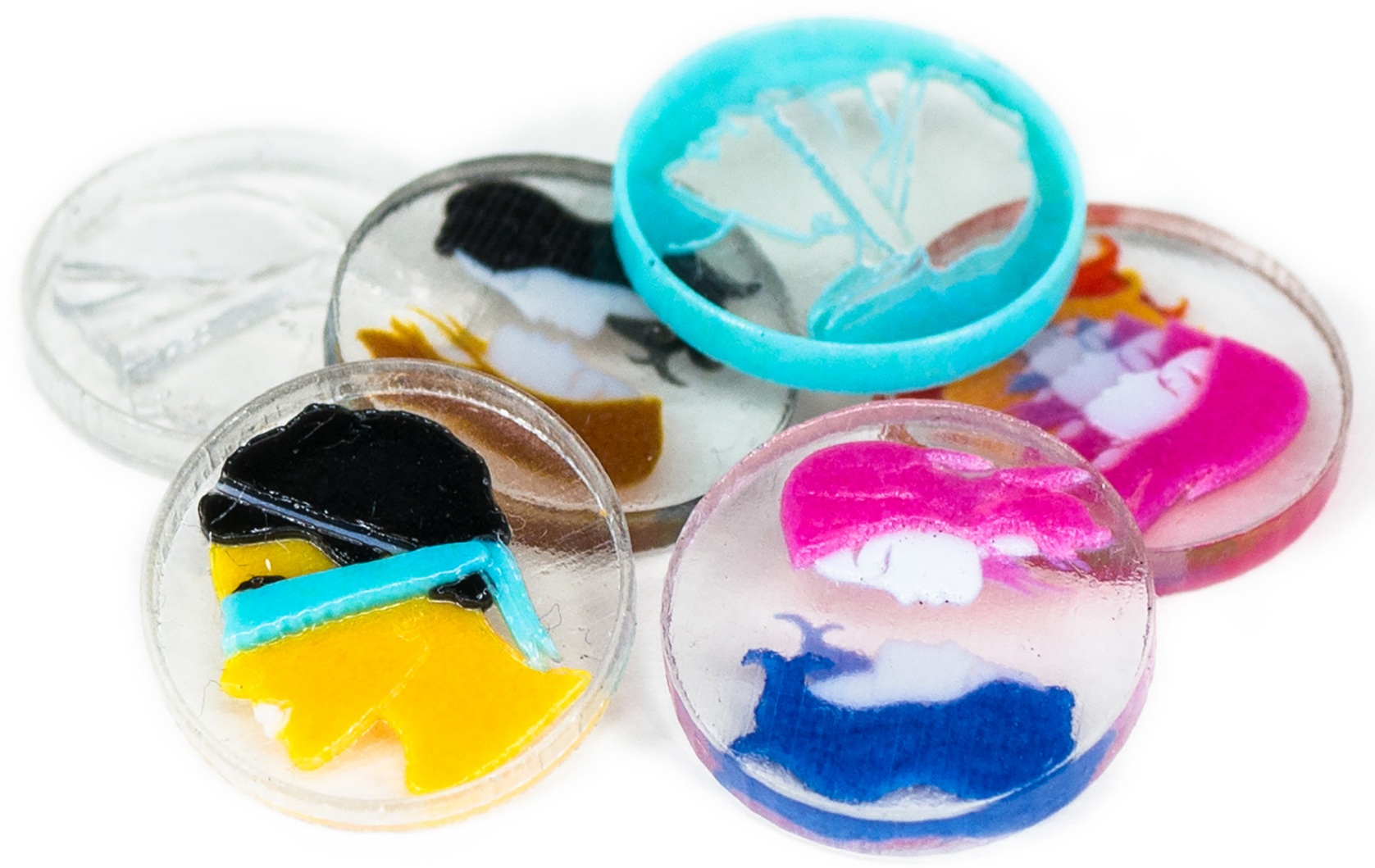

Figure 38. Batch 4 with embedded and embossed visuals.

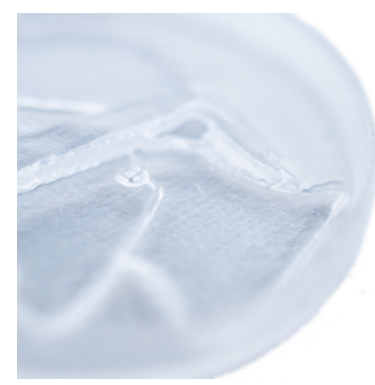

Figure 39. Assembly 19 detail with embossed visual.

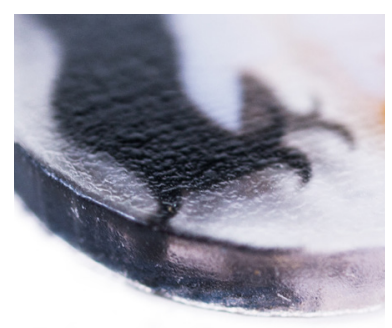

Figure 42. Assembly 22 detail with embedded visual.

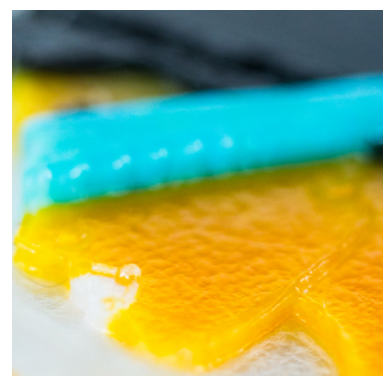

Figure 40. Assembly 20 detail with embossed visual.

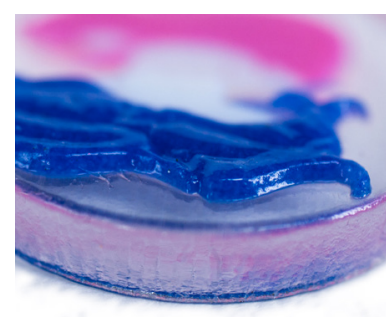

Figure 43. Assembly 23 detail with embossed visual.

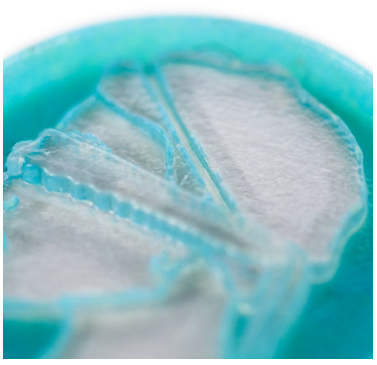

Figure 41. Assembly 21 detail with embossed visual.

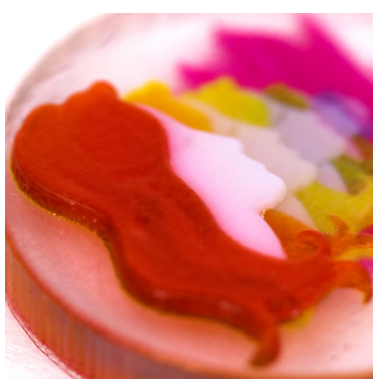

Figure 44. Assembly 24 detail with embedded visual. 


\section{Batch 4}

Looking to ancient Greek coins for inspiration a 'stamped' coin was created (Figures 39-41.). The imagery in this coin is a new model of the god of desire, Eros, depicted with a blindfold as a nod to the tongue-in-cheek classical paintings of him that depict his tendency not to look where he is pointing his arrows. This profile did not allow for as much detail or depth within the coin, therefore it was not repeated within this batch. Figures 42-44 depict a pair of women as if about to kiss. As in Batch 2, an embossed coin was explored alongside an embedded visual. Figure 44 shows the melding of the embossed and the embedded visuals to create the illusion of perspective between the women.

Through using the profiled coin, an optimum thickness was found for the coins to portray enough visuals and depth to create a cohesive design. This batch also explored how to use different levels within the depth, as can be seen in Figures 43-44. 


\section{Batch 5}

The purpose of this batch was to explore alternative forms for the coins. Previous experiments used a cylindrical form, but the use of more rounded forms allowed for more depth of imagery within the coin. This batch also used the Vivid resins (Cyan, Magenta and Yellow) to explore the translucency and colour properties of these resins, over the coloured White resin used in previous batches. $0.5 \mathrm{~mm}$ thickness was found to give the clearest colour in the Cyan and Magenta resins, as can be seen in Figure 47. It is difficult to see the details of the image when using the pure Yellow resin. Overall, the different shaped coins proved to be more visually stimulating than previous iterations, allowing for more angled graphics and layering.

Using the new coin profiles, it was found the convex shape was most successful as it allowed for more depth within the designs. 


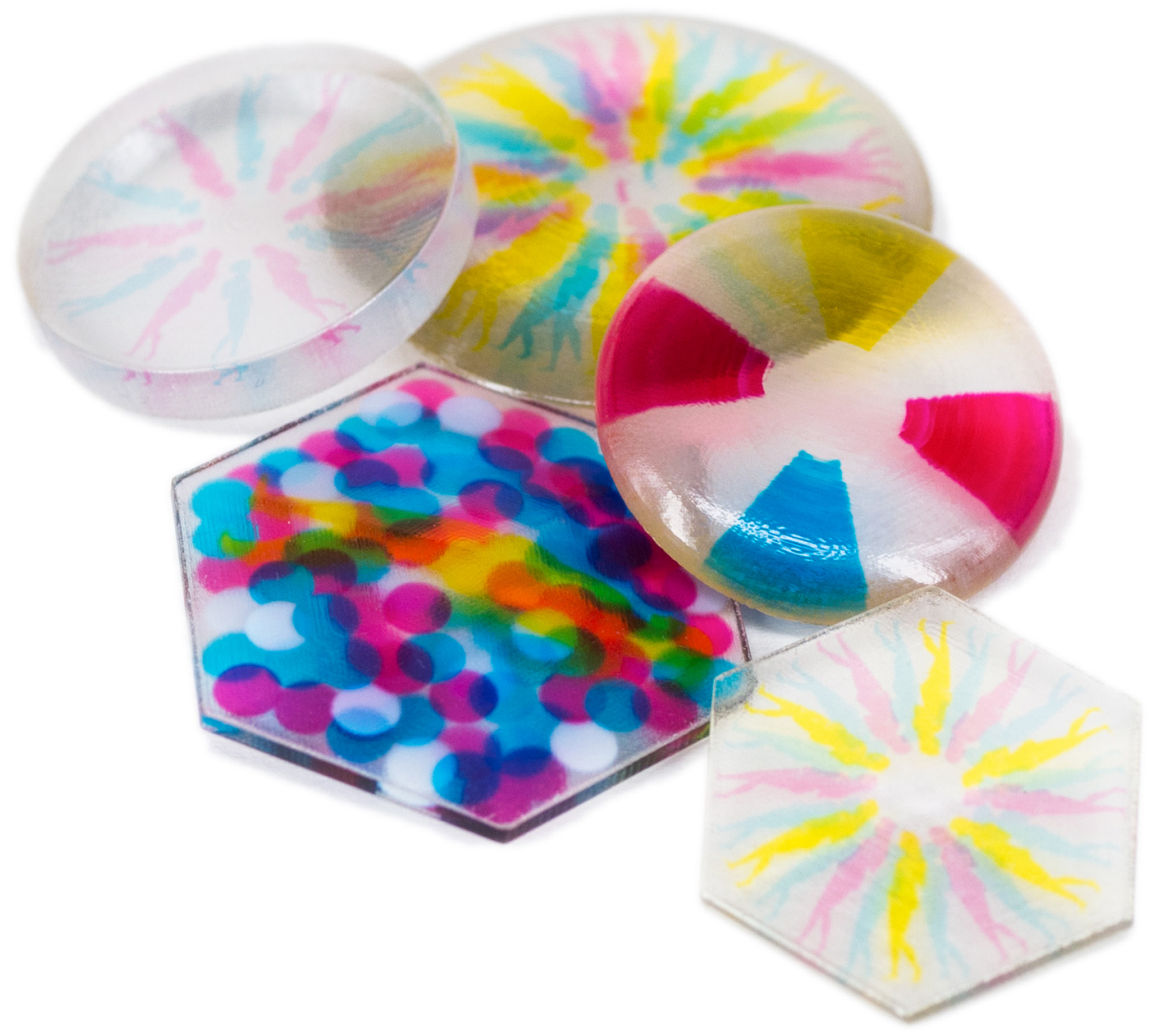

Figure 45. Batch 5 with embedded visuals.

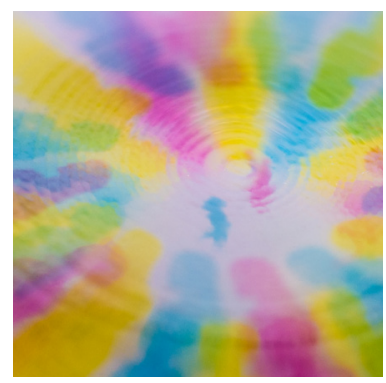

Figure 46. Assembly 25 detail with embedded visual.

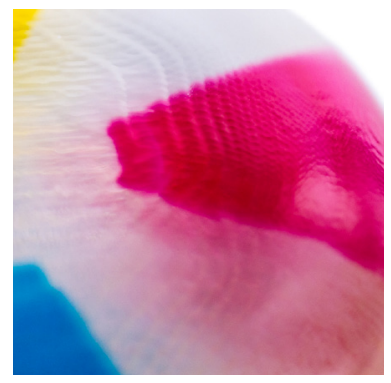

Figure 49. Assembly 28 detail with embedded visual.

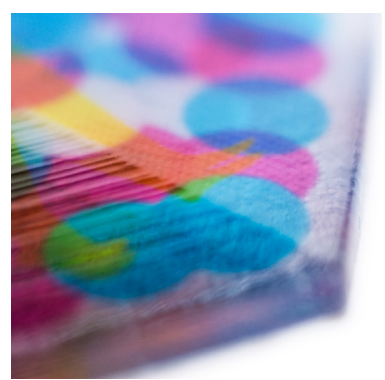

Figure 47. Assembly 26 detail with embedded visual.

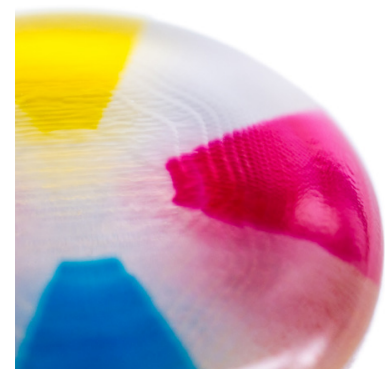

Figure 50. Assembly 29 detail

with embedded visual.

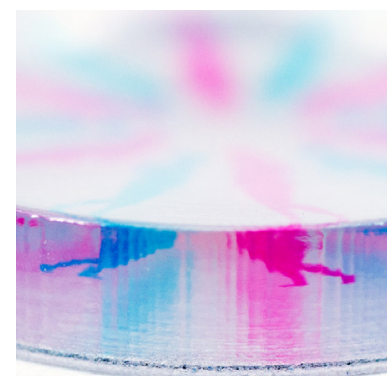

Figure 48. Assembly 27 detail with embedded visual. 


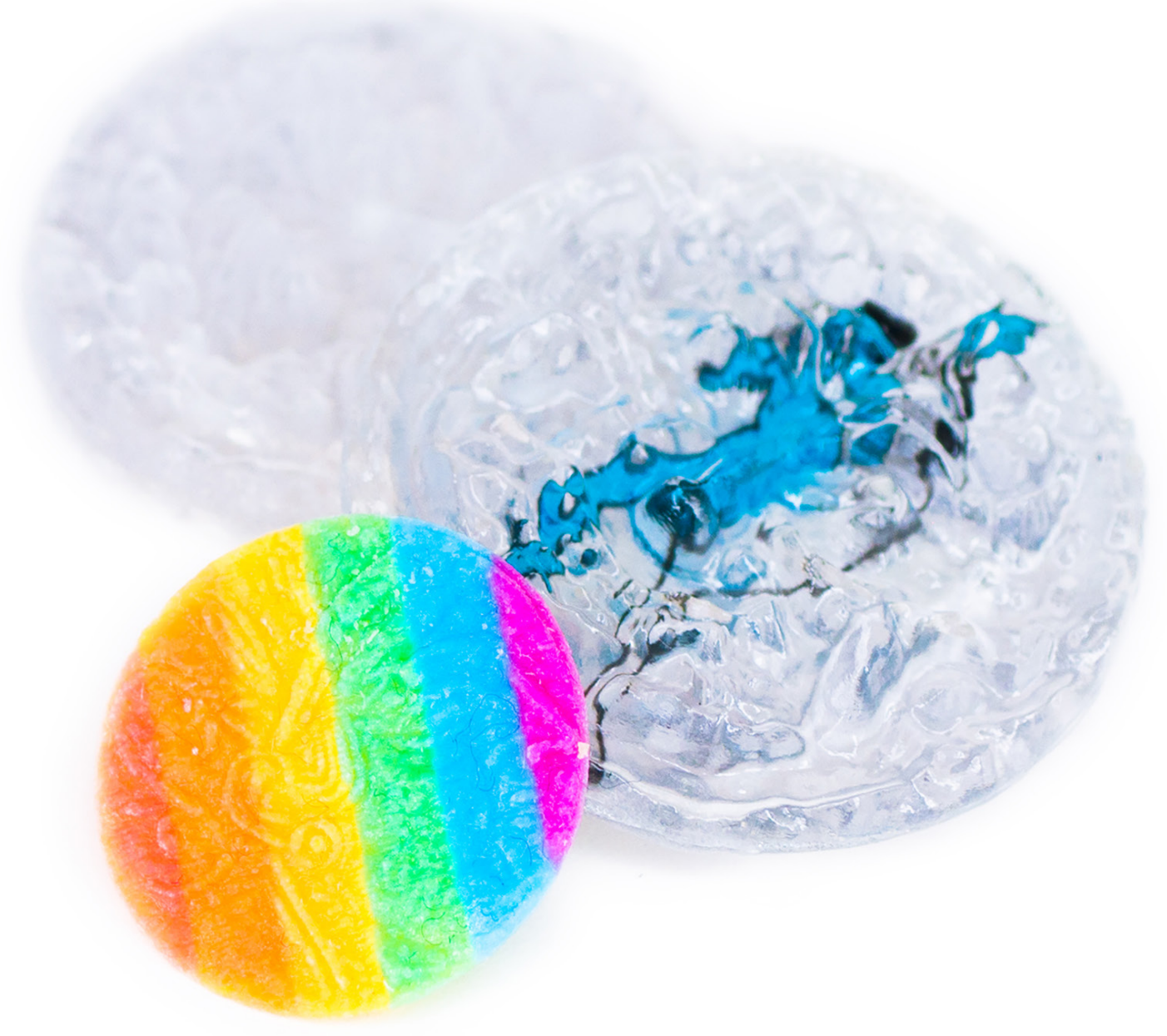

Figure 51. Batch 6 with embedded visuals.

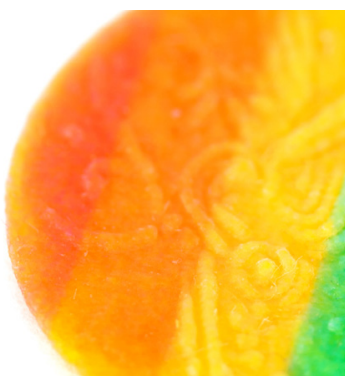

Figure 52. Assembly 30 detail with extruded visual.

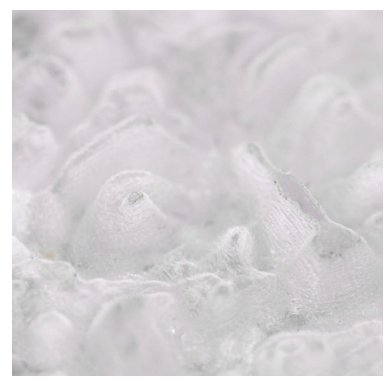

Figure 53. Assembly 31 detail with extruded visual.

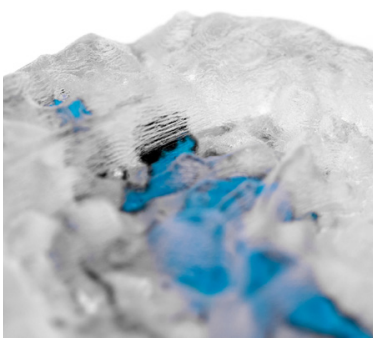

Figure 54. Assembly 32 detail with embossed and extruded visual. 


\section{Batch 6}

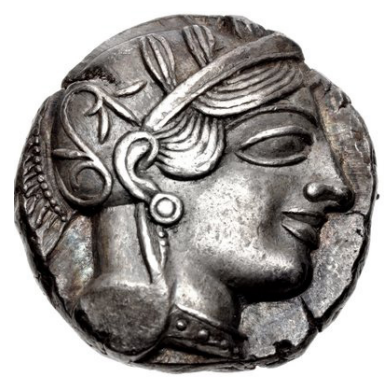

Figure 55. Tetradrachm of

Athens. From Ancient Greek coinage. Retrieved from https:// en.wikipedia.org/wiki/Ancient_ Greek_coinage

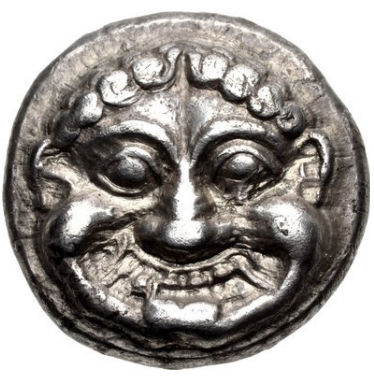

Figure 56. Obverse of coin with the face of Medusa. From Ancient Greek coinage. Retrieved from https://en.wikipedia.org/wiki/ Ancient_Greek_coinage

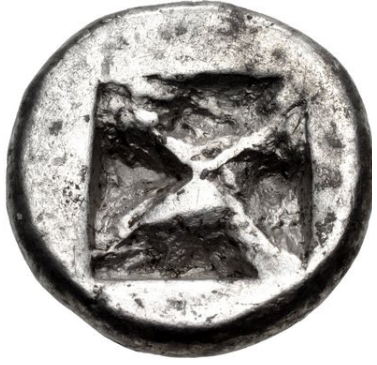

Figure 57. Reverse of Medusa coin with an Incu square. From Ancient Greek coinage. Retrieved from https://en.wikipedia.org/wiki/

Ancient_Greek_coinage

A new technique for image generation was used during this batch. Using Photoshop CC, an image of a coin was brought into the normal workspace and the background white was deleted. The image was then grayscaled and the Brightness and Contrast were used to make the blacks very dark, and the whites very light. Levels were also adjusted to make the contrast more apparent. Once the image was acceptable, a Gaussian Blur filter was applied to the image. Once the image was as desired, it was brought into the $3 \mathrm{D}$ workspace as a Two-Sided Solid Extrusion. From here the depth was adjusted to create large peaks and valleys within the image. Once the solid was ready, it was exported as an STL file to then be fixed within Meshmixer and printed. 
Now that the visual capabilities of the printer have been explored, the colours to be used in the final outputs can be refined. The six base colours were taken from the Gilbert Color font, as shown in Figure 58, and used in the following batches of prints. These colours are not the standard brights used in the flag, but a more muted version which does not detract from the visuals it portrays. 


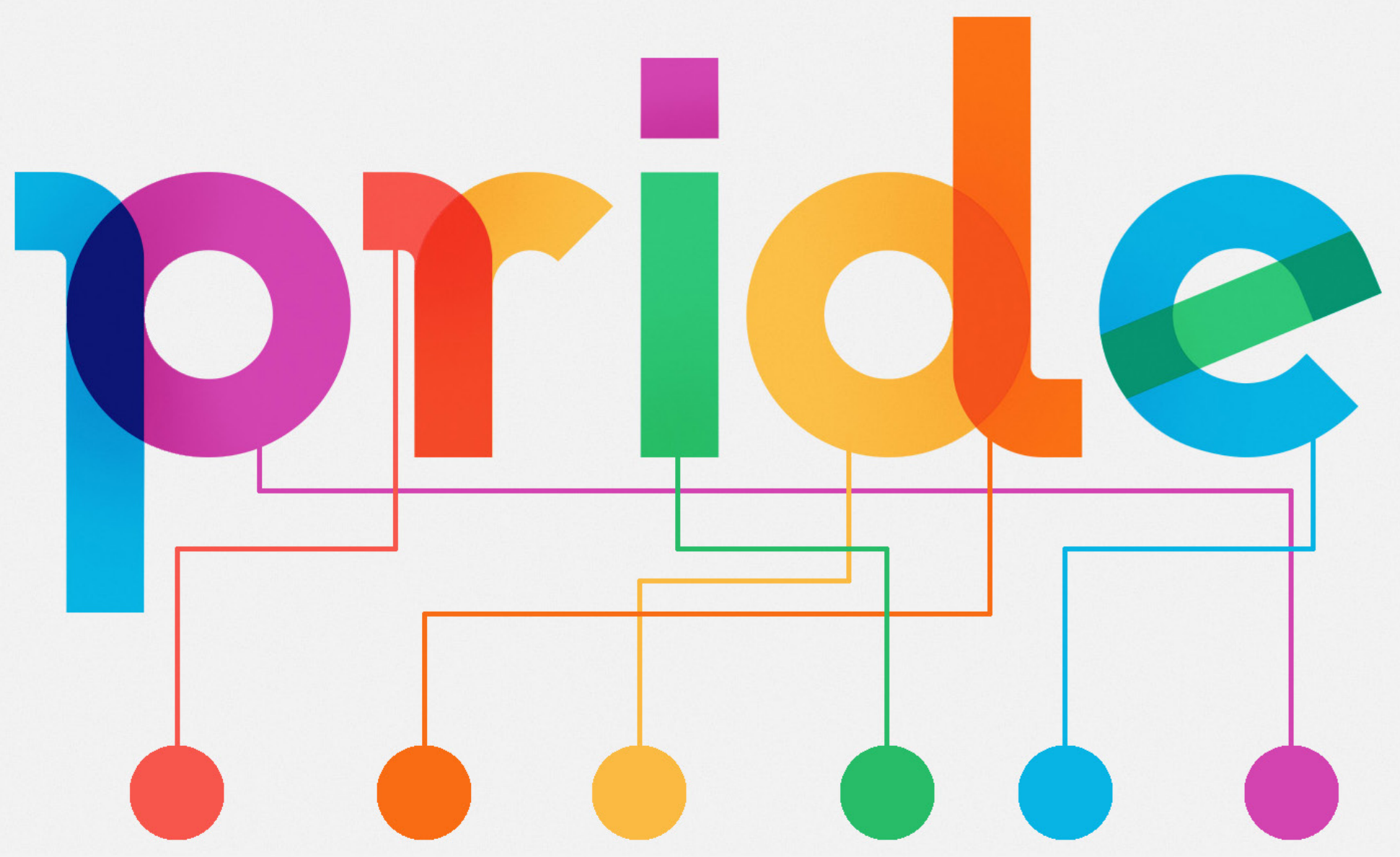

Figure 58. Colours isolated from the Gilbert Color font. 
Figure 59. Batch 7 with embedded visuals and faulty colours. 


\section{Batch 7}

This batch started exploring the colour scheme outlined above. Unfortunately, some of the prints did not print in colour during this batch. However, the prints that did work clearly showed the individual colours. 


\section{Batch 8}

This batch shows the colours working as intended from Batch 7. 


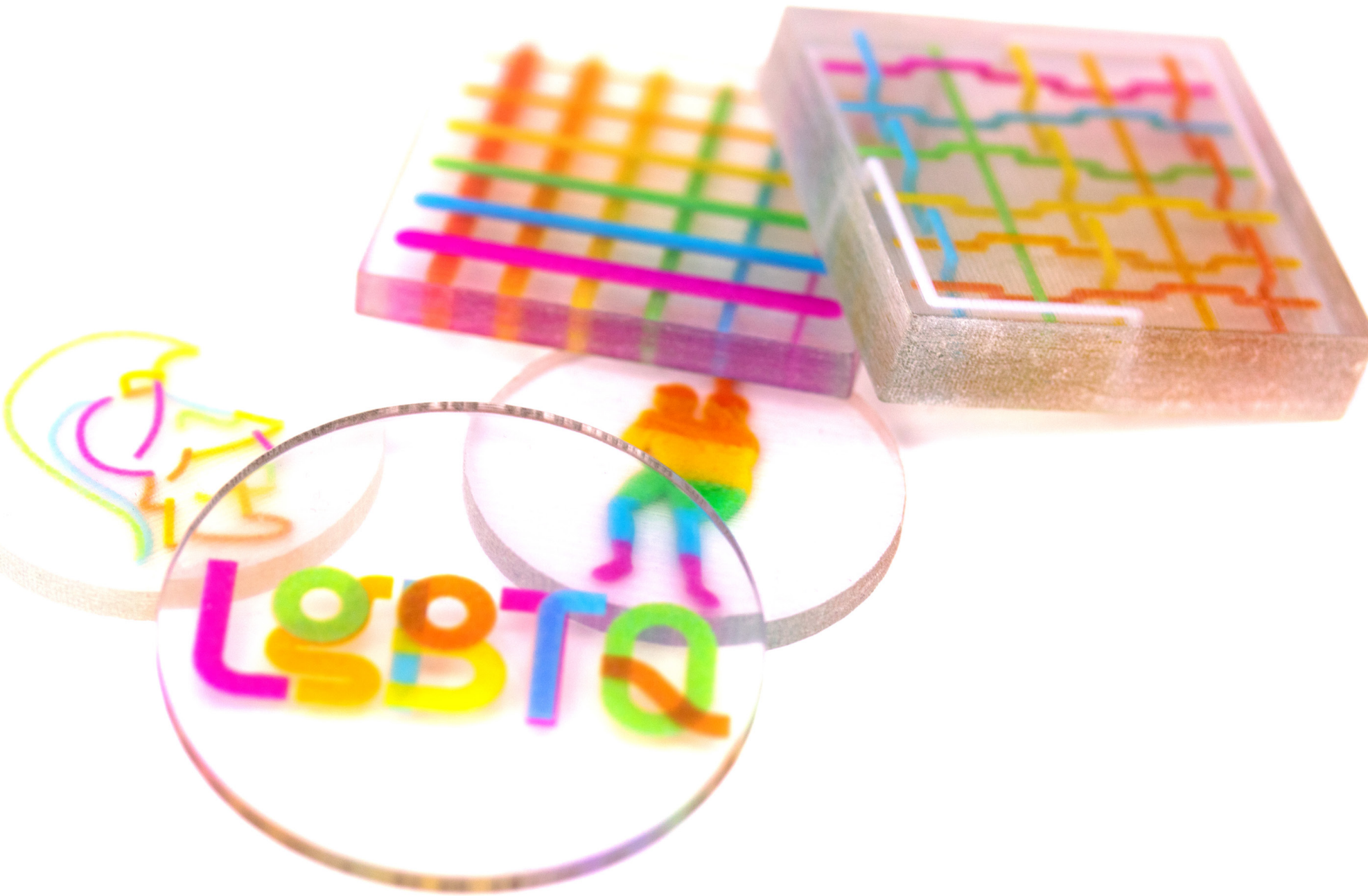

Figure 60. Batch 8 with embedded visuals.

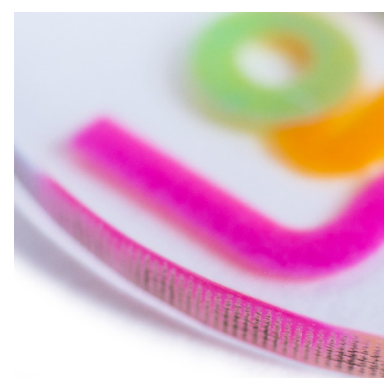

Figure 61. Assembly 33 detail with embedded visual.

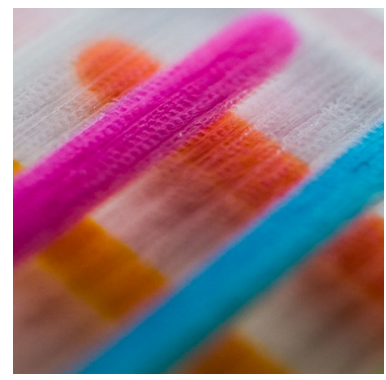

Figure 64. Assembly 36 detail with embedded visual.

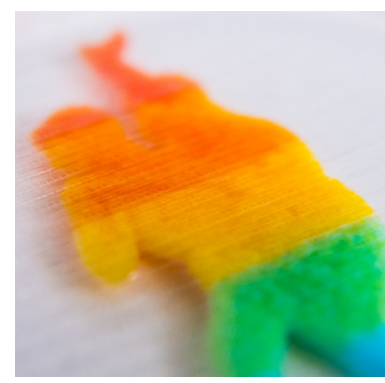

Figure 62. Assembly 34 detail with embedded visual.

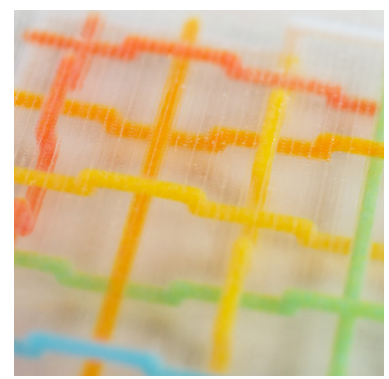

Figure 65. Assembly 37 detail with embedded visual.

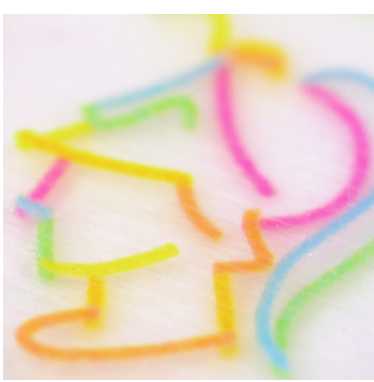

Figure 63. Assembly 35 detail with embedded visual. 


\section{Metal 3D printing}

To give the coins weight and value, a series of $3 \mathrm{D}$ printed metal edges were designed. 3D printing service Shapeways offers metal $3 \mathrm{D}$ printing in a variety of metals and finishes. Several different metals were used to create the edges to link the contemporary technology of $3 \mathrm{D}$ printing with traditional metals used during the Classical period. Silver was used heavily in currency, while bronze was used for ornamental pieces. As this research combines currency and ornamental pieces, both metals were used in this assessment.

The main restriction for this printing method is the strict design guidelines for printing in metal. As the printing method for the Silver and Bronze uses lost wax casting, the models have to be stable enough to withstand the many steps of the process. Lost wax casting is a method of $3 \mathrm{D}$ printing that prints the model in a wax that is then cast in plaster and the wax melted out to leave a plaster mold. Then molten metal is poured into the cast to form the final model. The metals using this method of printing had a minimum wall thickness of $0.8 \mathrm{~mm}$. The steel printing does not use the lost wax casting, instead using binder jetting to fuse the steel particles layer by layer with bronze to create the finished model. Steel requires a minimum thickness of $1.0 \mathrm{~mm}$ due to the fragility of the print before the bronze is added to the model. Even with this being accounted for, models got rejected for being prone to breaking, therefore the models had a minimum thickness of $2.0 \mathrm{~mm}$ as a buffer to avoid this issue.

Before any materials were chosen, sketches were used to explore the geometric possibilities. From this, Greek vase painting patterns were investigated and adapted to be printable in metal. Three patterns were chosen from this investigation, the net pattern, the spiral pattern and the palmette decoration. These patterns are simple enough that they are easily transferable into the digital 3D workspace to be $3 \mathrm{D}$ printed. 


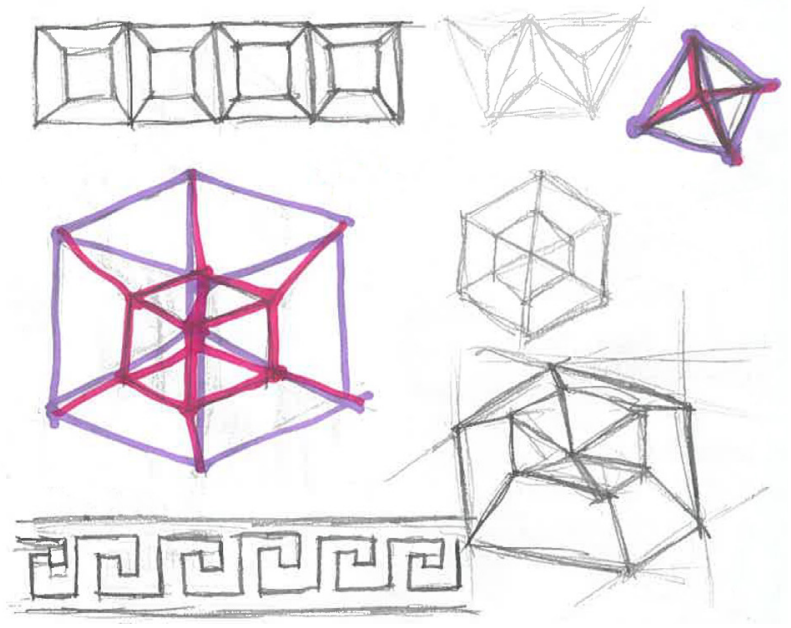

Figure 66. Initial geometric ideation for metal printing.
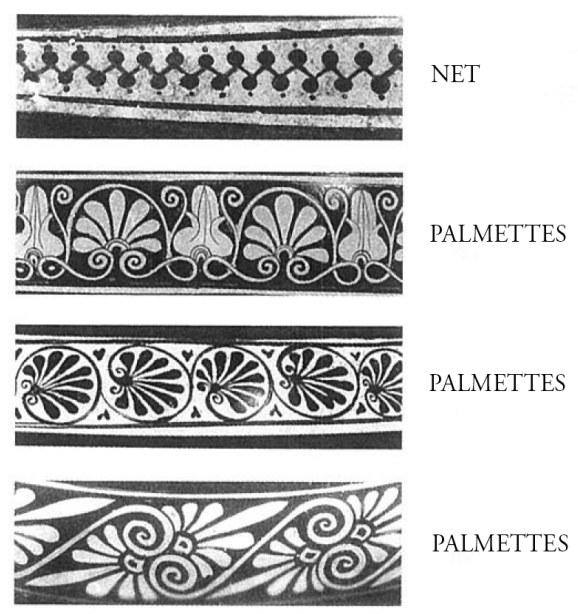

\section{PALMETTES}

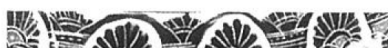

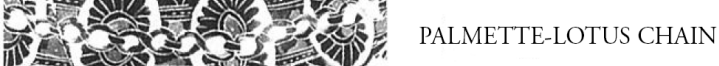

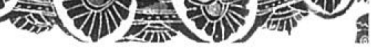

PALMETTES
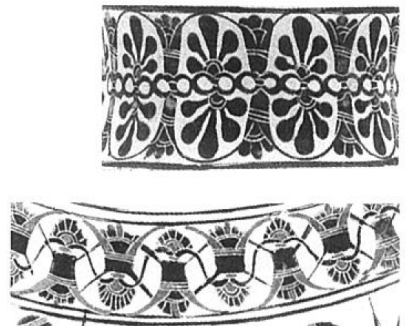

PALMETTE LOTUS FESTOON

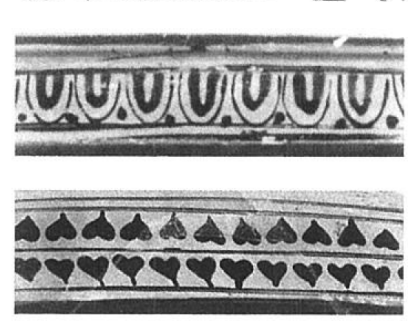

CYMATION

IVY

Figure 67. Greek patterns used in vase painting. 


\section{Concept I - Net}

This model was a test for metal $3 \mathrm{D}$ printing and was printed in bronzed steel as a cheaper alternative to bronze, while still giving the look of bronze (Figure 68). This concept assessed the capabilities of the metal 3D printers and if it was a viable method of printing to add to this research. This model was designed with the intention to insert a flat disc coin in the center, but after getting the model back, it proved very difficult to insert the coin without distorting the coin. Heating the Vero material in hot water softened it to the point at which it was about to be warped, but once it cooled off, the coin was left with marks on it from the attempted insertion. The resultant $3 \mathrm{D}$ print was weighty and detailed. Very fine details were lost, as Shapeways warned they would be, but none of the lost detail was crucial to the success of the design. The insertion of the coin into the ring was rethought after the attempt with a flat coin.

\section{Concept 2 - Palmette}

After the Net concept, the Greek inspiration continued, this time investigating more organic patterns. The palmette decoration and spiral pattern were used within this concept (Figure 69). Because of the problematic insertion of the coin found in the Net concept, this concept aimed to make the insertion of the coin easier. Using the palmette decoration as clips to hold the coin in place alleviated the previous issue. The use of clips allowed more room for the coin to move through while being inserted.

\section{Concept 3 - Baker}

The Baker ring is combining the contemporary with the classical, more so than the previous concepts. This ring looks similar to modern metal currency, with ridges on the edge of the ring, and raised text around the circumference of the ring. This ring is a tribute to Gilbert Baker, the creator of the Rainbow Flag, including his year of birth and death (Figure 70). The reverse side shows the original meaning of the colours in the rainbow flag translated into Ancient Greek (translations by Diana Burton) to relate it back to the classical influence:

\begin{tabular}{|c|c|c|}
\hline $\begin{array}{l}\text { Life (red): } \\
\zeta \omega n ́\end{array}$ & $\begin{array}{l}\text { Healing (orange): } \\
\text { úyírıa }\end{array}$ & 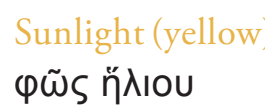 \\
\hline $\begin{array}{l}\text { Nature (green): } \\
\text { yaĩa }\end{array}$ & $\begin{array}{l}\text { Harmony (blue): } \\
\text { ápuovía }\end{array}$ & $\begin{array}{l}\text { Spirit (purple): } \\
\text { Өunós }\end{array}$ \\
\hline
\end{tabular}




\section{Summary}

Using the metal rings to add weight and value to the $3 \mathrm{D}$ printed coins created a collaboration with the $3 \mathrm{D}$ printed interiors that resulted in a more comprehensive design. Contrasting the colour 3D prints with the metal detail creates a clear link between the contemporary technologies, and the classical elements that have only been alluded to in previous experiments. This was achieved by using the classical materials with the contemporary method of $3 \mathrm{D}$ printing. The next step from this stage of experimentation was properly integrating the J750 3D prints with the $3 \mathrm{D}$ printed metal rings, which will be explored in the next section.

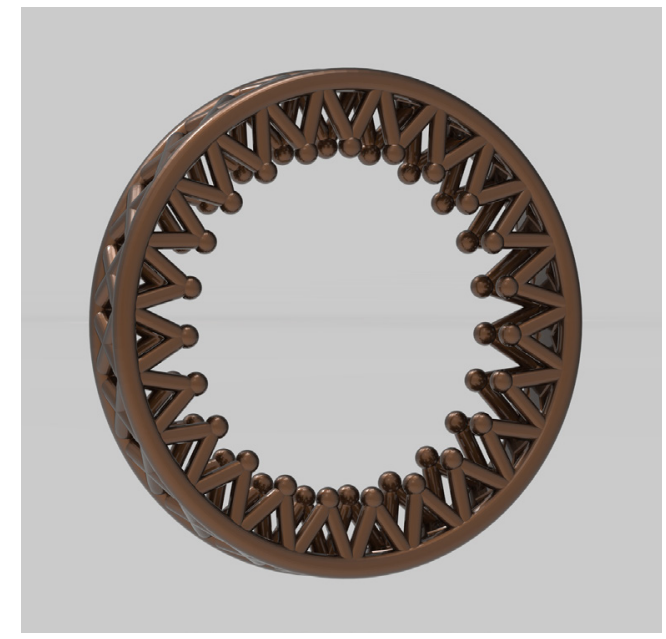

Figure 68. Render of Net metal ring.

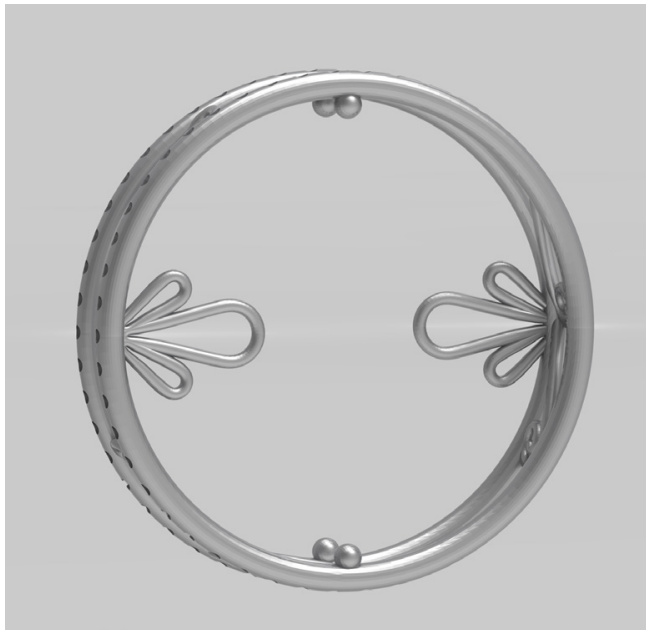

Figure 69. Render of Palmette metal ring.

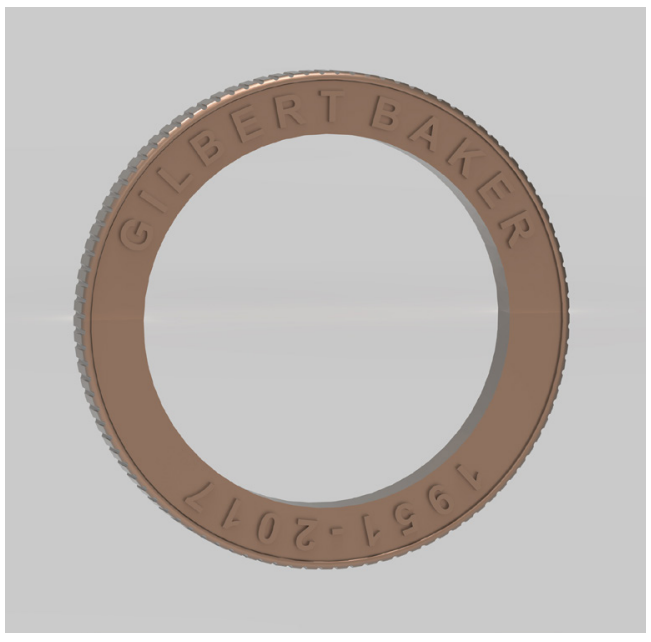

Figure 70. Render of Baker metal ring. 
Designed

Resolution 
This section will showcase the final outputs as the manifestation of this research. 


\section{Blue Medusa}

Within this output, the Photoshop extrusion method was pushed to create an abstract form. While this output does not show a link to the LGBT+ community, it was important to showcase the discovery of this technique.

Figure 71. Blue Medusa

in palm (right).

Figure 72. Close-up of

Blue Medusa (below).

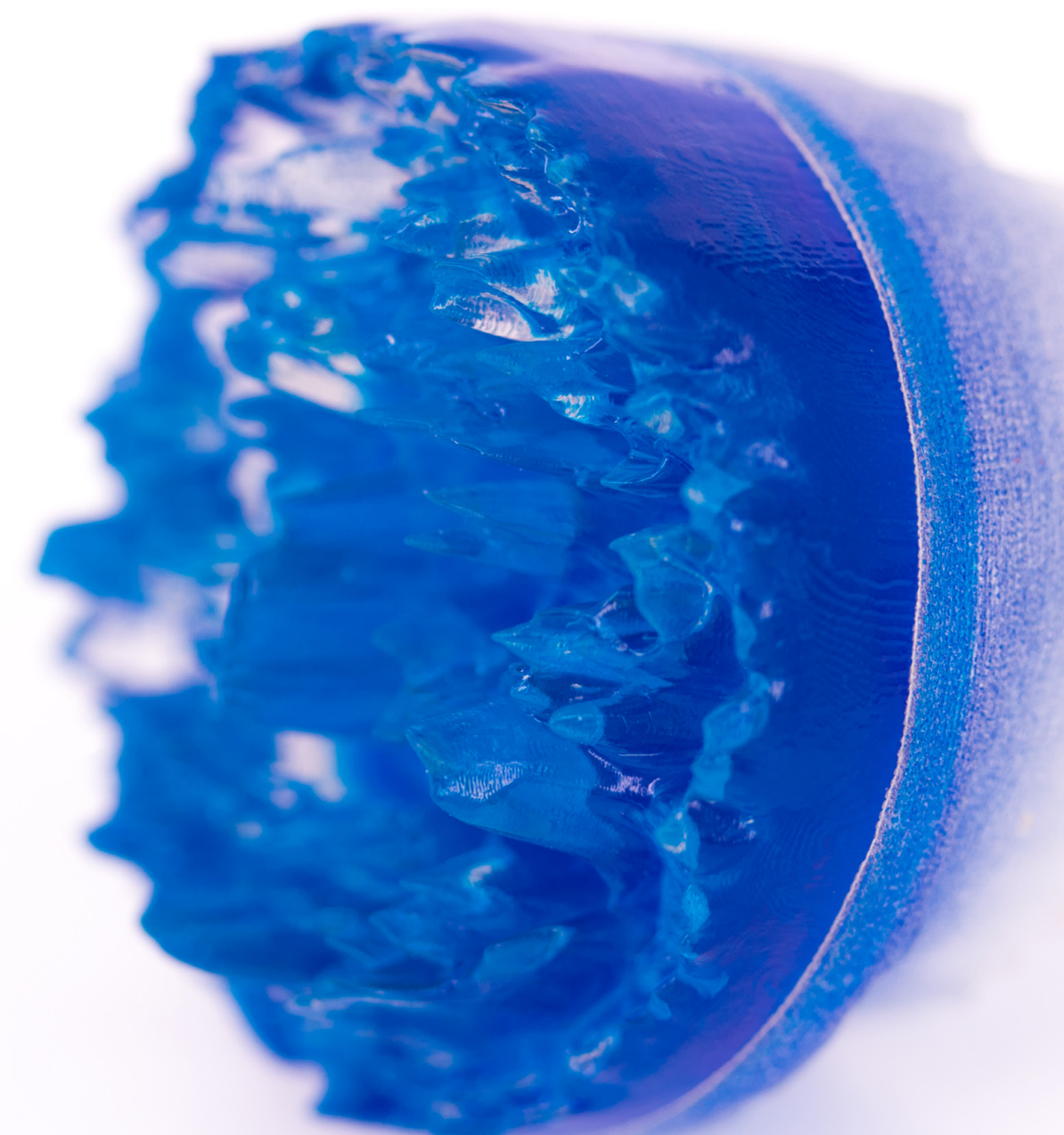




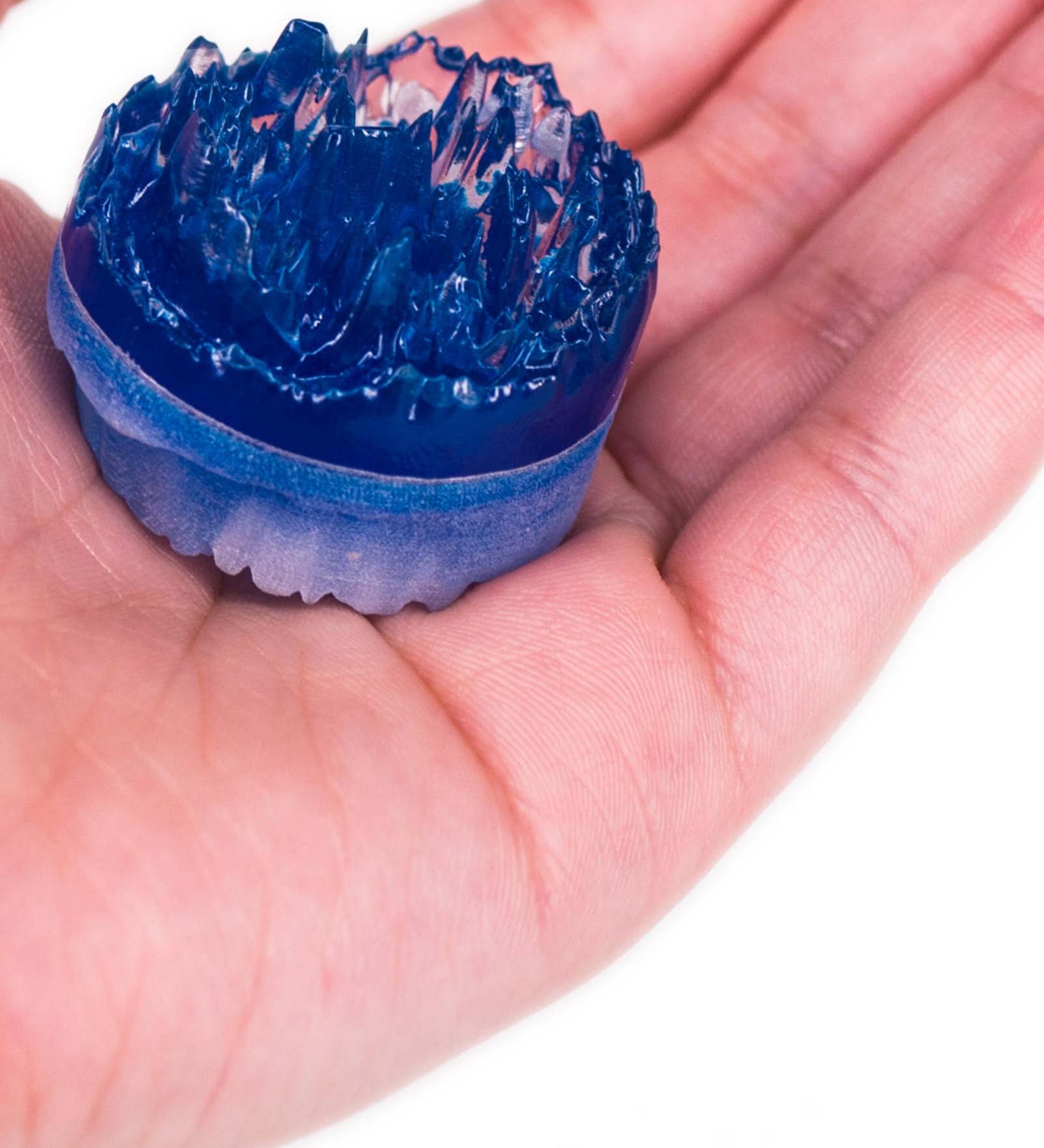




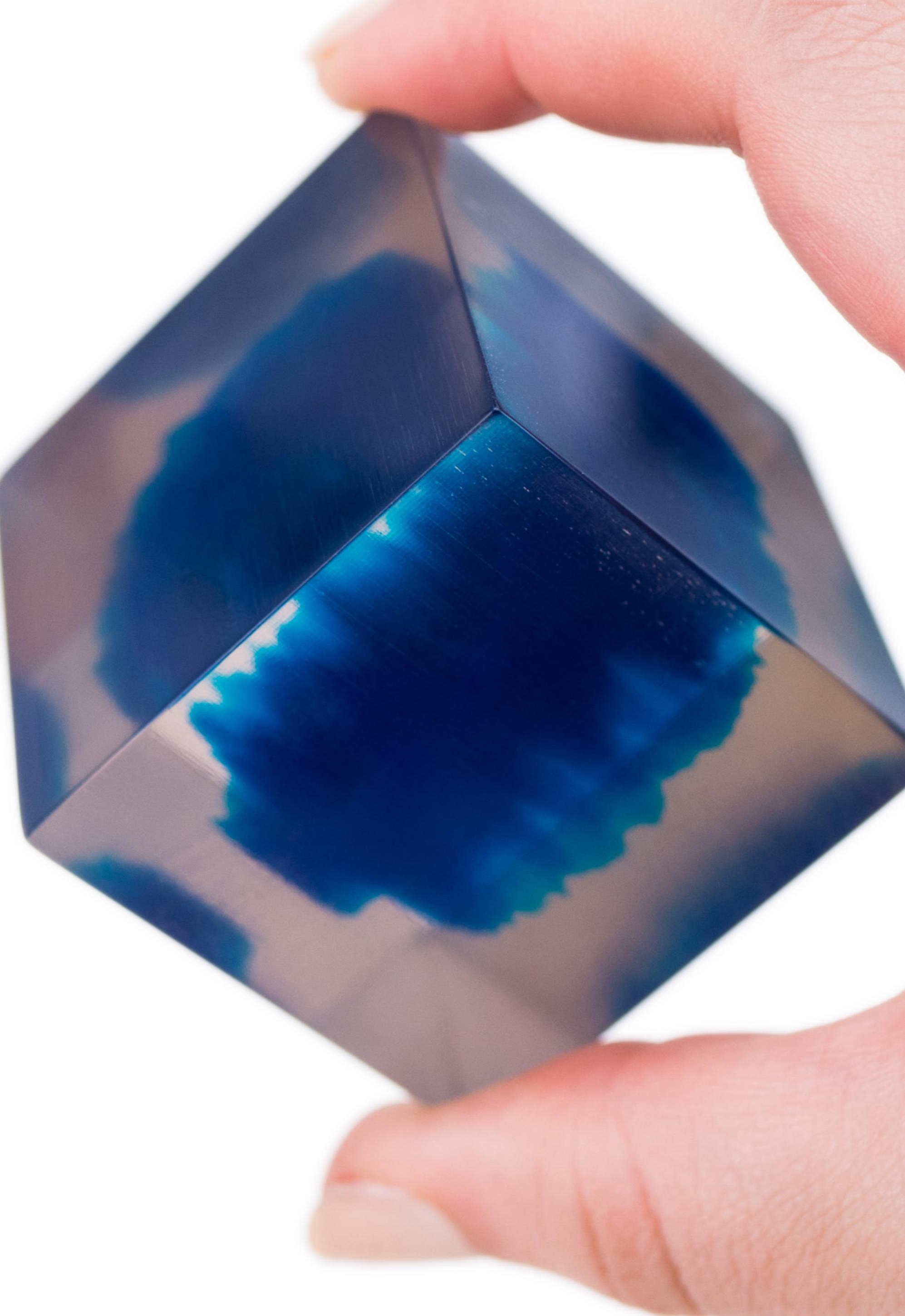




\section{Encapsulated Medusa}

Continuing the showcase of the Photoshop extrusion technique, this output shows how the extrusion looks encased in a transparent cube. The extrusion looks entirely different when inside the cube, even though it is the same model as Blue Medusa.

Figure 73. Encapsulated

Medusa with

backlighting (left).

Figure 74. Encapsulated

Medusa showing print

lines (below).

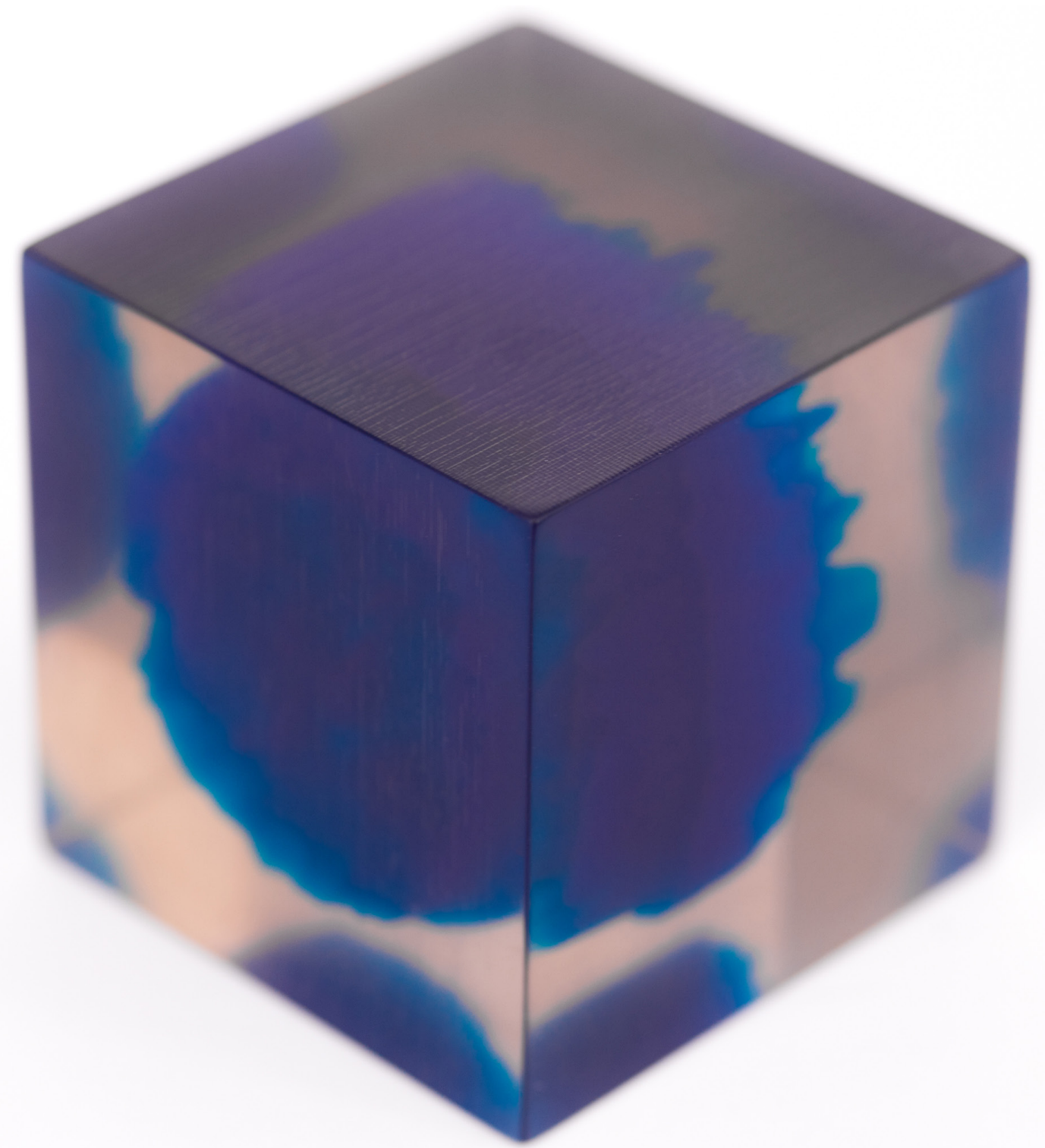




\section{Medusa Currency}

To bring the previous outputs to meet the metal rings developed in the previous sections, Blue Medusa was booleaned to slot into the Net ring. This overcomes the issue of insertion found after manufacturing while managing to still show off the metal $3 \mathrm{D}$ print.

Figure 75. Medusa

currency changing hands

(right).

Figure 76. Close-up

of Medusa currency

(below).

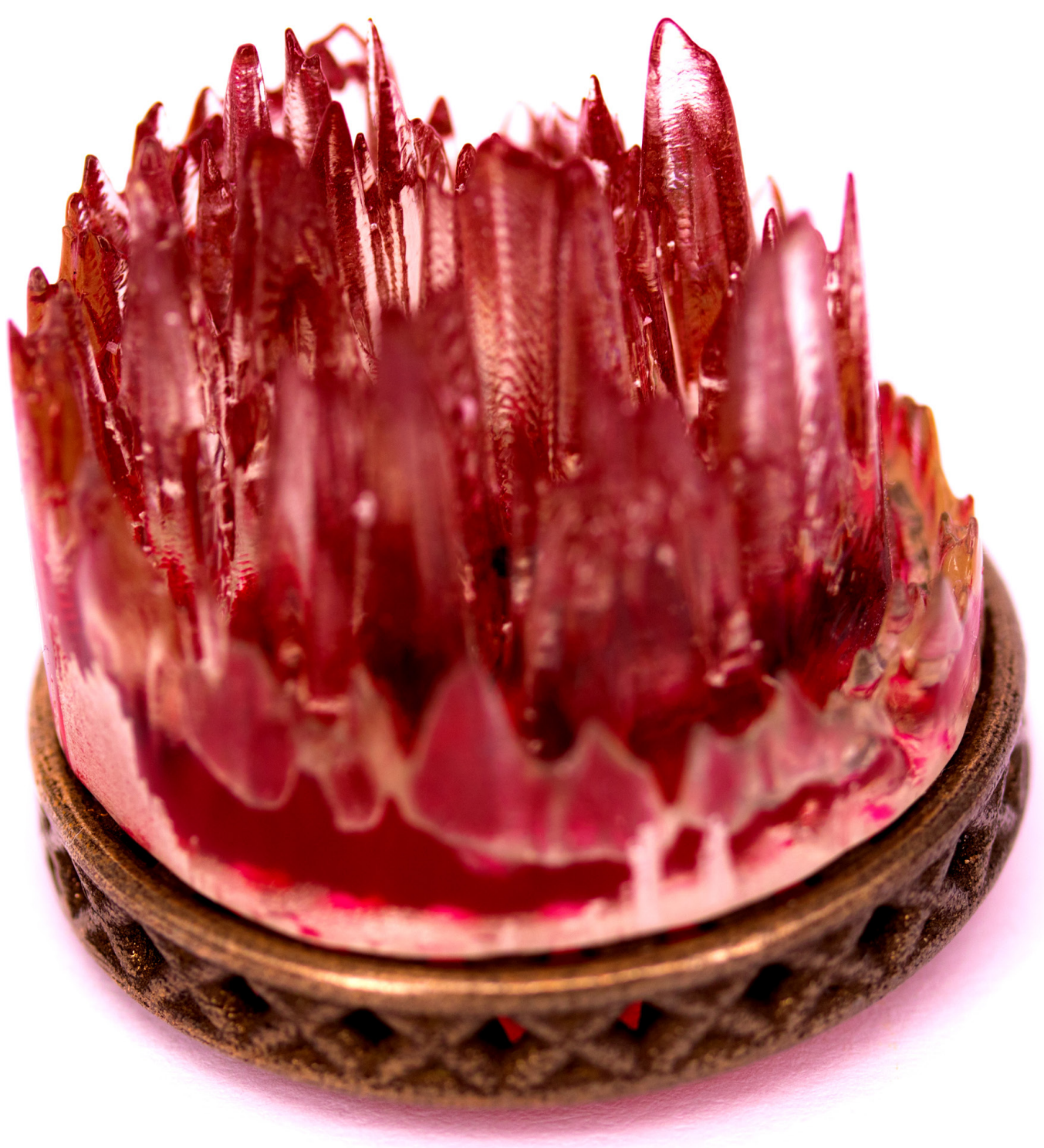




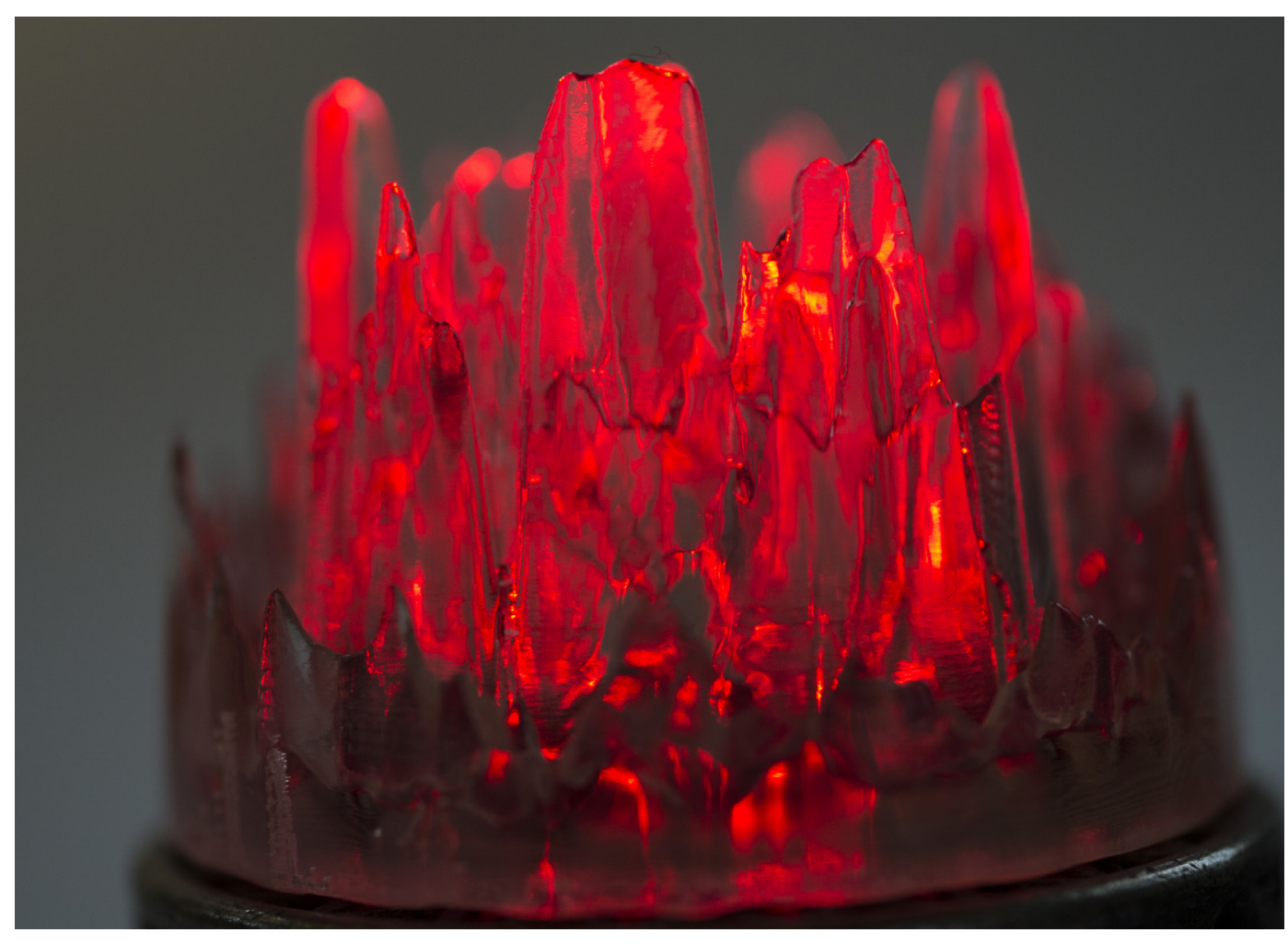

Figure 77. Side view of Medusa currency.

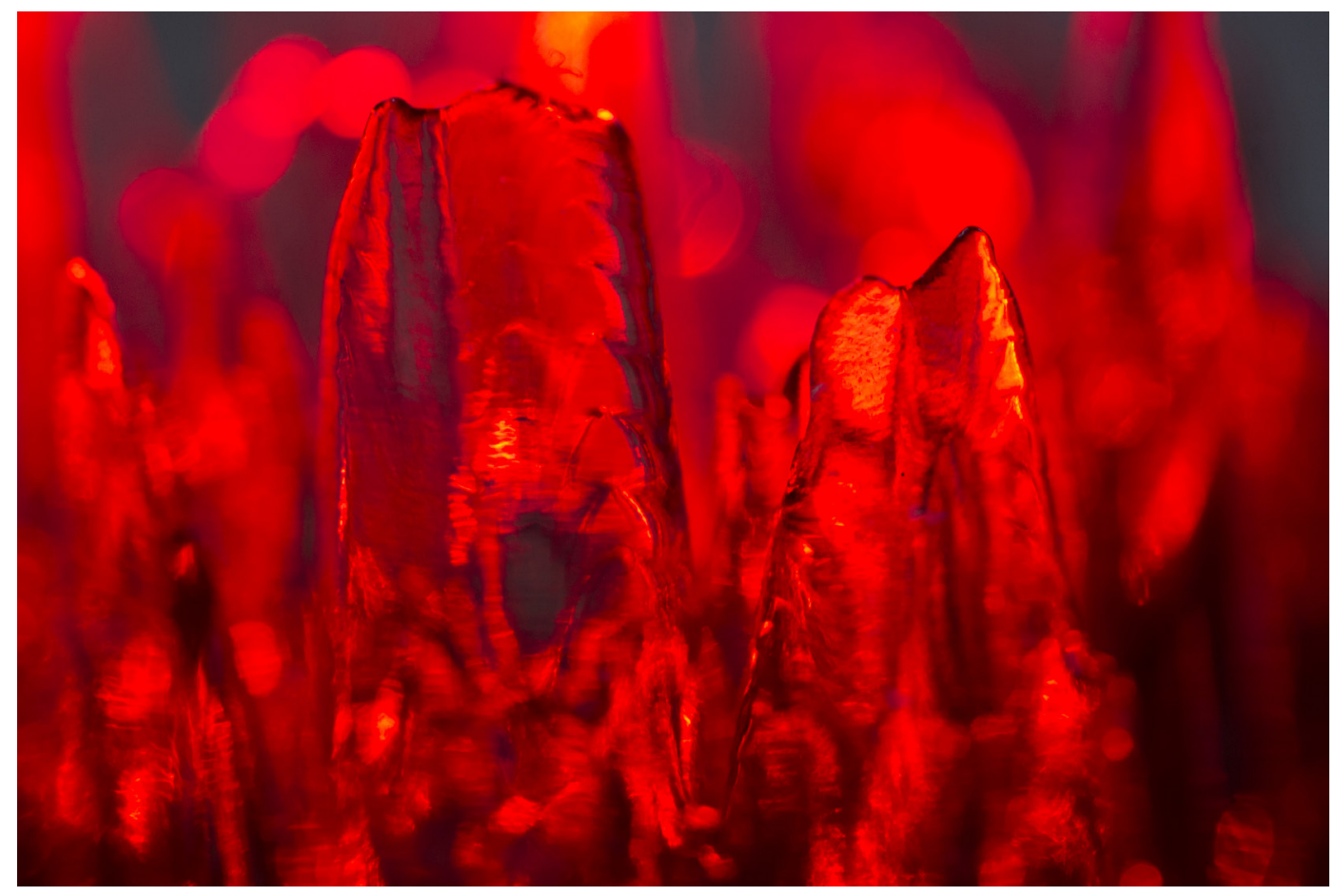

Figure 78. Close up of Medusa currency peaks and valleys. 


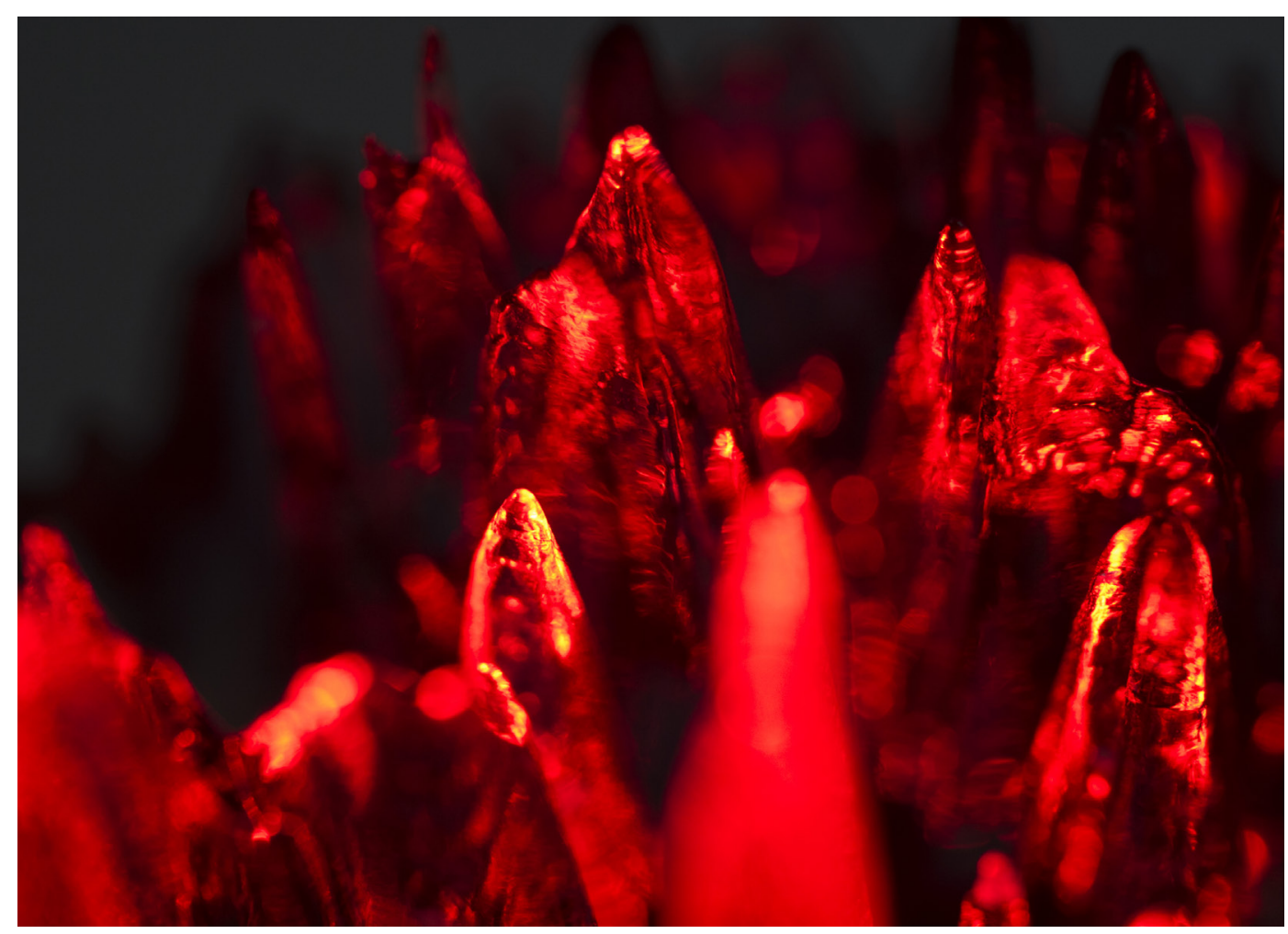

Figure 79. Light shining through Medusa currency.

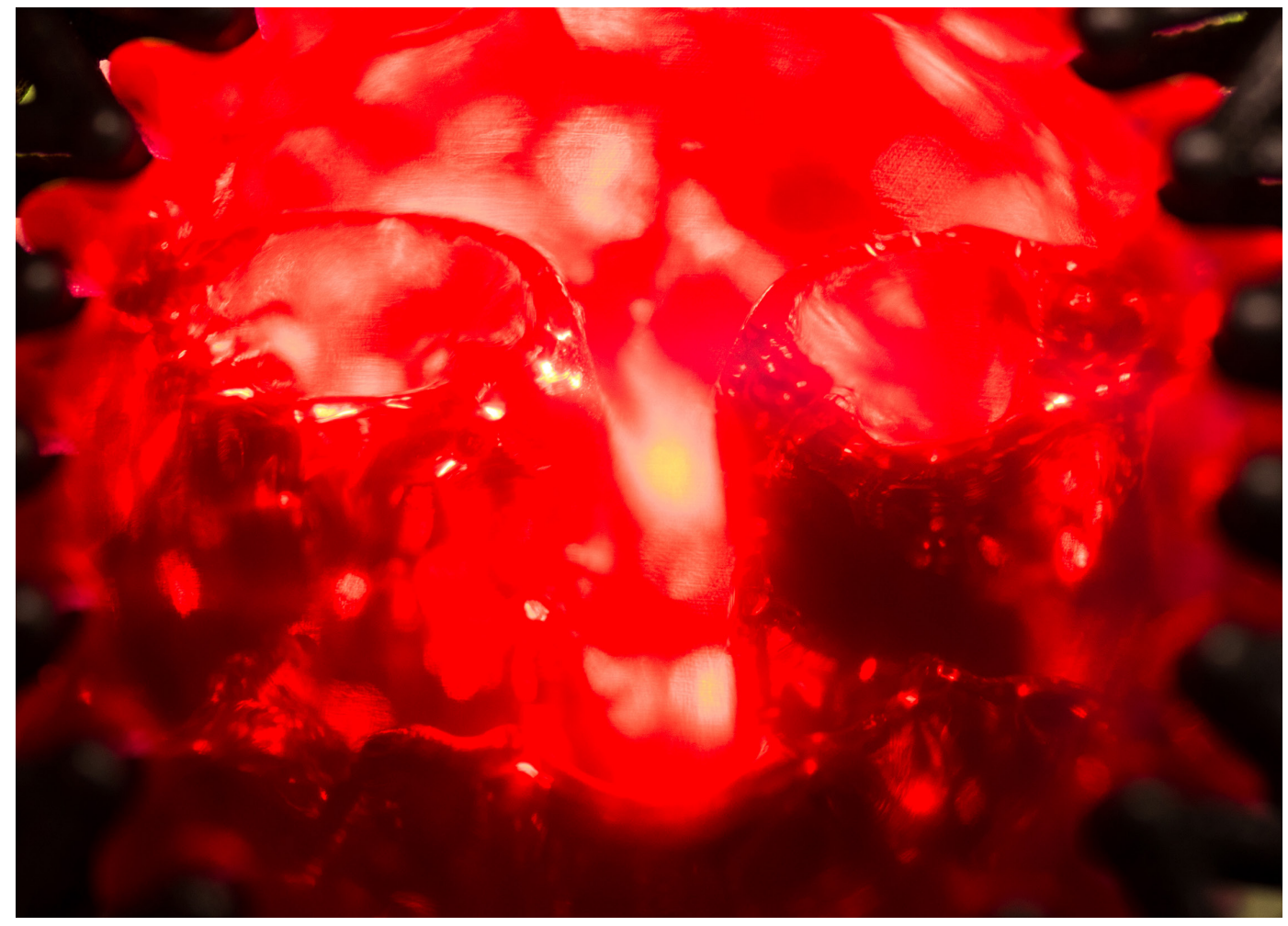

Figure 80. Light shining through the underside of Medusa currency. 
Figure 81. Trasngender red-figure close-up (left).

Figure 82. Close up of metal casing of Transgender red- figure (below).

\section{Transgender Red-Figure}

Using the duality of the palmette decoration, this output continues the look of duality to express gender issues. This output showcases the drawings of the transgender figures in a red-figure painting style from the introductory visual experiments in a split coin. Rather than using the VeroClear as in previous 3D prints, this output uses the straight pigmented resins. The pure colour resins give strong colour while still being transparent, allowing the viewer to see the visuals embedded within the coin. The split of the coin is not straight, but diagonal to allow for a gradient to form when viewing the coin from the top face. This tells the narrative of how society is gradually accepting that gender can be viewed as a spectrum, rather than the binary male-female model that has become ingrained in our society. The idea that there are only two genders is still prominent in many dissenting parties, equating gender to biological sex (i.e. the genitals/reproductive system an individual has). Gender is much more than biological, and is not fixed. An individual's gender can fluctuate between feminine and masculine and androgynistic, and need have no correlation to biological sex .

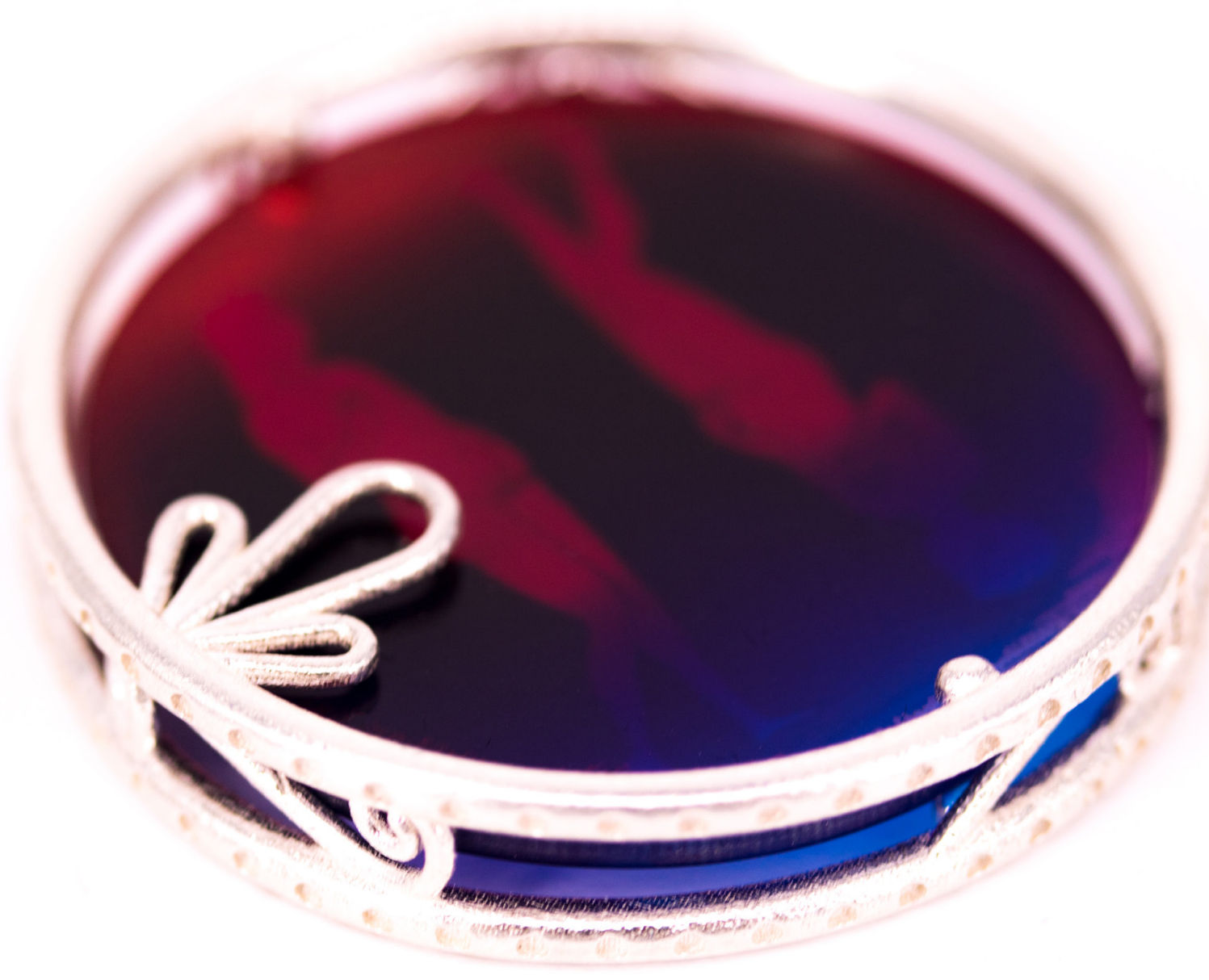




\section{Red-Figure coin: Tribute to Gilbert Baker}

Gilbert Baker, the creator of the Rainbow Flag, has been a huge inspiration to the topics in this research portfolio and therefore, a coin had to be made to honour his memory. The myth of Hermaphroditos and Salmacis has been revisited as a classical symbol for gender-deviancy, using the traditional red-figure colour technique for the figures, while the background is green and blue to reflect the forest and pond from the original myth.

Hermaphroditos was a handsome young man with whom the nymph, Salmacis, fell in love with while he was bathing in a pond in the forest. When he refused her proposition, she leapt onto his back and prayed to the gods that they would be united. This resulted in the fusion of their physiques, creating an androgynous form, and thus the myth was used as the explanation for the condition of hermaphroditism, where the organism has both male and female features or reproductive qualities.

The Hermaphroditos coin is surrounded by the bronze metal print Baker (Figure 70) on which Gilbert Baker's name and years of life are embossed on the obverse side, and the original meanings for the six colours of the Rainbow Flag are in Ancient Greek on the reverse.
Figure 83. Red-figure

tribute to Gilbert Baker metal casing close-up (right).

Figure 84. Obverse side of red-figure tribute to Gilbert Baker (below).

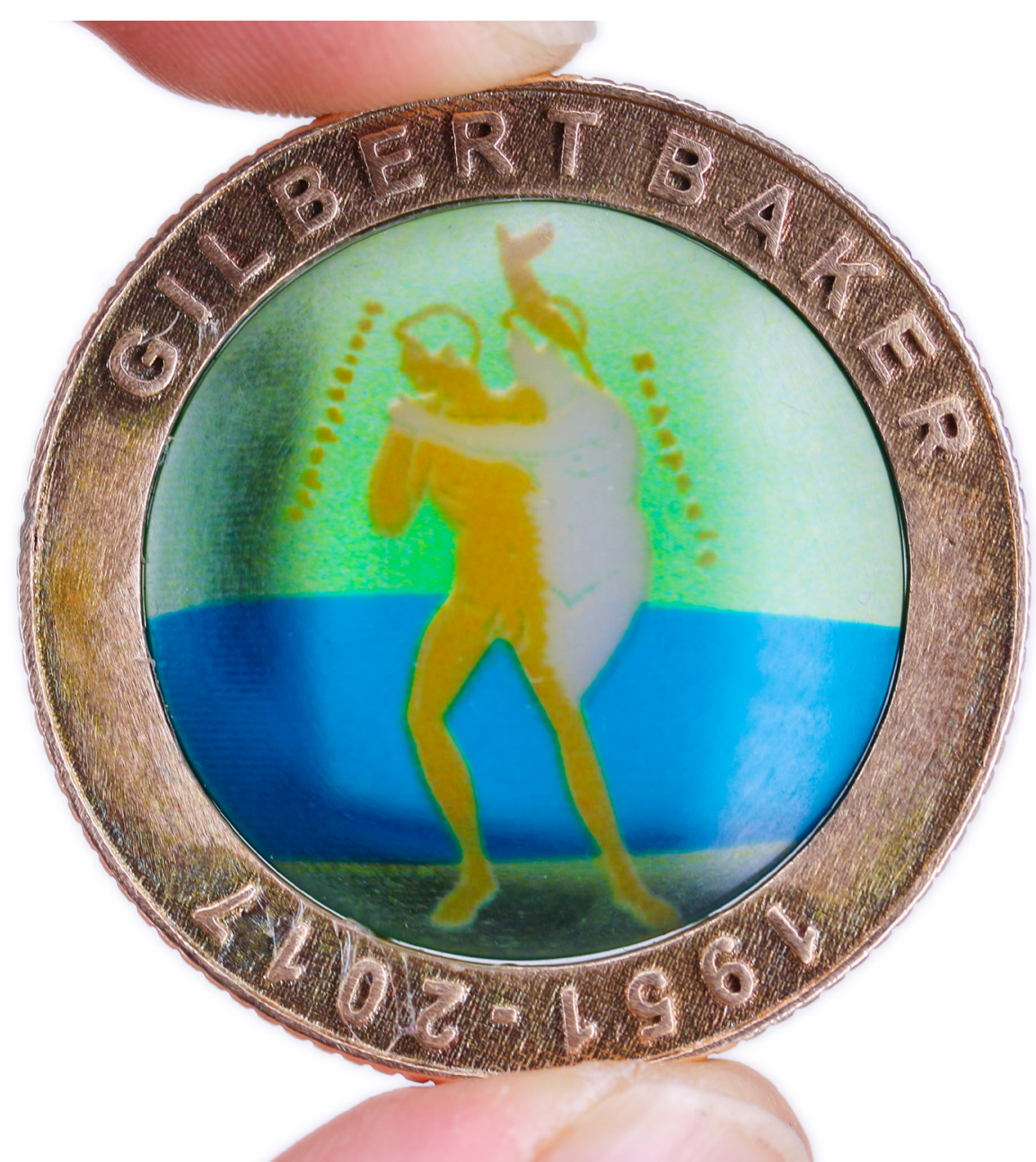




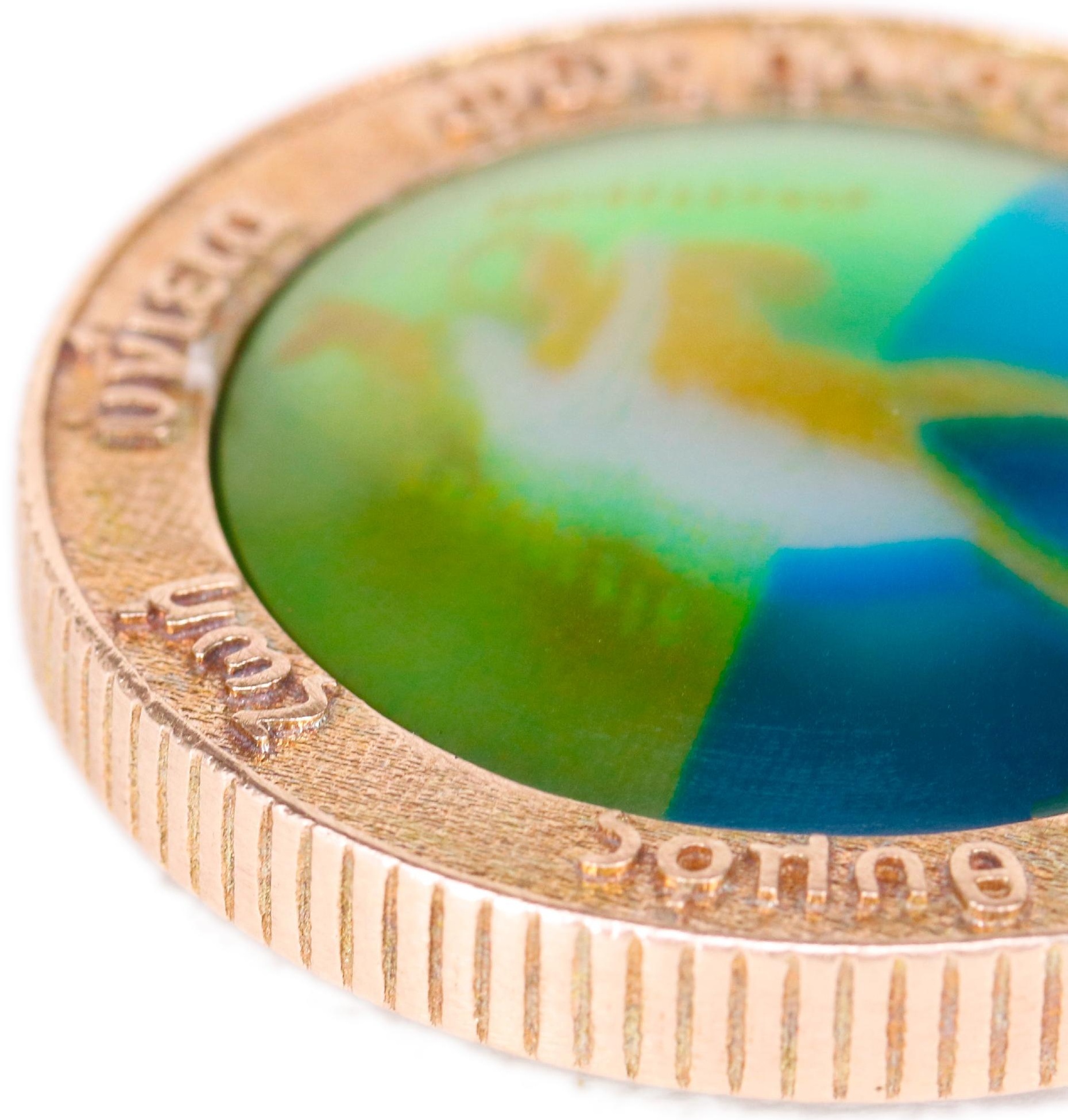




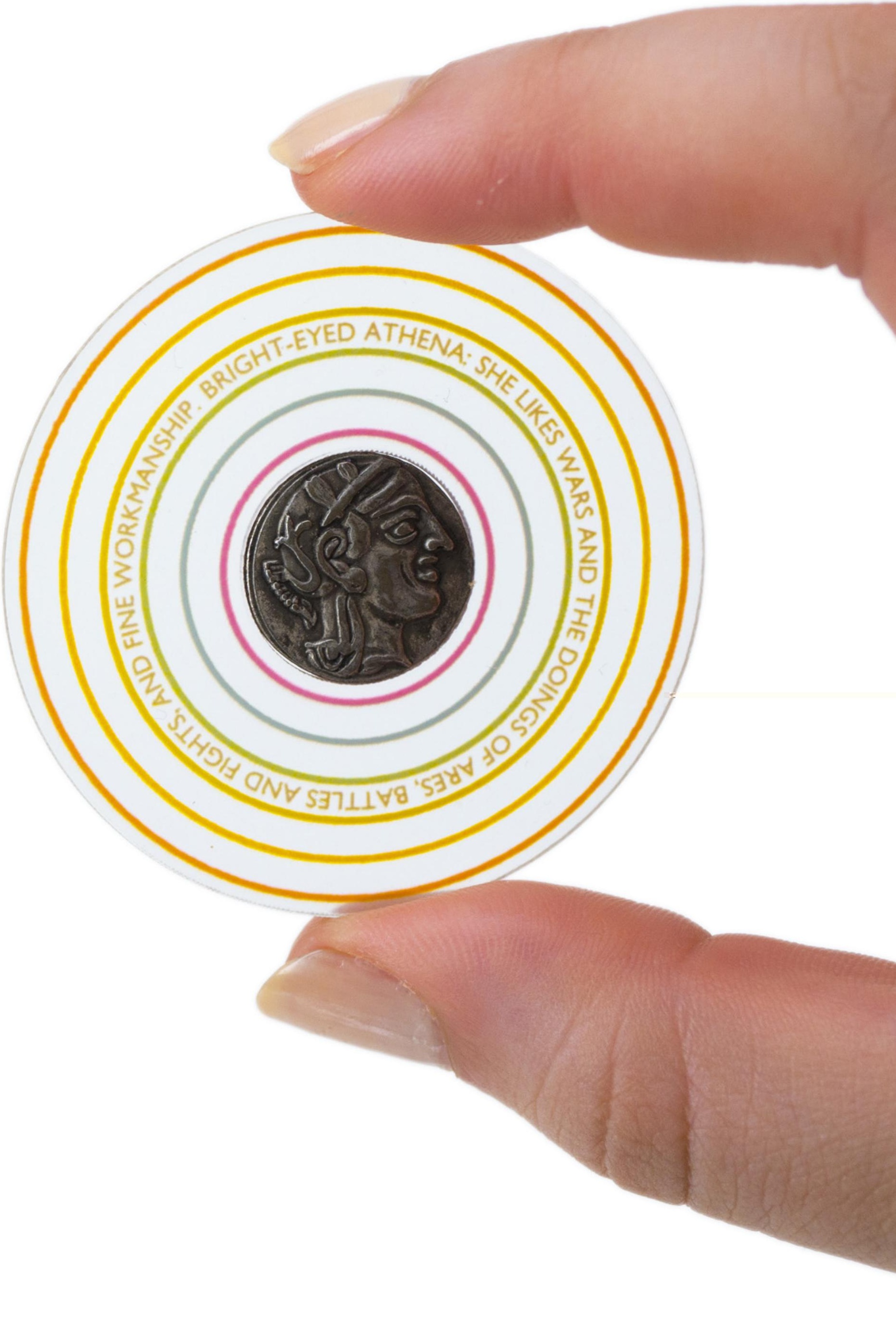


Figure 85. Digital

\section{Digital Athena}

This output turns the previous works inside out by encasing the metal coin within a ring of coloured $3 \mathrm{D}$ printed material. The coin chosen depicts Athena on one side and an owl and olive sprig on the other. This coin is from Athens, where Athena was the patron goddess. As Athens has featured prominently in this research into classical homosexuality and how it was portrayed in art, this coin was a good way to conclude the outputs, by bringing the research back to where it started - its classical influence. The hint of rainbow colours around the diameter of the coin links this coin with the previous works and successfully highlights the three way intersection this research was hoping to achieve.

Athena close up (left).

Figure 86. Close up of

coin insert showing an

owl, an olive branch and

the inscription $\mathrm{A} \Theta \mathrm{E}$

(below). 


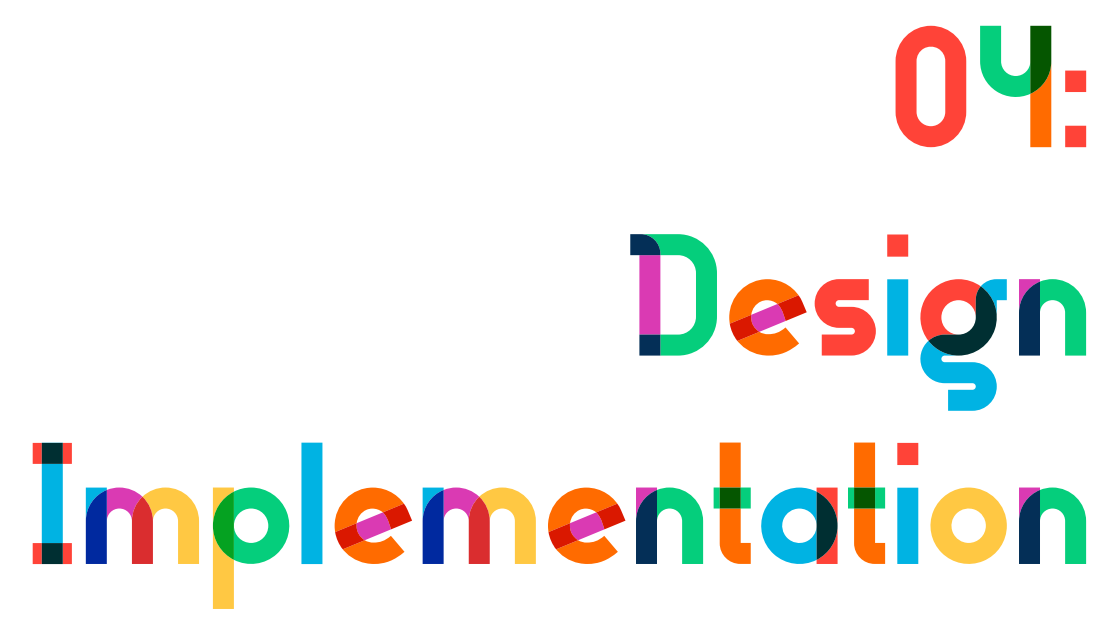


Discussion 
This section will discuss: the findings of this thesis and how they relate to previous research; the importance, implications and limitations within this research; and what future research could be done to expand on this research portfolio. 
This research explored how 3D printing technologies could be applied to classical formats to encourage a new way of visual storytelling. Within this research portfolio, areas of previous research were explored from both the Design and Classics fields through a literature and design precedent review revealing parallels between the methods of how they tell narratives visually. These parallels paved the way for exploring 3D technologies with classical artifacts to create new stories that reflect contemporary issues.

This research focused on the storytelling opportunities for 3D printing and how the methods of storytelling can evolve as technology improves. Following on from the Precious Printing project (Guy, Burton \& Challies, 2018), the case study Engagement supports the finding that the combination of Classics and $3 \mathrm{D}$ printing can be beneficial in a teaching environment as it promotes interest and passion for the topics in the students. This interest and passion can be taken from the classroom and translated into cultural settings, such as museums and heritage sites, to enhance the experience of visitors to such sites, as discussed by Capurro et al. (2015) and D'Agnano et al. (2015).

This thesis explored a new avenue for $3 \mathrm{D}$ printing and cultural heritage that is unexplored in past research. This avenue encompassed the use of digital technologies within the cultural heritage field to tell contemporary narratives. Digital technologies are often misrepresented as a method of creating perfectly identical objects when printed in a batch. While this can be true, it is not the whole truth. Digital technologies allow for randomness within their identicality. This can be seen in the models generated through the Photoshop extrusion method. The same image was used at the start of the process, but the variables that were acted upon it were different (e.g. Brightness \& Contrast, depth of extrusion) creating one-of-a-kind items. Printing defects can also appear in identical batches. This was evident in Batches 7 and 8 where the colour did not print as intended. There were also less dramatic defects, such as with the cube print which was printed twice. The first time it was printed, it was on a tray with another job, so opaque resin was tracked across to the clear resin, leaving an embedded trail of white. The second one printed was the only job on the tray, so this issue was not replicated. While both models were identical, circumstances outside of anyone's control created a totally unique object each time it was printed, demonstrating that creative 
serendipity can occur in contemporary technologies just as it did in classical artifacts.

One limitation of this study was the number of participants within the Engagement case study. The study was restricted to one class and one assignment; therefore, the pool of participants who completed the questionnaire was limited. The survey pool was 24 students, and the results obtained are accurate only for this instance. If the sample size was expanded or if the project was repeated with other classes, more insight could be gained from the students and how they respond to the combination of $3 \mathrm{D}$ printing and Classics. From this, a comparison could be drawn from the student feedback from different years to create a more detailed picture of the pedagogical applications of $3 \mathrm{D}$ printing and Classics.

This research is cross-disciplinary; therefore the implications of this research not only affect the Design field but the Classics field as well. The method of $3 \mathrm{D}$ printing is well-established in the 21 st century; this research shows a new use of this technology. This research assists in the exploration of new technology, the Stratasys J750 3D printer and its fullcolour capabilities. The exploration of this method of printing is essential as it expands on previous studies on the multi-material properties of the Stratasys J750, such as Tor Robinson's Master's thesis on 3D and 4D printing for film (2017) which focused more on materiality, and briefly covered colour capabilities. This thesis aimed to fill in the blanks previous research has neglected to create a complete picture of the technology. Colour and visual explorations of this technology open an avenue for creativity and expression that is currently uncharted (as the literature and precedent review in this thesis proves). This research blends Design with another discipline, creating meaningful research that encourages more collaborative research between faculties. For the Classics field, this research furthers the knowledge of how digital $3 \mathrm{D}$ technologies can be used to improve the museum experience (Capurro et al., 2015; D'Agnano et al., 2015) and acts as further testing of $3 \mathrm{D}$ printing within the cultural heritage field. From the findings of the case study, Engagement, it can be seen that there is a link between engagement and education. Using Classics and $3 \mathrm{D}$ printing to create new means of displaying work made the students "interested and passionate to do well" (Student 20, personal communication, September 9, 2018). 
Myth's adaptability allows it to remain relevant in a contemporary context as a way of approaching difficult subjects, as seen in the Engagement case study and through the use of LGBT+ community narratives. Translating the ancient iconography into bold and transparent 3D printed curios reflects the increasingly transparent nature of contemporary society when discussing gender and sexuality. Using the narratives from this community in a publication such as this brings down the veil of misunderstanding surrounding the individuals. These stories feature the contemporary narrative of gender as a spectrum and the history of Gilbert Baker. Telling these stories within the medium of 3D printing allowed for rich colour and transparency within the colours. This is reminiscent of the colourful nature of the LGBT+ community that includes people from all walks of life.

This publication may contribute to the movement reducing hate towards LGBT+ individuals. While this research does not explicitly target ending homophobia and homonegativity, the narratives play an interpretative role for the reader. Within the literature review, ancient attitudes towards homosexaulity were explored and showed the differences between ancient and contemporary homosexuality and how it is viewed by the societies. Not all readers of this thesis will come to the same conclusions as the author did; however, these differing conclusions create a more informed discussion between anti- and pro-LGBT+ parties. Any information for the wider population is a step in the right direction towards peace, which is a significant part of what makes this research valuable, and why it should continue in the future.

The following considerations for this branch of research would be to expand the printed formats to other classical objects, including pottery sherds, statues and jewellery. Branching out to different forms would further explore the capabilities of the $3 \mathrm{D}$ printing technology and the ways the collaboration between the Cultural Heritage field and the Design field will look in the future. Using different forms will form a natural link to exploring and expanding the narratives to be told through the objects. This thesis only focused on one contemporary narrative, the LGBT+ community; however, there were many topics also considered including feminism, politics, immigration and social media's impact on society. All of these could be explored through different forms, allowing for the form to speak more highly of the narrative it is telling. It is important to note that as this research moves 
forward, so too do the technologies being used. 3D printing technologies are developing very quickly. As this thesis is being published there is already a new Stratasys 3D printer, the J735, as an upgrade from the $\mathrm{J} 750$, which allows rigid and flexible clear resins to be printed in the same print. At the start of experimenting with the J750 and its colour capabilities, a lot of time went into making sure the colours were correct and that they would print as desired. Now, the J750 is Pantone Validated, making it the first 3D printer with colour-accuracy of this level (Stratasys, n.d.). 
Conclusion 
This research portfolio explores the capabilities of the Stratasys J750 through a marriage of $3 \mathrm{D}$ printing with classical artifacts. While at first glance the two fields may seem unrelated, this research portfolio has proven that there is the capacity for creative integration to benefit how narratives are told. Additionally, the multi-colour technology of the J750 may satisfy the accurate reproduction of artifacts and heritage sites.

Using the LGBT+ community as a lens through which to focus this research, there has been an increase of discussion from those who have come into contact with this research while it was being developed. This is a step forward in tangible communication for more open legislation surrounding societal "issues" such as same-sex marriage and transgender rights.

The possibilities of $3 \mathrm{D}$ printing may be endless, and we are only just scratching the surface of what it is capable of. Not only does the technology have practical uses, but it also has creative purposes. This research portfolio shows one exploration of this creativity, and how it can be used to tell stories within the Classical Studies field. This thesis also shows LGBT+ community narratives in a qualitative research output, rather than a quantitative research paper. This research shows the community as more than a statistical point of interest, but as a highly creative community that deserves to be normalised within society rather than sensationalised. 
References 
Abrehart, D. (2009). LGBT - Lesbian, gay, bisexual: But why transgender? Retrieved December 13, 2018, from https:// web.archive.org/web/20090703020520/http://www. mother-ship.com/blog/lgbt-lesbian-gay-bisexual-butwhy-transgender-1721

Adămuţ, A. (2011). Philosophical aspects of homosexuality in Ancient Greek. Philosophy, Social and Human Disciplines, $11,11-22$.

Aeschylus. (2009). Fragments (A. Sommerstien, Trans.). Cambridge, MA: Harvard University Press. (Original work published ca. 525-456 B.C.)

Al-Baghdadi, M. (2018). 3D scanning, 3D virtual reality, and 3D printing for Najaf holy city's cultural heritage and identity. International Journal of Energy and Environment, 9(5), 515-528. Retrieved from https:// search.proquest.com/docview/2138558972?.rfr id=info $\% 3$ Axri $\% 2$ Fsid $\% 3$ Aprimo

Altman, D., Aggleton, P., Williams, M., Kong, T., Reddy, V., Harrad, D., Reis, T., \& Parker, R. (2012). Men who have sex with men: Stigma and discrimination. Lancet, 380, 439-45. https://dx.doi.ord/10.1016/S01406736(12)60920-9

Ancient Greek coinage (n.d.). In Wikipedia. Retrieved July 11, 2019, from https://en.wikipedia.org/wiki/Ancient_ Greek_coinage

Archer, B. (1995). The Nature of Research. Co-Design, 2(11), 6-13.

Arthur-Katz, M. (1989). Sexuality and the body in ancient Greece. Mètis. Anthropologie des mondes grecs anciens, 4(1), 155-179. https://doi.org/10.3406/ metis. 1989.934

Beard, M., \& Henderson, J. (2001). Classical art from Greece to Rome. Oxford, NY: Oxford University Press. 
Bontempo, D., \& D’Augelli, A. (2002). Effects of at-school victimization and sexual orientation on lesbian, gay, or bisexual youths' health risk behavior. Journal of Adolescent Health, 30(5), 364-374.

Bregman, H., Malik, N., Page, M., Makynen, E., \& Lindahl, K. (2013). Identity profiles in lesbian, gay, and bisexual youth: The role of family influences. J Youth Adolescence, 42, 417-30. https://dx.doi.org/10.1007/s10964-012$9798-\mathrm{z}$

Capurro, C., Nollett, D. \& Pletinckx, D. (2015). Tangible interfaces for digital museum applications: The Virtex and Virtex Light systems in the Keys to Rome exhibition. Proceedings of Digital Heritage, 271-276. https://doi.org/10.1109/ DigitalHeritage.2015.7413881

Cooper, L. (2016). Statistics and bisexuality. Retrieved October 24, 2018, from https://bi-ed.com/2016/10/02/statistics-andbisexuality/

Coughenour, C. (2016, June). Chance Coughenour: How your pictures can help reclaim lost history [Video file]. Retrieved from https://www.ted.com/talks/chance_ coughenour_how_your_pictures_can_help_reclaim_ lost_history?language $=$ en

D’Agnano, F., Balletti, C., Guerra, F., \& Vernier, P. (2015). Tooteko: A case study of augmented reality for an accessible cultural heritage. Digitization, 3D printing and sensors for an audio-tactile experience. The International Archives of the Photogrammetry, Remote Sensing and Spatial Information Sciences, XL-5(W4), 207-213. http://doi:10.5194/isprsarchives-XL5-W4-207-2015

D'Augelli, A. (2002). Mental health problems among lesbian, gay, and bisexual youths ages 14 to 21 . Clinical Child Psychology and Psychiatry, 7(3), 433-456. 
D'Augelli, A. (2006). Developmental and contextual factors and mental health among lesbian, gay, and bisexual youths. In A. Omoto \& H. Kurtzman (Eds.), Sexual orientation and mental health: Examining identity and development in lesbian, gay, and bisexual people (pp. 37-53). Washington, DC: American Psychological Association.

D’Augelli, A., \& Hershberger, S. (1993). Lesbian, gay, and bisexual youth in community settings: Personal challenges and mental health problems. American Journal of Community Psychology, 21(4), 421-448.

D’Augelli, A., \& Hershberger, S. (1993). Lesbian, gay, and bisexual youth in community settings: Personal challenges and mental health problems. American Journal of Community Psychology, 21(4), 421-448.

del Toro, G. (Producer \& Director), \& Dale, J. (Producer). (2017). The shape of water [Motion picture]. United States: TSG Entertainment.

Dover, K. (1978). Greek homosexuality. London, England: Gerald Duckworth \& Co. Ltd.

Frayling, C. (1993). Research in art and design. Royal College of Art Research Papers, 1(1), 1-5. Retrieved from http:// researchonline.rca.ac.uk/384/3/frayling_research_in_art_ and_design_1993.pdf

Fry, S. (2018). Mythos. London, England: Penguin Books.

Garofalo, R., \& Harper, G. W. (2003). Not all adolescents are the same: Addressing the unique needs of gay and bisexual male youth. Adolescent Medicine: State of the Art Reviews, 14(3), 595-612.

Goldhill, S. (1996). Greece. In R. Willis (Ed.), World mythology: The illustrated guide (pp. 10-16). London, England: Duncan Baird Publishers. 
Gossart, J. (ca. 1517). Hermaphroditus and Salmacis [Painting]. Rotterdam, Netherlands: Museum Boijmans Van Beuningen. Retrieved from https://www.wga.hu/ html_m/g/gossart/05mythol/3hermaph.html

Gould, J. (1999). Myth, memory, and the chorus: 'Tragic rationality'. In R. Buxton (Ed.), From myth to reason (pp. 107-116). Oxford, NY: Oxford University Press.

Graf, F. (1993). Greek Mythology: An introduction (T. Marier, Trans.). Baltimore, MD: The John Hopkins University Press.

Guy, B., Burton, D., \& Challies, Z. (2018). Creative expression through tangible narrative: How $3 D$ printing may complement our pedagogical investigation of heritage. Forthcoming.

Halperin, D. (1990). One hundred years of homosexuality: And other essays on Greek love. New York, NY: Routledge.

Harper, G., Brodsky, A., \& Bruce, D. (2012). What's good about being gay? Perspectives from youth. Journal of $L G B T$ Youth, 9(1), 22-41. https://dx.doi.org/10.1080/1936165 3.2012 .628230

Harper, G., \& Schneider, M. (2003). Oppression and discrimination among lesbian, gay, bisexual, and transgendered people and communities: A challenge for community psychology. American Journal of Community Psychology, 31(3/4), 243-252. Retrieved from https://link.springer.com/content/ pdf/10.1023\%2FA\%3A1023906620085.pdf

Henrichs, A. (1999). Demythologizing the past, mythicizing the present: Myth, history, and the supernatural at the dawn of the Hellenistic period. In R. Buxton (Ed.), From myth to reason (pp. 223-248). Oxford, NY: Oxford University Press.

Homosexual (n.d.). Retrieved June 17, 2019, from https://www. etymonline.com/word/homosexual 
Hubbard, T. (2006). History's first child molester: Euripides' Chrysippus and the marginalization of pederasty in Athenian democratic discourse. Bulletin of the Institute of Classical Studies (Supplement 87), 223-244. Retrieved from http://www.jstor.org/stable/43768120

Kertzner, R. M., Meyer, I. H., Frost, D. M., \& Stirratt, M. J. (2009). Social and psychological well-being in lesbians, gay men, and bisexuals: The effects of race, gender, age, and sexual identity. American Journal of Orthopsychiatry, 79, 500-510. https://dx.doi.org/10.1037/ a0016848

Lear, A. (2014). Ancient pederasty: An introduction. In T. Hubbard (Ed.), A companion to Greek and Roman sexualities (pp. 102-27). Chichester, England: Blackwell.

Lissarrague, F. (1990). The sexual life of satyrs. In D. Halperin, J. Winkler \& F. Zeitlin (Eds.), Before sexuality: The construction of erotic experience in the ancient Greek world. (pp. 53-81). Princeton, NJ: Princeton University Press.

Liu, R., \& Mustanski, B. (2012). Suicidal ideation and selfharm in lesbian, gay, bisexual, and transgender youth. American Journal of Preventive Medicine, 42(3), 221-228. https://doi.org/10.1016/j.amepre.2011.10.023

Martin, B., \& Hanington, B. (2012). Universal methods of design: 100 ways to research complex problems, develop innovative ideas, and design effective solutions. Beverly, MA: Rockport Publishers.

Pilkington, N., \& D’Augelli, A. (1995). Victimization of lesbian, gay, and bisexual youth in community settings. Journal of Community Psychology, 23(1), 34-56.

Percy, W. (1996). Pederasty and pedagogy in archaic Greece. Chicago, IL: University of Illinois Press.

Reeder, E. (Ed.). (1995). Pandora: Women in classical Greece. Princeton, NJ: Princeton University Press. 
Reisz, B. (Producer). (2018). Troy: Fall of a city [Television series]. United Kingdom: British Broadcasting Corporation.

Riordan, R. (2005). Percy Jackson and the lightning thief. New York, NY: Miramax.

Robinson, V. (2017). Colour 3D/4D printing for film (Master's thesis). Victoria University of Wellington, Wellington, New Zealand.

Rosario, M., Hunter, J., Maguen, S., Gwadz, M., \& Smith, R. (2001). The coming-out process and its adaptational and health-related associations among gay, lesbian, and bisexual youths: Stipulation and exploration of a model. American Journal of Community Psychology, 29, 133-160. https://dx.doi.org/10.1023/A:1005205630978

Russell, S. T., \& Consolacion, T. B. (2003). Adolescent romance and emotional health in the United States: Beyond binaries. Journal of Clinical Child \& Adolescent Psychology, 32, 499-508. https://dx.doi.org/10.1207/ S15374424JCCP3204_2

Ryan, C., Huebner, D., Diaz, R., \& Sanchez, J. (2009). Family rejection as a predictor of negative health outcomes in White and Latino lesbian, gay, and bisexual young adults. Pediatrics, 123(1), 346-462.

Savin-Williams, R., \& Cohen, K. (1996). The lives of lesbians, gays, and bisexuals: Children to adults. Fort Worth, TX: Harcourt Brace College Publishing.

Shapiro, H. (1994). Myth into art: Poet and painter in classical Greece. Oxford, England: Routledge.

Shilo, G., \& Savaya, R. (2012). Mental health of lesbian, gay, and bisexual youth and young adults: Differential effects of age, gender, religiosity, and sexual orientation. Journal of Research on Adolescence, 22(2), 310-325. https:// dx.doi.org/10.1111/j.1532-7795.2011.00772x 
Skinner, M. (2014). Sexuality in Greek and Roman culture (2nd ed.). Chichester, England: Blackwell.

Smith, M. (1996). Ancient bisexuality and the interpretation of Romans 1:26-27. Journal of the American Academy of Religion, 64(2), 223-256. https://doi.org/10.1093/jaarel/ LXIV.2.223

Stern, J. (1999). Rationalizing myth: Methods and motives of Palaephatus. In R. Buxton (Ed.), From myth to reason (pp.215-222). Oxford, NY: Oxford University Press.

Stone, T. (2010). Managing the design process: Concept development, an essential manual for the working designer. Beverly, MA: Rockport.

Stratasys Limited. (n.d.). J735 and J750: Bring your most imaginative ideas to life. Retrieved June, 17, 2019, from https://www.stratasys.com/3d-printers/j735-j750

Telljohann, S., \& Price, J. (1993). A qualitative examination of adolescent homosexuals' life experiences: Ramifications for secondary school personnel. Journal of Homosexuality, 26(1), 41-56.

Ubisoft Quebec. (2018). Assassin's Creed Odyssey [Steam]. (2018). Quebec, Canada: Ubisoft.

Vincent, M., Coughenour, C., Remondino, F., Gutierrez, M., Manuel, V. \& Fritsch, D. (2015). Crowd-sourcing the 3D digital reconstructions of lost cultural heritage. Proceedings of Digital Heritage, 171-172. https://doi. org/10.1109/DigitalHeritage.2015.7413863

Vranich, A. (2018). Reconstructing ancient architecture at Tiwanaku, Bolivia: The potential and promise of 3D printing. Heritage Science, 6(1), 1-20. https://doi. org/10.1186/s40494-018-0231-0

Willis, R. (1996). Introduction. In R. Willis (Ed.), World mythology: The illustrated guide (pp.10-16). London, England: Duncan Baird Publishers. 
Aooendix 


\section{Apoendiu A}

Key terms - Design 
3D - 3-dimensional

In reference to an object that has three dimensions: height $(\mathrm{y})$, width ( $\mathrm{x})$ and depth (z).

$3 \mathrm{D}$ printing -

A technique that builds physical objects by layering materials one on top of the other.

AM - Additive Manufacturing

The process of manufacturing objects using $3 \mathrm{D}$ printing.

CAD - Computer-Aided Design

An acronym coined in the 1970 s associated with software that utilises the technological capabilities of a computer to replace manual drafting processes with an automated system.

\section{FDM - Fused Deposition Modelling}

An additive manufacturing technique, created by Charles Hull in 1986, in which heated material (commonly plastics) is extruded through a nozzle to build up a solid part layer by layer.

\section{PLA - Polylactic Acid}

A biodegradable thermoplastic which can be used as a $3 \mathrm{D}$ printing material.

\section{RTD - Research through design}

A term coined by Sir Christopher Frayling (1993) that validates creativity and research through making as a method of research.

\section{SLS - Selected Laser Sintering}

An additive manufacturing technique in which a thermal source is focused on a bed of powder particles to selectively fused particles to produce a solid part. 


\section{Aooendiy B}

Timeline - 3D printing 
1984 Stereolithography apparatus machine (SLA) invented and patented by Chuck Hull.

Standard tessellation language (.STL) file format created.

1986 Selective Laser Sintering (SLS) developed and patented by Carl Deckard, Joe Beaman, and Paul Forderhare.

1988 Fused Deposition Modelling patented by Scott Crump.

Stratasys founded by Crump.

1993 Electron beam melting (EBM) was patented.

2005 Selected Deposition Lamination (SDL) developed by Mcor Technologies Ltd.

SDL introduces colour printing.

2005 The Self-Replicating Rapid Prototyper (A 3D printer that prints the majority of its components itself) is developed thanks to the RepRap Project. All products created by this project are published with open source licences.

2008 Bre Pettis, Adam Mayer, and Zack "Hoeken" Smith found MakerBot Industries.

2017 The Stratasys J750 is released by Stratasys as the first full-colour multi-material $3 \mathrm{D}$ printer. 


\section{Apoendiu C}

Key Terms - Classical History 
BCE - Before Current Era

A religiously neutral term used to indicate the time before the start of the Common Era (or 0 AD). Similar to BC (Before Christ) as a notation of time in the Gregorian calendar.

\section{CE - Current Era}

A religiously neutral term used to indicate the time after the start of the Common Era (or 0 AD). Similar to AD (Anno Domini, 'in the year of our Lord') as a notation of time in the Gregorian calendar. 


\section{Aopendiy D}

Timeline - Classical History 


\begin{tabular}{|c|c|}
\hline c. $1150-1000$ BCE & Dark Ages \\
\hline c. $1000-750 \mathrm{BCE}$ & Geometric Period \\
\hline c. $1000-900 \mathrm{BCE}$ & Protogeometric \\
\hline c. $900-750 \mathrm{BCE}$ & Geometric \\
\hline c. $750-625 \mathrm{BCE}$ & Orientalising Period \\
\hline c. $625-480 \mathrm{BCE}$ & Archaic Period \\
\hline $600 \mathrm{BCE}$ & Black-figure \\
\hline $530 \mathrm{BCE}$ & Red-figure \\
\hline c. $480-400 \mathrm{BCE}$ & Classical Era \\
\hline c. $480-460 \mathrm{BCE}$ & Early Classical (Severe Style) \\
\hline $460 \mathrm{BCE}$ & White-ground \\
\hline c. $460-430 \mathrm{BCE}$ & High Classical (Golden Age) \\
\hline c. $430-400 \mathrm{BCE}$ & $\begin{array}{l}\text { High Classical (Peloponnesian } \\
\text { Wars) }\end{array}$ \\
\hline c. $400-323 \mathrm{BCE}$ & Late Classical \\
\hline 400-380 BCE & $\begin{array}{l}\text { Steep decline in quality of Attic } \\
\text { vase-painting }\end{array}$ \\
\hline 360-350 BCE & End of Attic vase-painting \\
\hline c. $323-50 \mathrm{BCE}$ & $\begin{array}{l}\text { Hellenistic Period } \\
\text { Spread of Greek culture } \\
\text { throughout the Mediterranean. }\end{array}$ \\
\hline
\end{tabular}

Key:

Italicised text indicates the time period.

Bold text indicates the emergence of a painting style. 


\section{Aopendiy E}

Engagement case study documents and student work 


\title{
Case Study Information Sheet
}

\section{Page I}

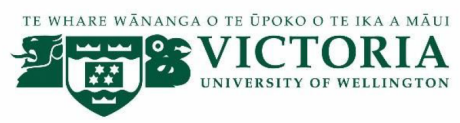

\author{
Unifying classical artifacts and modern commentaries \\ INFORMATION FOR PARTICIPANTS IN ANONYMOUS SURVEY AND IMAGE USE.
}

You are invited to take part in this research. Please read this information before deciding whether or not to take part. If you decide to participate, thank you. If you decide not to participate, thank you for considering this request.

Who am I?

My name is Rose Lastovicka and I am a Masters student in Design Innovation at Victoria University of Wellington. This research project is work towards my thesis/publication.

What is the aim of the project?

This project is to investigate the relevance of digital technologies, such as 3D printing, in communicating narratives. I will investigate if 3D printing can be used to improve understanding of such artifacts through the blending of classical and modern design methods.

This research has been approved by the Victoria University of Wellington Human Ethics Committee 0000026535 .

\section{How can you help?}

You have been invited to participate because of your enrolment in CLAS111. If you agree to take part you will complete 2 surveys. The surveys will ask you questions about your opinions on the 3D printing project you took part in during this course. The surveys will take you 10 minutes each to complete.

What will happen to the information you give?

This research is anonymous. This means that nobody, including the researchers will be aware of your identity. By answering it, you are giving consent for us to use your responses in this research. Your answers will remain completely anonymous and unidentifiable. Once you submit the survey, it will be impossible to retract your answer. Please do not include any personal identifiable information in your responses.

Personal details will be collected only for those who consent to the use of photos of their images in the thesis and/or publications, or wish to request a copy of the final report. All 


\section{Case Study Information Sheet}

personal details will be received separately from the survey data. This ensures that your answers to the survey questions are anonymous.

\section{What will the project produce?}

The information from my research will be used in my Masters thesis.

If you have any questions or problems, who can you contact?

If you have any questions, either now or in the future, please feel free to contact either:

\section{Student:}

Rose Lastovicka

roselastovicka@gmail.com

\section{Supervisor:}

Bernard Guy

Lecturer - Industrial Design

School of Architecture and Design

044636291

bernard.guy@vuw.ac.nz

Supervisor:

Dr Diana Burton

Lecturer

School of Art History, Classics and Religious Studies

044636784

diana.burton@vuw.ac.nz

Human Ethics Committee information

If you have any concerns about the ethical conduct of the research you may contact the Victoria University HEC Convenor: Dr Judith Loveridge. Email hec@vuw.ac.nz or telephone +64-4-463 6028. 


\section{Case Study Survey Questions}

2010

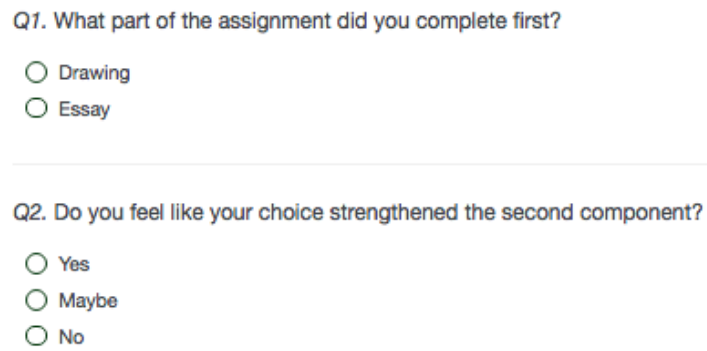

Q7. Was there another vase shape or painting style you would have liked to have used in this project?

$\mathrm{O}$ Yes

M Maybe

O No

Q8. Please explain your answer to Question 7:

Q9. Is there any other feedback you have for this project? 


\section{Consent to use images form}

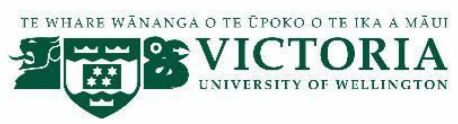

\section{Unifying classical artifacts and modern commentaries}

\section{CONSENT TO USE IMAGES ANONYMOUSLY}

This consent form will be held for 2 years.

Researcher: Rose Lastovicka, Victoria University of Wellington.

- I have read the Information Sheet and the project has been explained to me. My questions have been answered to my satisfaction. I understand that I can ask further questions at any time.

- I agree to have images of my work anonymously used in the final publication.

I understand that:

- I may withdraw from this study at any point before $26 / 10 / 2018$, and any information that I have provided will be returned to me or destroyed.

- The identifiable information I have provided will be destroyed on 31/07/2020.

- $\quad$ Any information I provide will be kept confidential to the researcher and the supervisors.

- I understand that the results will be used for a Master's thesis and/or academic publications.

I would like to receive a copy of the final report and have added my email Yes $\square \quad$ No $\square$ address below.

Signature of participant:

Name of participant:

Date:

Contact details 
Participant I

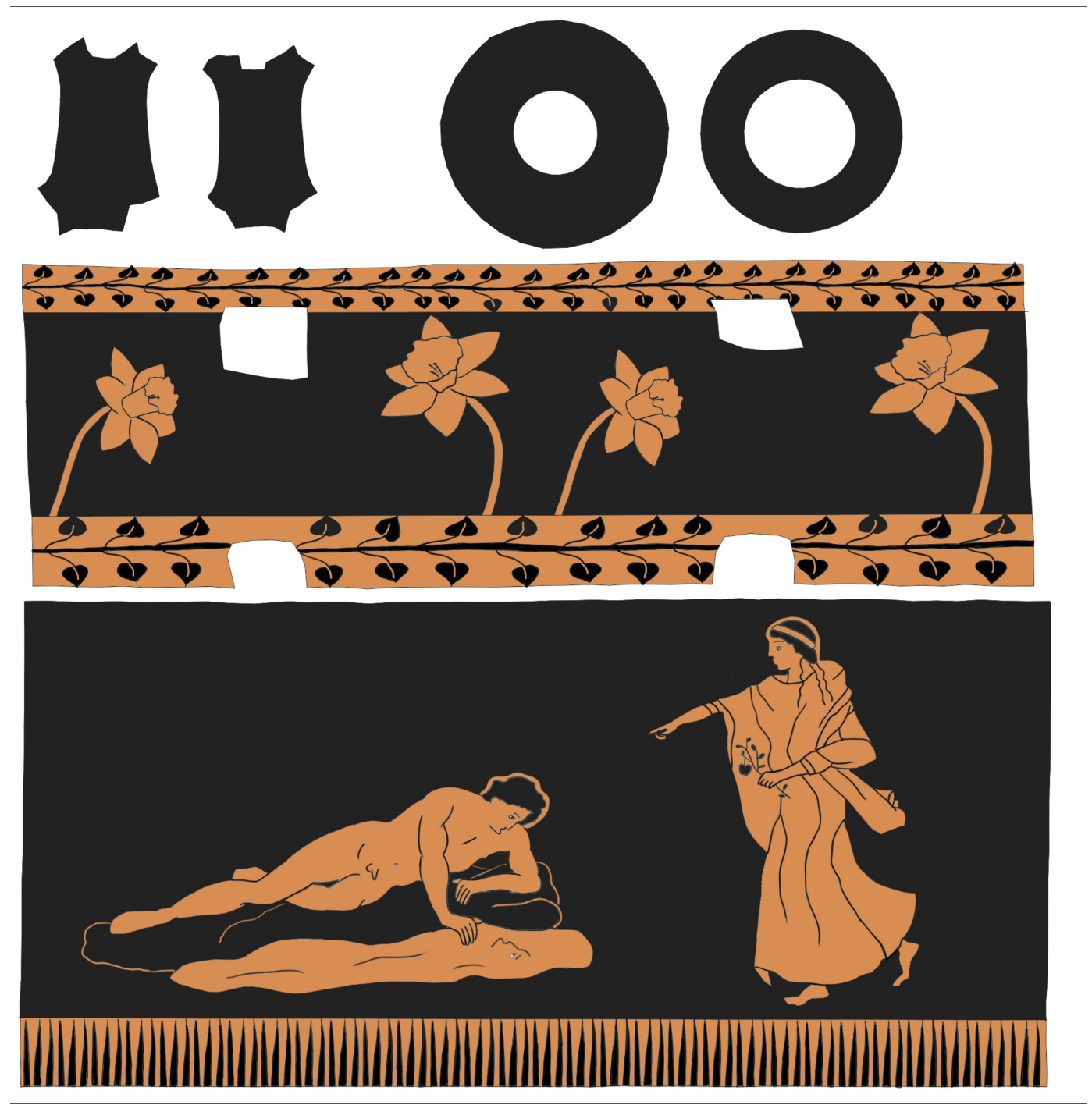

Figure E1. Participant 1 vase illustration. Printed with permission. 
The myth I have selected to portray is the myth of Narcissus. In this myth, the attractive young male Narcissus turns down many people infatuated with him, because he is so proud of his own appearance that he does not feel attraction to anyone else. Once he turns down the nymph Echo, the other nymphs call for revenge, and it is the goddess Nemesis that leads him to a pool, where he sees, and falls in love with, his own reflection. Totally in love, he stays by the poolside until he eventually withers away and turns into the narcissus flower. I have chosen to depict this particular myth because it is a good metaphor for the age in which we live now. Everyone is so obsessed with their own self-image, and the way in which it is portrayed. People go to great lengths in order to achieve 'ideal' and desired looks. Plastic surgery, make-up, strict diets and exercise regimes are examples of this. In much the same way that Nemesis took advantage of Narcissus' vanity, the media, marketing companies, and manufacturers take advantage of the vanity of today's society. The make-up industry is incredibly successful and is fuelled by celebrities creating their own makeup lines, encouraging consumers to buy products to achieve a certain 'look'. Perhaps an even more direct reflection of the myth is society's obsession with 'selfies'. Photos taken of oneself for the sole purpose of showcasing your image to others. This type of photo, with the sole focus being one's face, seems almost a direct comparison to Narcissus falling in love with his reflection, and being so obsessed he could not leave.

The scene of the myth I have chosen to depict is when Narcissus sees his reflection for the first time. This is the moment of action, where the climax of the story occurs. The figures depicted are Narcissus at the pool, and the goddess Nemesis. Nemesis can be identified by the apple branch she carries in her hand. This is an attribute she has been depicted with before, most notably in the statue of Nemesis found at Rhamnus, one of the few depictions of the goddess in Greek art. The pose she stands in is one of divine retribution, as it is revenge and retribution that she deals with as a goddess. The flowers that decorate the neck of the vase are narcissus flowers, the flower that Narcissus eventually turns into after withering away at the pool side. I feel this specific moment demonstrates both society's obsession with the self through Narcissus, and also the way this obsession is exploited by companies, through Nemesis' using Narcissus' obsession against him. 
Participant 2
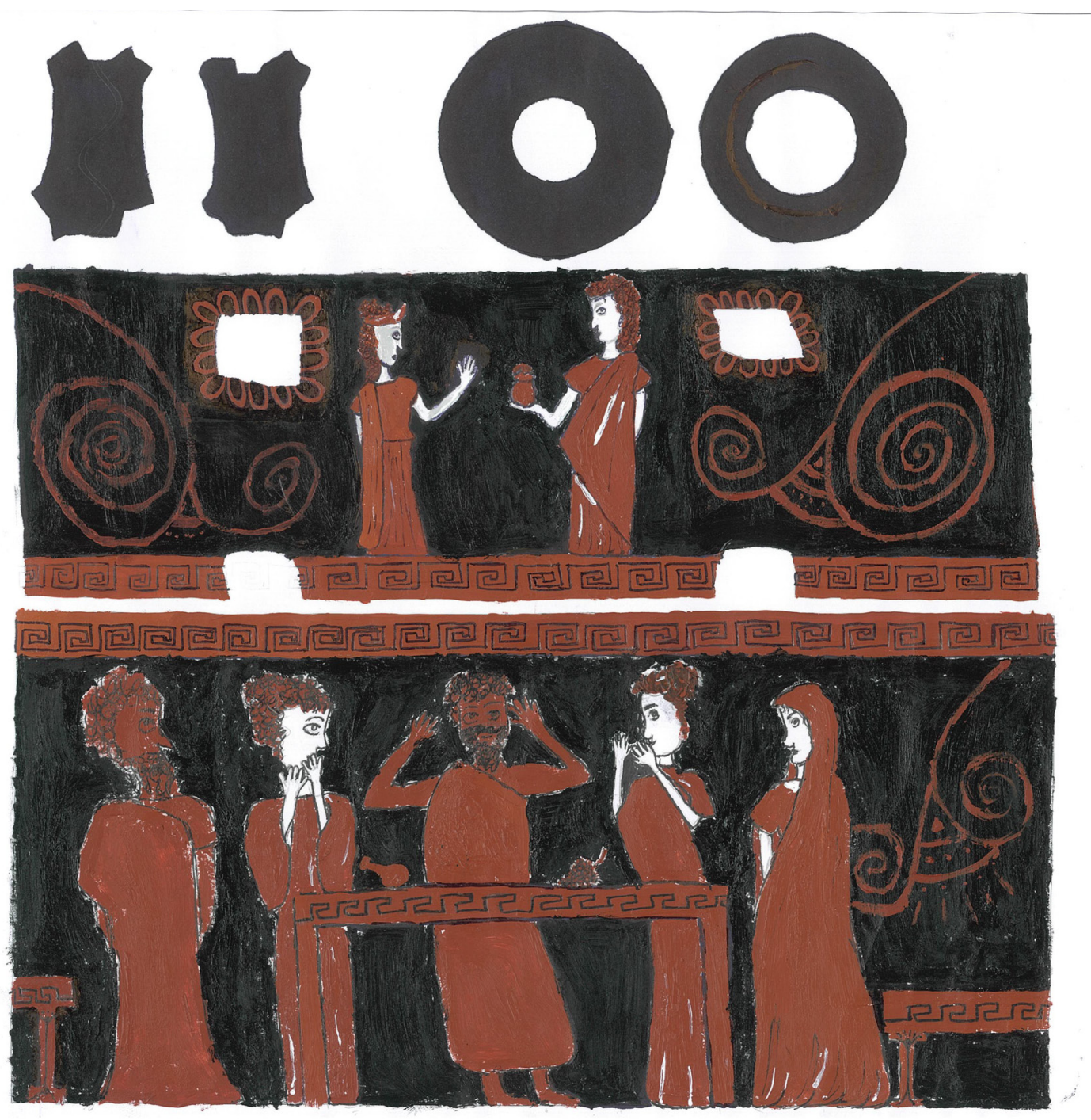

Figure E3. Participant 2 vase illustration. Printed with permission. 
The myth I chose to depict is the English story of Cap o' Rushes. The story starts with a baron asking his three daughters how much they love him; the first daughter informs him that she loves him as much as kings love gold, the second as much as queens love diamonds and the third daughter, Cap o' Rushes, tells him she loves him as much as food loves salt. Angered by this the father threw her out of their home, and later she meets a prince who asks her to marry him. The father, unaware that Cap o' Rushes is alive and regretting banishing her from his home, is invited to the wedding. At the banquet, nobody eats more than a bite of food because Cap o' Rushes asked for the chefs to leave out the salt. Her father upon trying the food bursts into tears after realising how much his daughter loved him all along and they are reunited. I picked this story because as a child it was one of my favourites to tell, so much so, that despite not reading the story in years I can still recite the plot without notes. The reason I liked this story was because I would use it as a rebuttal against people (namely my nana) who did not like to put salt in their food. The way I have chosen to depict this myth is with the two sisters on the neck of the amphora with the gifts they were given (a pouch of gold coins for the first daughter and a tiara for the second) then on the body is a synoptic scene in which the father is still unaware that Cap o' Rushes is alive and the moment she reveals her face. The father has his hands up beside his head an act of lamenting with two mourners beside him; his face is also looking out from the vase which is only done when a one is showing intense emotion. The style / picked was red-figure, and following painting practices, I left the women's skin unpainted. On top of this, I also added bits of white through-out the painting for decorative purposes. The patterns I chose to use were tongues around the places for the handles, a meander pattern around the bottom of the neck and top of the body and a key pattern on the banquet table and the two reclining chairs that disappear out of the sides of the scene. Vase-painting also dictates that there should not be a lot of big blank spaces, so I added a spiral motif in both corners of the neck and one corner of the body. 


\section{Participant 3}

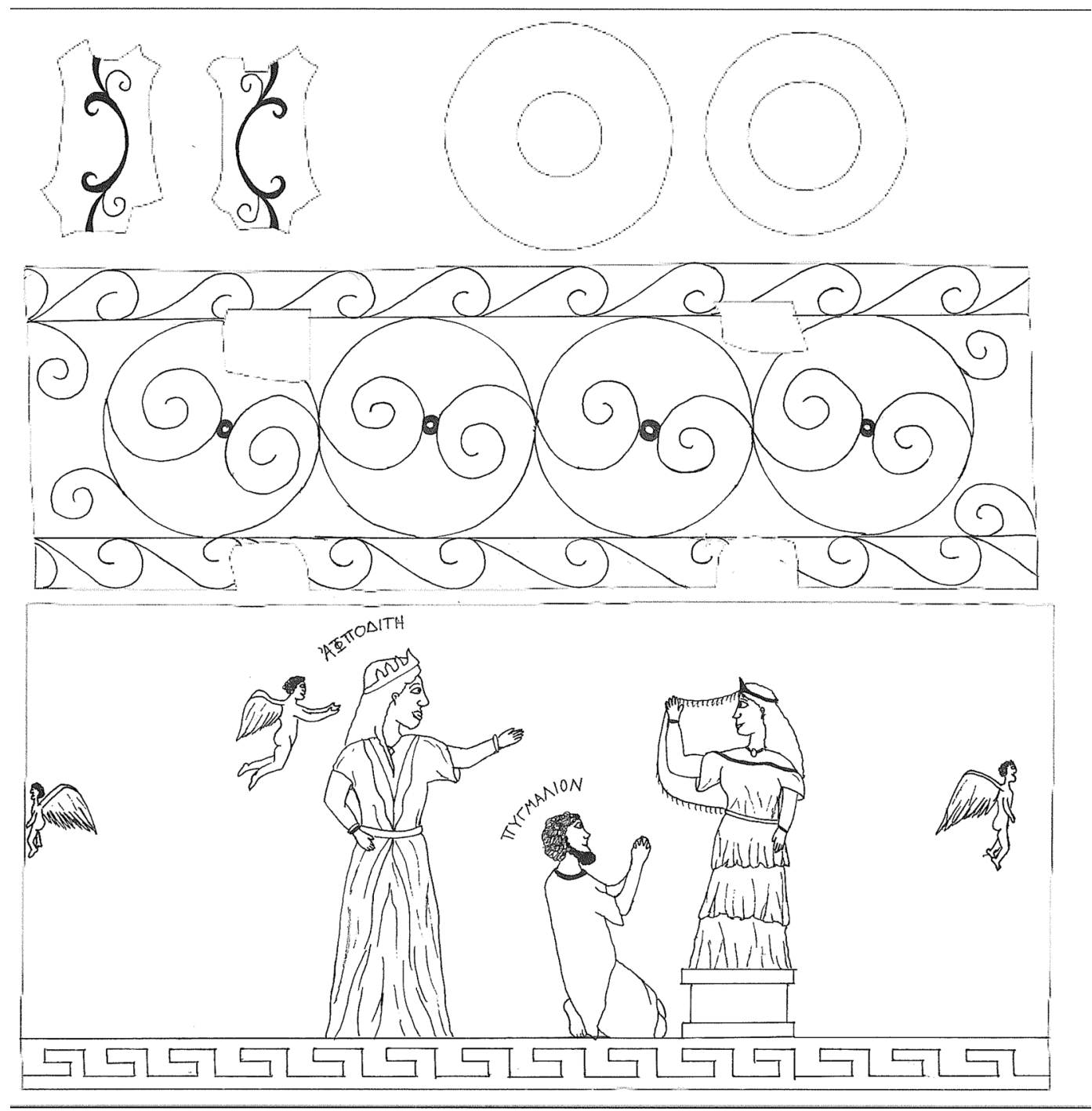

Figure E5. Participant 3 vase illustration. Printed with permission. 
The story of Pygmalion' and his bride is an unusual one, by today's standard at least. The myth contains two main themes that are however ideas prevalent in the 21st century. The idea of true love beating all is a common theme throughout different forms of media, and is much celebrated by the human race. The less savoury view of this myth is also coming to fruition, for the first time in history humans can create something and fall in love with it, and have it respond. While the ending of the Pygmalion myth is certainly positive, it seems unlikely that those who repeat it in real life will end up with the same blessed happiness in their lives.

The scene pictured is when Pygmalion returns home after praying to the Goddess Aphrodite for his true love, the statue he created partially out of disdain for the women in his town. To his delight the he has been blessed by the Goddess and his love, the statue, has come to life and become his bride. Pop-culture is riddled with stories of men loving something thought to be unattainable, only for that love to be returned regardless of circumstance. Films such as 'There's Something About Mary', 'Knocked Up', and even 'The Mask' are all popular or well known stories that feature men falling in love with women more sophisticated, beautiful, or intelligent than them. In all of these the man proves himself in some roundabout way and his love ends up being reciprocated by the woman. Often it is just as likely that those characters in real life would have as much chance as being with their loves as Pygmalion, minus the blessing of Aphrodite.

On a less romantic note, human beings falling in love with something non-human is also a theme on the rise in society. While 'The Shape of Water' is a great example of this the reality is disturbing on another note. Through the wonder of technology amazing advancements have been made for humanity, one of these being sexbots. ${ }^{2}$ Although it sounds like something out of a sci-fi novel the race for fully automated sexbots has been commenced for many years. Largely in China and the United States of America, workshops have been developing android partners for both males and females, not simple one either, ones that are programmed to respond to the human as though they were a real person also. While in ancient myth a man falling in love and being with his own creation may not seem so distruring, when put into modern day context it is something many more people would find issue with. It is absolutely possible that one day the creators of these androids will follow Pygmalion's lead and fully love their creation, and perhaps be loved in return by them.

The myth of Pygmalion is one that has been mirrored many, many times in Hollywood and pop-culture, and may yet be actually retold in real life as technology advances. Although both loving your own creation and true love coming true despite any circumstances are ideas that the vast majority of people from the twenty first century can relate to, the concept of both are ones that the human race is oddly obsessed with. Humanity's obsession with the idea of true love and newer developments in terms of $\mathrm{Al}$ and android creation are ones that seem to be predicting a revival of stories such as Pygmalion's, for better or for worse. 
Participant 4

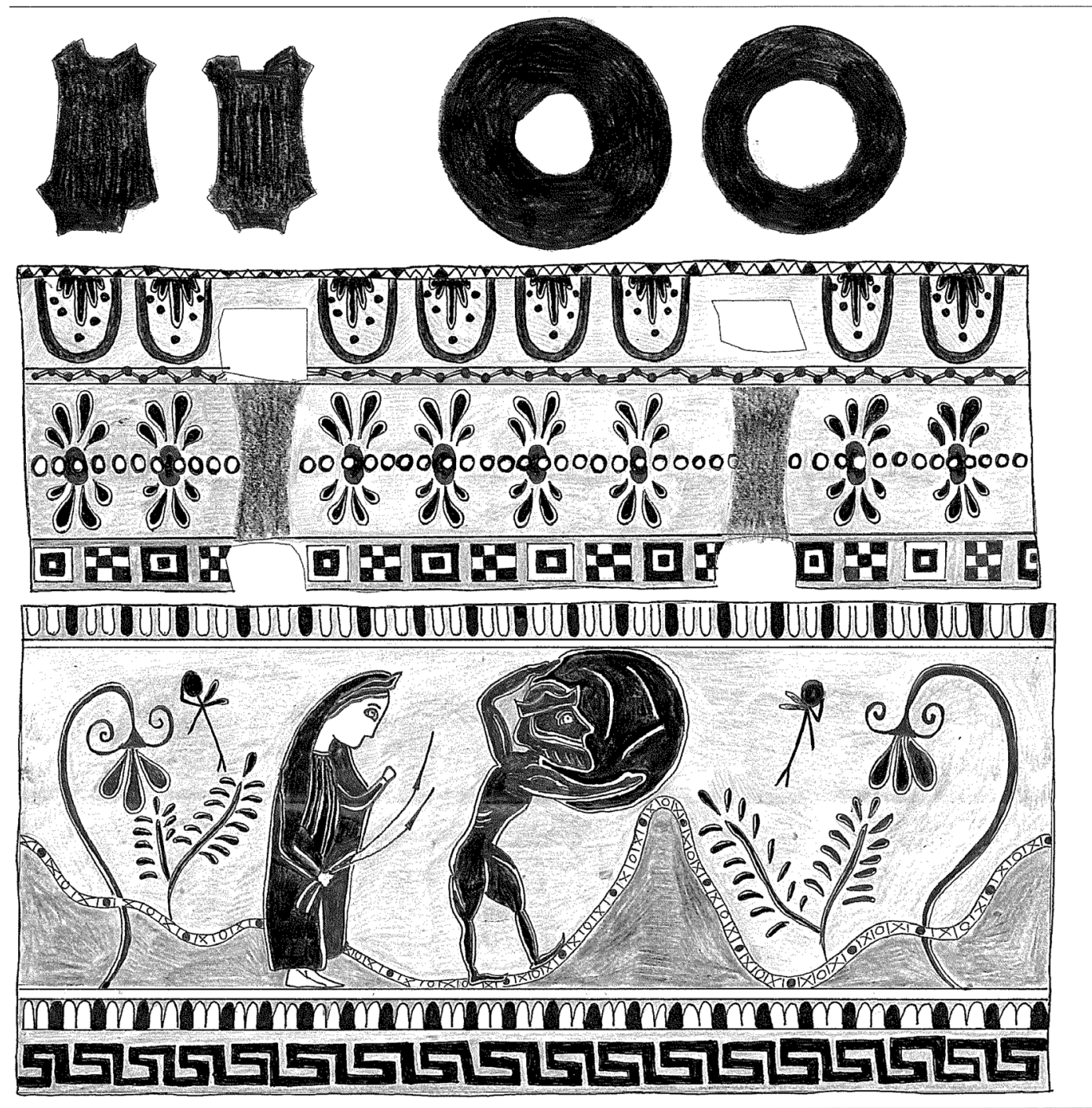

Figure E7. Participant 4 vase illustration. Printed with permission. 
The myth I chose to depict on the Amphora vase was the myth of Sisyphus. The myth entails Sisyphus, the King of Ephyra, being eternally punished for his crafty and deceitful behaviour. Sisyphus' punishment comes in the form of being forced to push a heavy boulder up a steep hill in the underworld. However, his punishment is essentially eternal as upon getting the boulder to just about the top of the hill it rolls down to the bottom again.

On my vase, I depicted Sisyphus holding his boulder as he climbs the hill. He has been depicted wearing a crown as he was the King of Ephyra. He is also depicted with a beard to illustrate that he was not a youth but an older man. I have also included Persephone in this depiction of the myth as she was supervising Sisyphus. She has also been illustrated with a crown as she was said to be the Queen of the underworld. She is heavily robed as this is a known attribute of hers as well as the sheaf's of wheat as like her mother Demeter, she is associated with the grain and agriculture. Persephone also has her arm in a raised and bent position gesturing that she may be pitying Sisyphus slightly. I have also depicted her in white as this is typical for women in this style of vase painting. I have also included psychai on the vase as I wanted a way of showing that this is taking place in the underworld. The decorative features are primarily for their decorative purpose, however, I did try to incorporate different designs taking inspiration from other vases as viell. I decided to do my Amphora in attic black figure as I believed this would be the most effective for this myth.

I chose this myth because when reading about it I interpreted it in a way in which it was relevant to myself and my society also. I think that the fact that Sisyphus has to carry this heavy boulder all the way up the hill only to have it fall back down again is very discouraging. An emotion many of us feel far too often. In analysing this myth, 1 personally interpret a message of not giving up even when tasks and effort seem futile. Many of us in life are carrying huge metaphorical boulders with us through our every-day lives and just when we think we can let go of it, we find ourselves right back where we started. It is important, however, that we realise and appreciate just how close we actually are to getting there. Though we know that Sisyphus is destined to do this forever, we however have hope to persevere through seemingly futile efforts to success. 


\section{Participant 5}

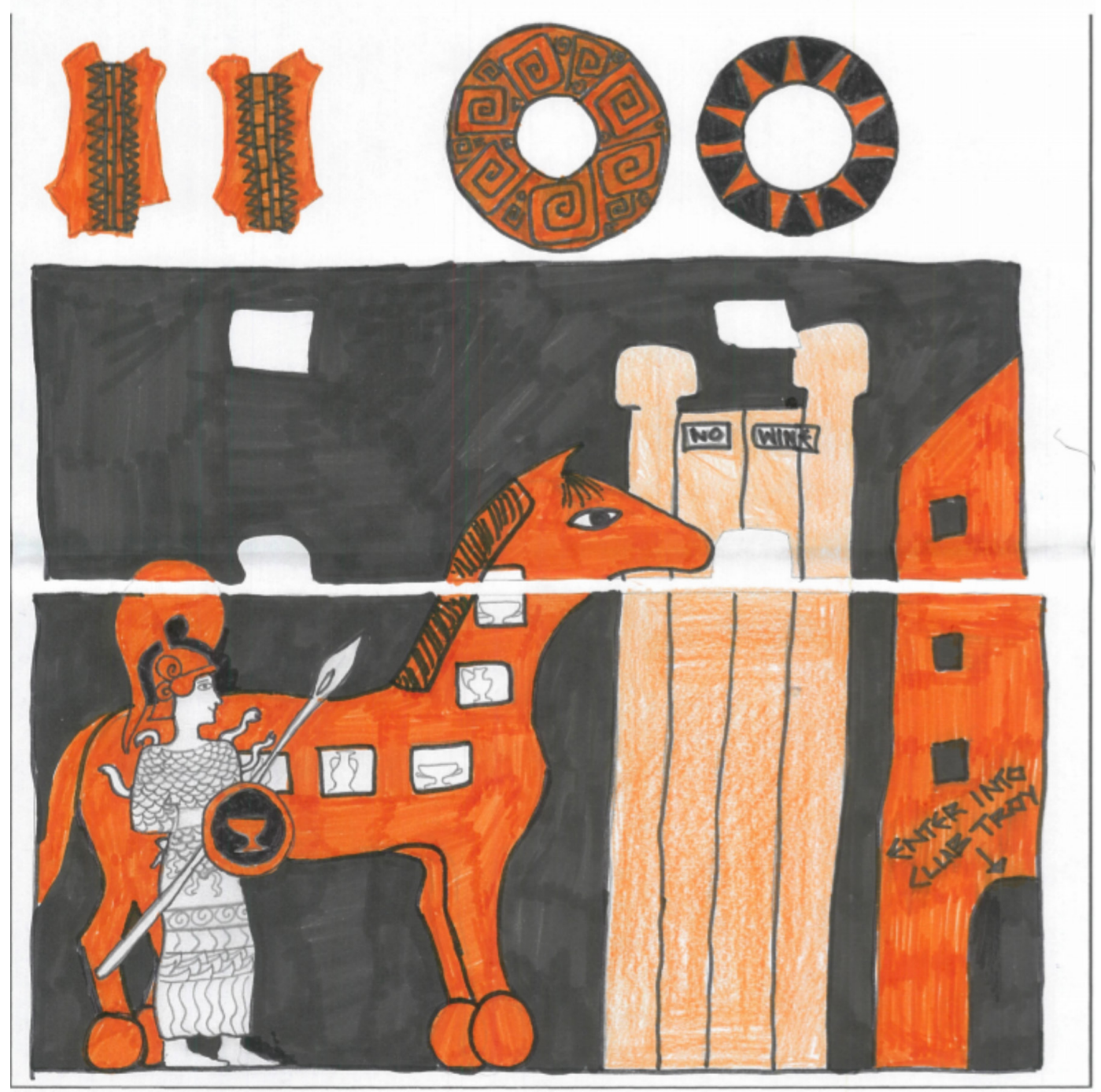

Figure E9. Participant 5 vase illustration. Printed with permission. 
The sack of Troy and the Trojan horse is most famously mentioned in Homer's 'The Odyssey', book 8.

A bard sings a tale of Epeus making a hollow wooden horse with the help of wise Athena. The Horse is used to conceal the hero Odysseus and his fellow Greek warriors. The Greeks are then dragged into Troy ironically by the Trojans themselves, who have been tricked into thinking the horse has been left as a blessing to the gods. Without wise Athena and the Trojan horse, the city of Troy may not have been infiltrated and the war may not have even been a Greek victory. The Greeks attacking Troy and winning the war prompted the evacuation of a few Trojans. One of which is Aeneas, the son of Aphrodite and mystical founder of Rome. Aeneas is the famous hero in Virgil's Aeneid, the most famous Roman epic. The Trojan horse has huge relevance to Greek and Roman mythology, particularly through the form of epics like The Odyssey and The Aeneid.

On my vase I have depicted Athena, the Trojan horse, the impenetrable gates of Troy and finally, Troy itself. However, I have adapted this myth to hold relevance to my generation. I have done this by altering two objects within the myth; the treasures held within the hollow belly of the horse and the nature of what's behind the gates of Troy. The original epic's soldiers, who filled the secret sections of the horse, have been replaced with amphoras of Dionysos' wine. Additionally, Troy is no longer a city of trapped civilians, soldiers and royalty, it is the new and improved 'Club Troy' - a hotspot for Muses, Charites and general partygoing ancient civilisations.

I have done this to show the lengths our young generation will go to, in order to get a drink into a club. In the modern age, the cost of university, living necessities and entertainment can be hard to keep up with, despite our free course fees and healthy student loans. Unfortunately, the often abused substance of alcohol is a huge part of entertainment for young adults. It causes destruction to the body, much like the Greeks destroyed the city of Troy.

The costs of alcohol are an evil necessary for most of our tumultuous university experiences. However, alcohol bought in a club are unnecessary additions to the costly student lifestyle. Hence the need arises to conceal cheap alcohol, when attempts are made to infiltrate a night-club. Athena's ideas on concealing dangerous and havoc-inducing goods closely relate to my own. On numerous occasions our university students have tried to smuggle alcohol into bars and clubs. Perhaps we could learn something from wise Athena, when we try and make these schemes work. Except, the vehicles we use to smuggle wine into clubs probably won't be giant wooden horses, although it would be useful if it could be. 
Participant 6
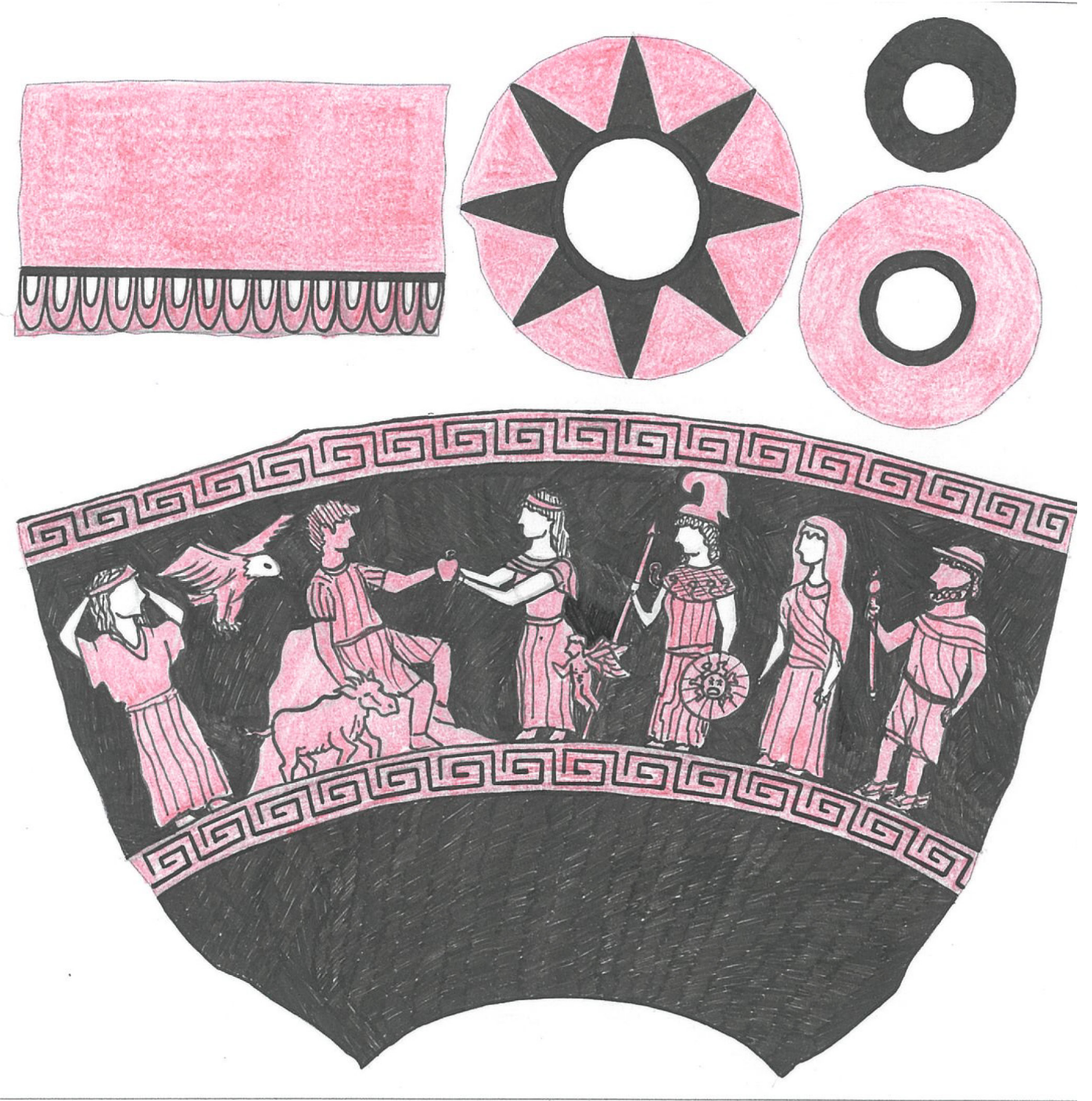

Figure E11. Participant 6 vase illustration. Printed with permission. 
My scene depicts the moment in which Aphrodite is chosen by Paris as "the most beautiful" (Morford, Lenardon, and Sham 2015, 477), as he presents her with the inscribed apple. It is comprised of six figures, each of which holding importance to the myth, and is displayed on a lekythos vase - the vessel's funerary association relating to the fall and subsequent death of Troy, which later results from this initial decision. On the left stands Hecuba in a long draping dress and painted white skin, conveying both her royalty and the idealized representation of women in Greek standards. She stands facing Paris with both hands in her hair, a pose of mourning as his decision later dictates the downfall of Troy as prophesized to her at his birth. She is unable to stop his choosing just as she is unable to stop the fall of Troy thus her presence in the scene foreshadows the conflict to come. Beside her, Paris sits on a mound which represents Mt. Ida, with a goat at his side to convey his role as a shepherd. He is beardless, highlighting his youth, and his left arm is stretched out presenting the apple to the willing Aphrodite. Between Paris and his mother, an eagle flies in the air to represent the presence of Zeus, as it is one of his sacred animals and it is he who chose Paris to settle the argument between the goddesses. Aphrodite somewhat centers the scene, reaching forward to take the apple from Paris. She - along with the two goddesses which follow - also has white painted skin. Her dress is long and Eros floats low at her side, helping to distinguish her character. Athena and Hera stand subsequently behind Aphrodite, also facing Paris' direction - Athena, with her attributed spear, helmet, aegis, and bearing her medusa headed shield; with Hera, veiled and regal beside her. Finally, Hermes stands at the right end of the scene. He initially brought the goddesses to Paris at Zeus' request and thus watches the prior's judging unfold. He bears his signature petasos and winged sandals, with the kerykeion held in his right hand. The scene is framed with a key pattern along both the top and bottom, with the lower half of the lekythos' body being black. A tongue pattern circulates the base of the neck where it meets with the shoulder, with a ray pattern fanning out from below it, stopping where the shoulder and body join. The remainder of the neck is red, as is the base, with the vase's lip being black. This scene relates to the "girls against girls" idea, common in today's society. Too often do women allow men to dictate their worth and beauty - the concept of being "the most beautiful" decided by men, much like Paris' choosing between he goddesses. Though evolving, many young women still turn on one another to prove themselves to men, opposed to seeking worth within themselves, warping the self-image of young and impressionable girls. 


\section{Participant 7}

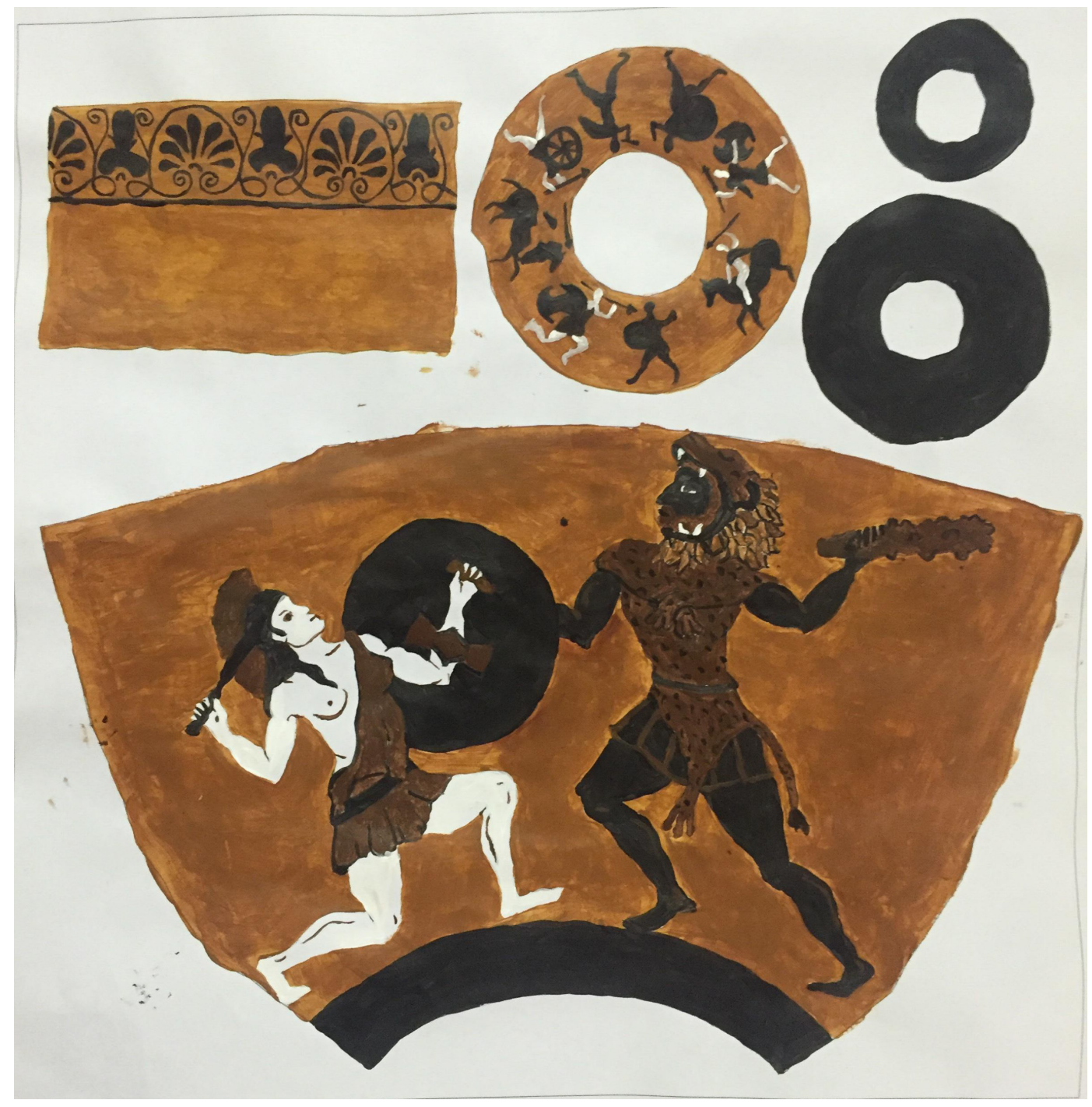

Figure E13. Participant 7 vase illustration. Printed with permission. 
The Amazons of ancient Greek myth have often been depicted in a sexual portrayal, whether this be a result of the sexualisation of immortals in Greek culture and myth, their often-revealing primitive attire or perhaps their modern-day relation to the infamous Wonder Woman. Wherever their sexual portrayal stems the Amazon women have throughout history, both in the ancient world and the modern one been seen to embody female sexuality in the form of powerful and independent warriors. Whilst we have come to recognize the sexualisation of woman as a negative thing I think in protest of the mythological Amazon women the combination of fierce power, wisdom and sexuality resonates a certain element of feminism. In an ancient world where the concept of feminism did not play a part in society, it is particularly interesting that the Greeks depicted these woman as strong and wise warriors - vessels of feminism.

I found it interesting that they were viewed as equal opponents to male Heroes such as the depicted Heracles. It is for this reason I chose to depict the amazons in the more Greek rendition of their attire rather than their normal use of animal skins, especially lion and leopard skins which would show they are foreign, and for this particular myth I think it's important that the Amazons appear as worthy opponents because it highlights how these Amazonian warriors were worthy opponents for the great Heracles. It also represents a notable balance between war and peace.

In order to show the prowess and unrelenting abilities of the Amazons, the form of the myth I have chosen to depict is Heracles and the belt of Hippolyta in which Heracles is tasked to complete The Belt, the $9^{\text {th }}$ of his 12 labors. In the version I have chosen to depict Hippolyta, the queen of the Amazons. This depiction shows how she and her tribe of women warriors do not give up willingly in their fight against Heracles and his men. This myth highlights the brave and fearless nature that the Amazon warriors were known for. Regardless of them being an entirely female tribe, they were courageous enough to fight any opponent whom threatened them, even those as mighty as Heracles. I feel this myth is a relevant in today's society as the courage this tribe of women warriors were able to display in a male dominant world highlights the fact that women have no reason to ever be discriminated or sexualized in any society as they too can be just as fierce and powerful as any male can be. 
Participant 8

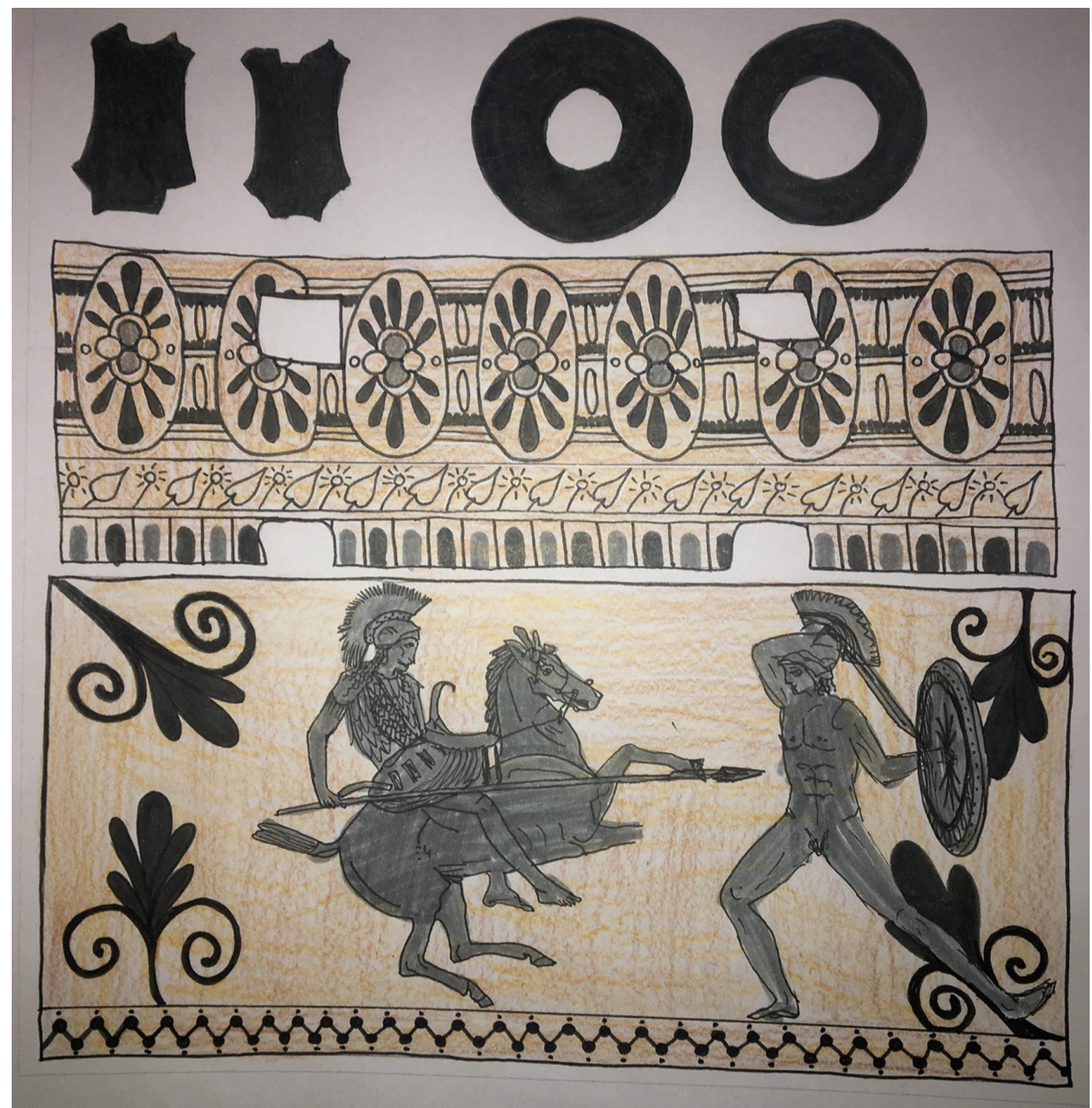

Figure E15. Participant 8 vase illustration. Printed with permission. 
The relevancy to current events for the vase I created in Fig 1.1, applies to the Amazonomachy, in which the Ancient Greeks fought against the tribe of warrior women called The Amazons. The Amazons come from the east in the Asia Minor region and are a cavalry of archers. In Greek myth, the Amazons are formidable opponents although are almost always defeated. This can be linked to a superiority complex held by most Ancient Greeks in which a hierarchy existed of the divine order which was, primarily the Gods, then Greek mortals, and at the bottom of the chain was barbarians, undesirables, monsters, beasts and foreigners. The Amazons come under the category of foreigners as they are originally from the East, this means that in any mythical battle in which the Amazons would face the Greeks, they would most certainly lose the fight.

Feminism is a current political ideology which advocates for the rights of women within equal rights of both sexes. The Amazons were an all-female cavalry of warriors. This in itself is a considerable exhibition of feminism within The Ancient World. However, the fact that the Amazons would lose the wars they fought against the Greek army suggest a weakness and more insignificant standing in women compared to men. Since this time women have come a long way in terms of gaining back their rights and equality. This concept of women taking back their rights has been depicted in the altered representation of the Amazonomachy on the Amphora in Fig 1.1. Mythical battles were often representative of applicable and real-life achievements in Ancient Greece (Tarbell 1920). In fig 1.1, the Amazonomachy is representative of the real-life battle for women of equal pay and treatment in our current world.

In Fig 1.1, I have depicted a moment within the Amazonomachy in which the Amazon woman is about to spear the Greek warrior. The current vase has been slightly adapted from original vases where the Amazons are usually, although thought of as strong and worthy opponents in battle, defeated by the superior Greek warriors. To display the current political ideology of feminism and its gradual uprising, Fig 1.1 is depicting the Amazon warrior winning the battle over the Greek man on an equal playing field. 
Participant 9
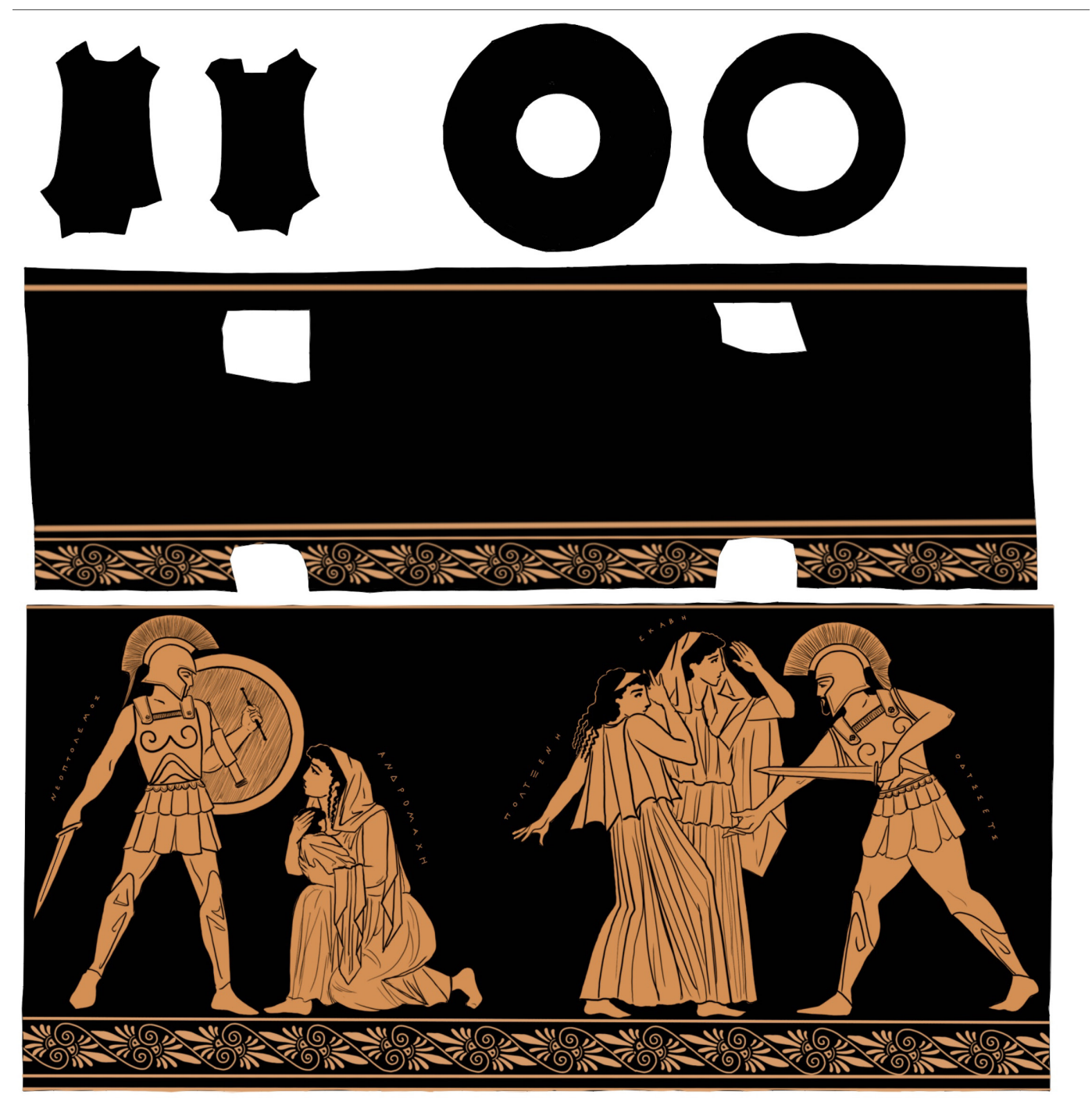

Figure E17. Participant 9 vase illustration. Printed with permission. 
My vase depicts two episodes from the sack of Troy: the deaths of Astyanax and Polyxena. I chose to focus on the separation of the two children from their mothers (Andromache and Hecuba).

My choice of myth is based on contemporary events, namely the Trump administration's separation of migrant families at the US-Mexico border. More than 2500 children have been separated from their families, and for many parents the whereabouts of their children are unknown. ${ }^{1}$ The different systems for youths and adults mean that the children, some just young toddlers, are appearing at hearings alone. ${ }^{2}$ I have tried to use scenes from myth as a lens to view the heart-breaking experiences of these migrant families.

With this in mind, I adapted each myth somewhat to relate better to my focus on separated families: in both cases, I have chosen the moment of separation between mother and child, rather than focus on the death that follows. On the first side is Andromache and her son Astyanax, being threatened by Neoptolemus. Astyanax is to be killed to prevent him growing up to avenge Troy; in most versions Odysseus is responsible for this (Euripides, Trojan Women 719-786). I depicted Neoptolemus here simply because he is more frequently shown with Astyanax's body in art. ${ }^{3}$ On the other side is Hecuba with Polyxena, recoiling from Odysseus as he advances towards them. While Euripides depicts Polyxena going willingly to be sacrificed to Achilles (Hecuba 541-551), I chose to show her as frightened, primarily to ensure my message about the trauma of a divided family was unambiguous. I also wanted to avoid misguiding or confusing a viewer who is unfamiliar with the myth. I was partly inspired by the Vivenzio hydria ${ }^{4}$ for my treatment of the Greeks, avoiding the typically heroic view of them to emphasise the at times horrific roles they played in the Trojan War.

Overall my treatment of these two episodes is intended to bring the focus onto the emotions of the mothers, echoing the plight of real families today. While the details of their experiences differ, myth continues to be relevant to us as a lens through which to view their struggles.

Figure E18. Participant 9 essay. Printed with permission. 


\section{Participant 10}
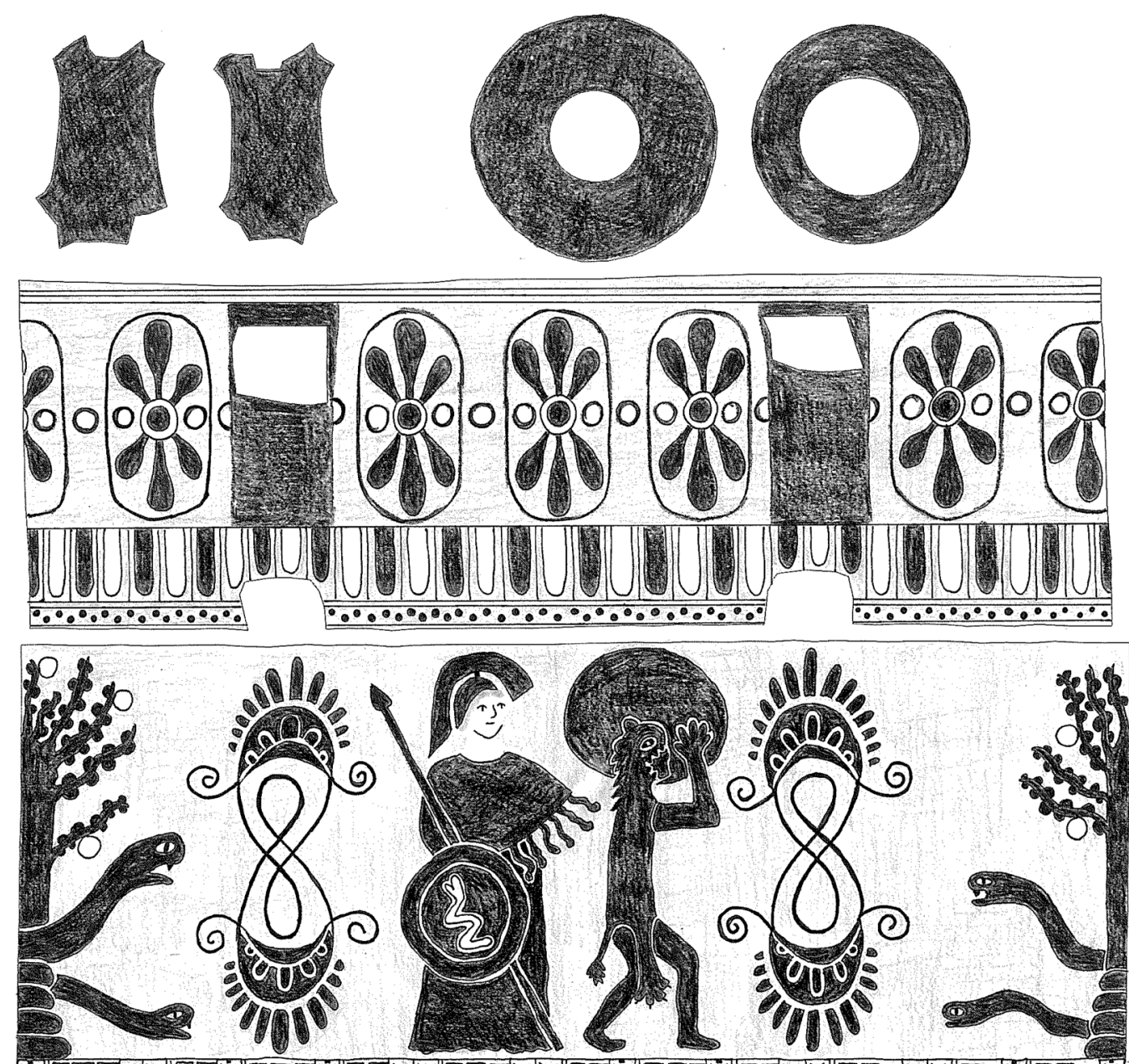

X) 
My vase depicts the myth of Hercules attempting to obtain golden apples from the Garden of the Hesperides. Hercules is assigned the labour by Eurystheus, the king of Tiryns, and in this version he must ask Atlas for help as he cannot go near the tree himself. In order for Atlas to retrieve the apples, Hercules offers to hold the Heavens for him until the task is complete.

The moment I have chosen to depict is Hercules struggling to hold the Heavens, having recently take it from Atlas. Athena is behind Hercules, helping to hold the Heavens with only one arm as she is a god, and therefore much stronger than Hercules. On the other side of the vase is the tree in the Garden of the Hesperides with the golden apples. This tree is guarded by Ladon whom I have depicted as multiple snakes wound around the tree, rearing in a defensive position. Atlas does not appear on the vase as he is still journeying to the Garden of the Hesperides.

I chose to depict this particular moment in order to centre the focus on Hercules' struggle in holding up the Heavens, as he is only able to achieve this through the help of Athena. This particular myth is very relevant to my identity as a Christian. For example, Hercules represents myself on a daily basis, illustrating the struggle I go through to balance my personal life, family life, friendships, study, and social time, represented by the Heavens. Athena represents God who helps me carry these things. Without Him I would be unable to maintain all the different areas of my life without letting something fall.

For me, this relates particularly closely to the verses "Come to me, all you who are weary and burdened, and I will give you rest... For my yoke is easy and my burden is light." (Matthew 11:28, 30) Although Hercules is a demigod, able to complete tasks mortal men could never attempt, he still requires the help of a god to help him achieve this labour. This is a moment on his journey where he is struggling, something universal which we all deal with whether we believe in God or have another faith.

I included the tree with the golden apples as it is relevant to this myth, but also because for me it represents eternal life. The golden apples are Hercules' end goal; once he has attained them and brought them back to Eurystheus, his labour is complete. The snakes are representative of Satan, and the Biblical connection between the two influenced my decision to illustrate Ladon as snakes. This particular depiction illustrates the end goal of spending eternal life with God, and the trials we must face in order to reach lt. 

